\title{
Transnationalism and Development: The Impact of Remittances to Timor-Leste
}

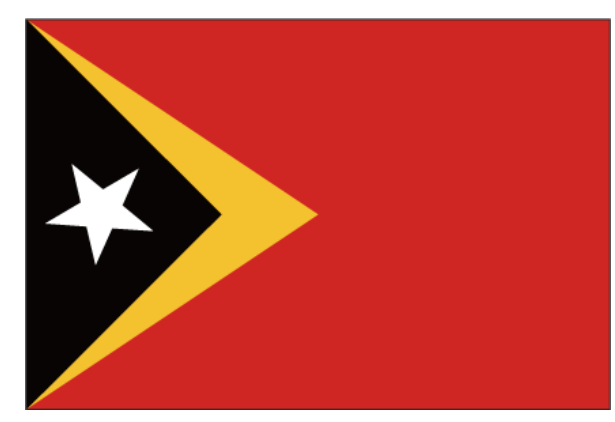

By

\section{BRIGIDA BRITES SOARES}

\begin{abstract}
A thesis
Submitted to the Victoria University of Wellington in fulfilment of the requirements for the degree of Masters in Development Studies
\end{abstract}

School of Geography, Environment and Earth Science Victoria University of Wellington 2015 


\section{ACKNOWLEDGEMENT}

Firstly, I thank my father EduardoSoares and motherFernanda Brites and my daughter TanisiaBritesGalucho for their moral support and prayers foreverything I do.

I would like to express my gratitude to my research supervisor Dr. Alan Gamlen. His supervision during my research and his encouragement has provided the spirit for me to accomplish my thesis.

Heartfelt thanks go to my interviewees for sharing their experiences. This thesis would not have been possible without their willingness to participate and I also thank them for their hospitality during my field work.

I am grateful to the New Zealand Agency for International Development (NZaid) and its team for their support for me in pursuing this Masters of Development Studies (MDevStud) at Victoria University of Wellington.

My deepest thanks also go to Mr.Ilidio Ximenes da Costa and Virginia Vicente do Rego for their assistance. They helped me to choose this study area and suitable participants who have been very important in enabling me to successfully complete my fieldwork.

I am also indebted to my mentor and ISO Helen Barnard and Linsell Richards. Their kind support helped me to be able to pursue this master degree.

Finally, I thank my colleagues for sharing their valuable ideas through classroom and informal discussions. Learning together with you all was where I realized learning comes not only from teachers but also from colleagues. 


\begin{abstract}
The aim of this thesis is to Explorer the impact of remittances, sent from Timorese workers in the United Kingdom of Great Britain, Northern Ireland, South Korea and Australia, on the Development of TimorLeste.

The research in this study is from three different perspectives. Firstly, the migration processes and the remittance service providers, which are involved in managing the transfer of remittances from Timorese workers overseas to their families at home. Secondly, the remittance is used by recipient familieson the consumption (durable and non-durable goods). Finally, the remittance is used on human capital investment and business investment. From these three perspectives, this thesis examines how remittances contribute to the development of Timor-Leste. Using a qualitative method, the study addresses one main question: What is the impact of remittances to Timor-Leste?
\end{abstract}

The study was underpinned by qualitative research conducted in Timor-Leste, which has a total population of 1.1 million. I administered the field research in 7 locations to 30 participants. These included 10 remittance receiving households in the urban district of Dili and 10 from the rural areas of Baucau, Lospalos, Viqueque, Ainaro, Covalima and Oecusse. Another 10 interviewees were migrant workers domiciled in the United Kingdom of Great Britain and Northern Ireland, South Korea and Australia. The interviews also conducted with relevant Government institutions regarding the process of emigration to work in United Kingdom of Great Britain, Northern Ireland, South Korea and Australia. Also, bank and non-bank institusions as the channel used to transfers remittances from the host countries of the migrants to their families at home.

In adopting a combination of theoretical approaches, especially the New Economy of Labour Migration, I argue that remittances have a positive contribution to the development of household participants' welfare, the development of human capital and they enable remitters and their families in Timor-Leste to start small and medium businesses. The study also found that the ultimate use of remittances is variously invested in productive and unproductive sectors. I further argue that the positive impact of remittances on peoples' lives significantly increases the numbers of overseas migrants, which attracts a greater flow of remittances into the country and that urgent government policies are needed to facilitate these more easily. 


\section{DEDICATION}

This thesis is dedicated to three people who have had a significant influence on my life.

My father, Eduardo Soares,

Who allowed me to chase my dream and stood next to me until the dream came true. He is my continuous source of inspiration and a constant source of silent support.

My mother, Fernanda Brites,

A remarkable woman, who taught me, all aspects of life, especially being patient to achieve all of my dreams and for her unconditional love.

My Beloved Daughter, TanisiaBritesGalucho,

A sweet honey pie, who always inspired me to stand and head up to facing all the challenges in life, particularly during my writing processes.

I am so grateful to all of them who had so much faith and believed in my capability to achieve my Masters one day.

\section{Here I am}

$* * * * * * * * * * * * * * * * * * * * * * * * * * * * * * * * * * * *$ 


\section{Table of Content}

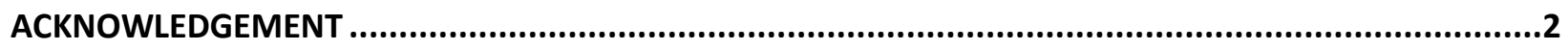

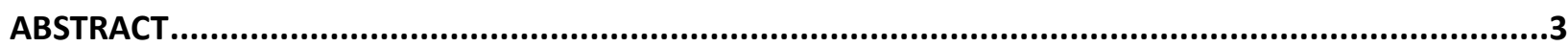

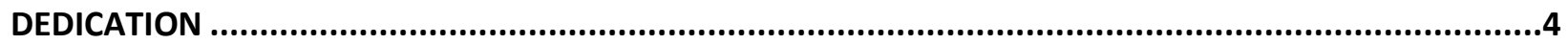

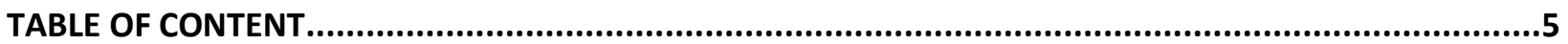

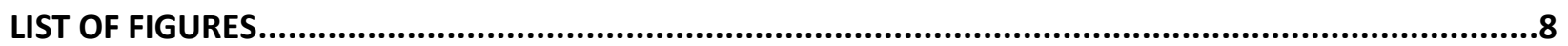

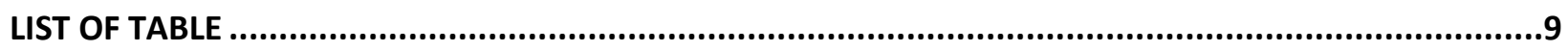

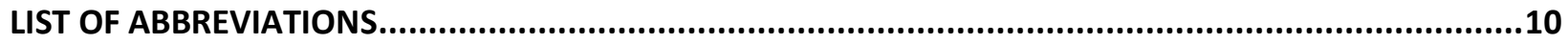

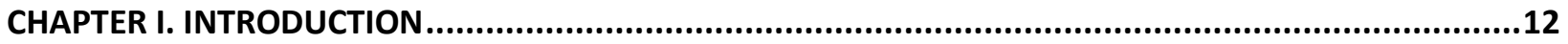

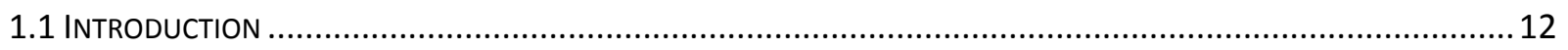

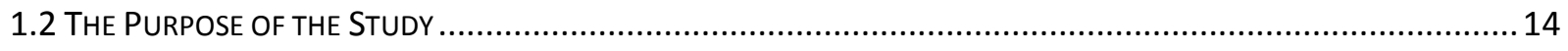

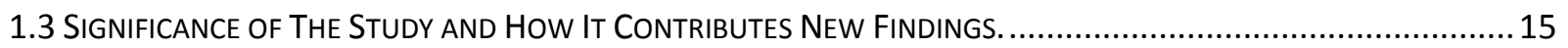

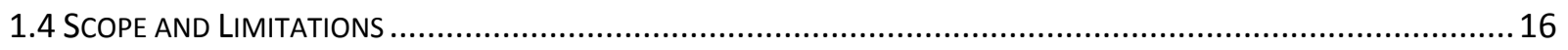

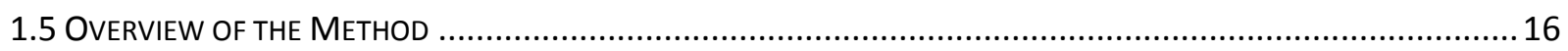

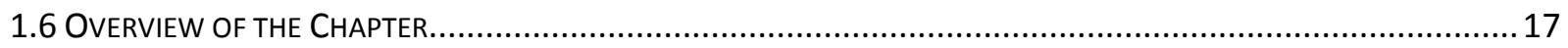

CHAPTER II. MIGRATION CHALLENGES AND DEVELOPMENTIN TIMOR-LESTE ..................................20

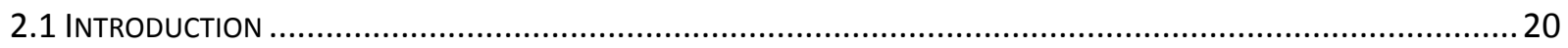

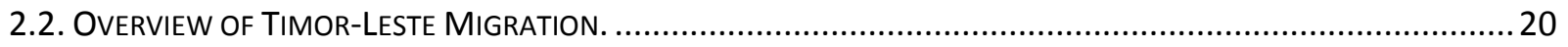

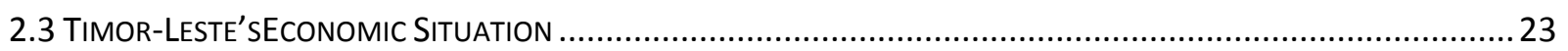

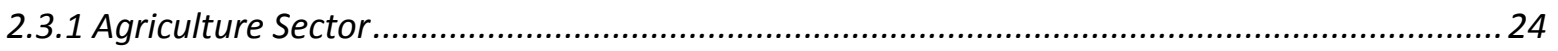

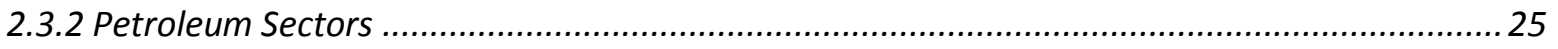

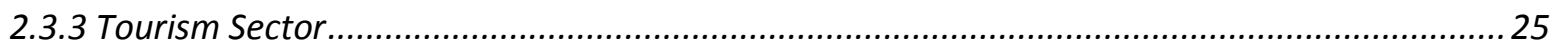

2.4 New Settlement of Timorese in Northern Ireland, England, South Korea \& $\quad$ Australia. ............26

2.4.1 New Settlement in United Kingdom of Great Britain and Northern Ireland ..........................27

2.4.2 New Settlement of Timorese Migrant Workers in South Korea\& Australia.............................. 28

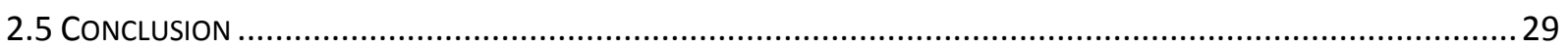

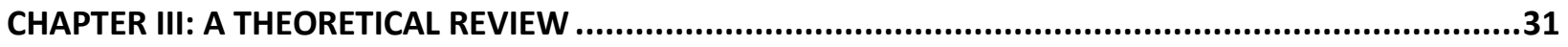

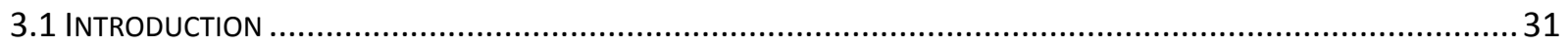

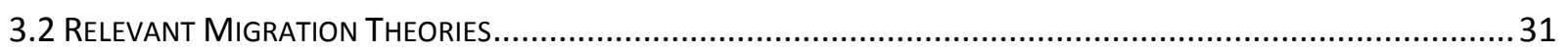

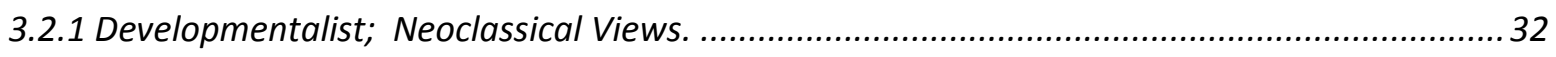

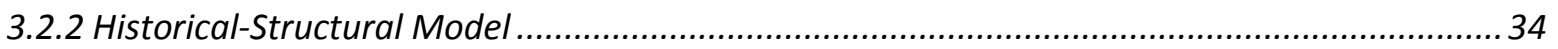

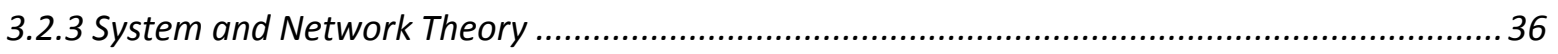

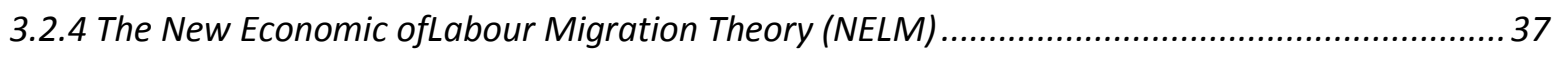

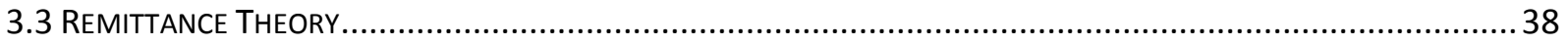

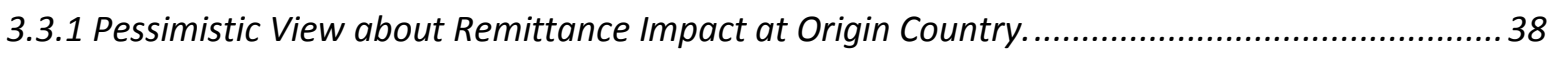

3.3.2 Optimistic View about Remittance Impact at Origin Country............................................... 41

3.4 THE MigRATION ISSUES AND REMITTANCE IMPACT IN TIMOR-LESTE..................................................... 43 
3.4.1 Migration and Remittance Data in Timor-Leste.

3.4.2 Migration and The Flow of Labour Migration from Timor-Leste to Destination Country

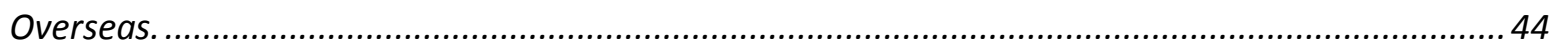

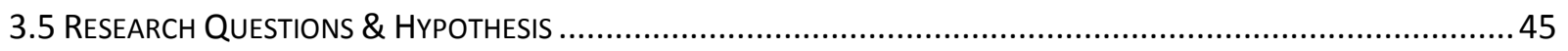

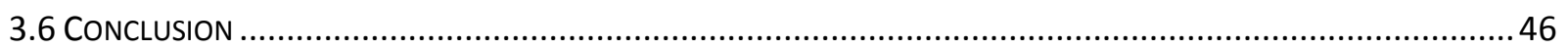

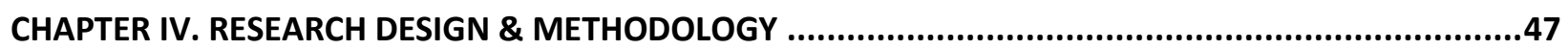

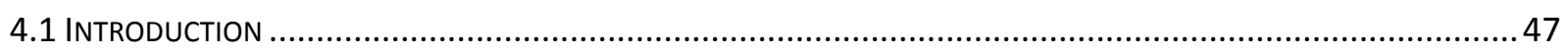

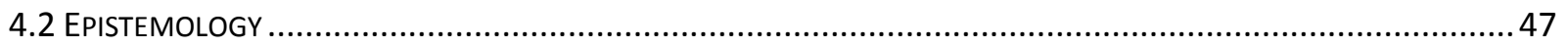

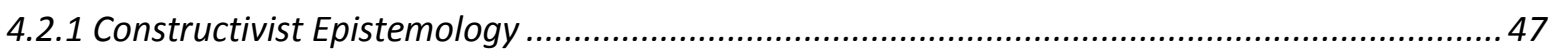

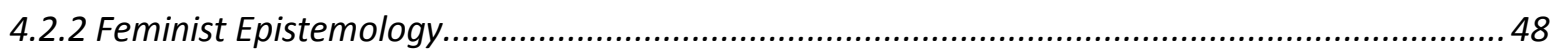

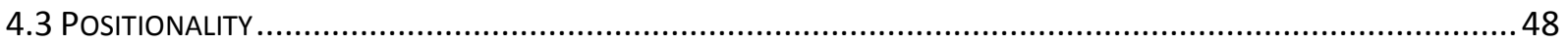

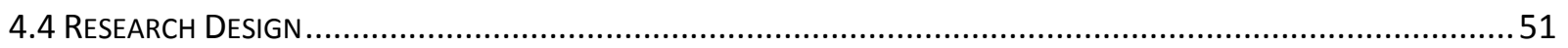

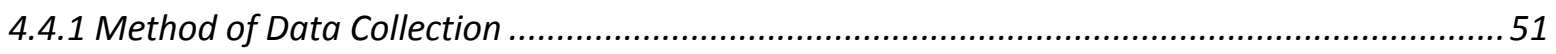

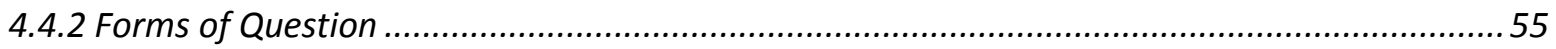

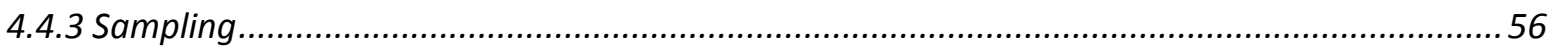

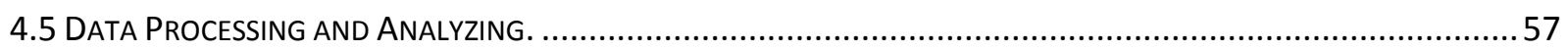

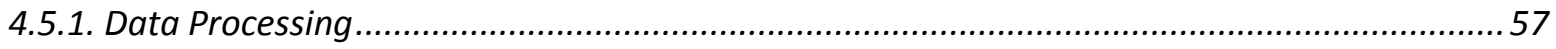

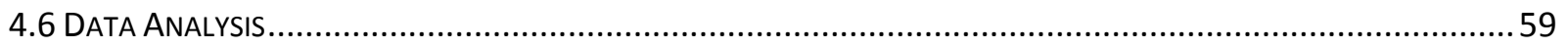

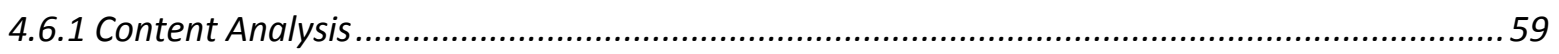

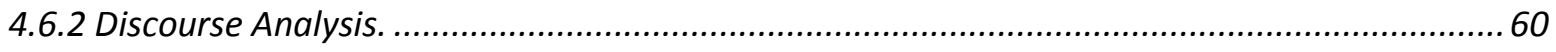

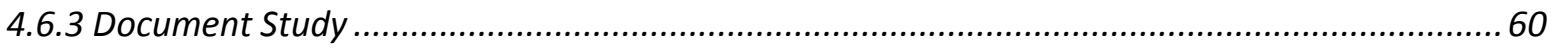

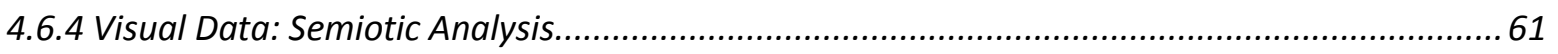

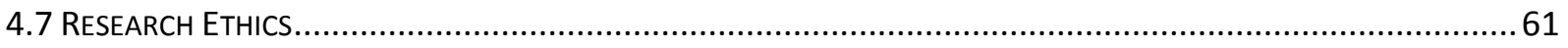

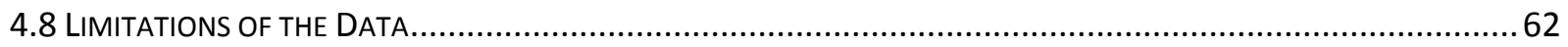

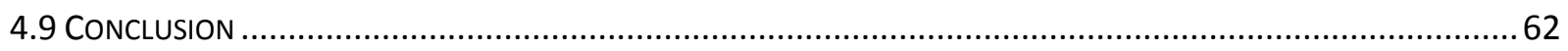

CHAPTERV. RESULTONE: MIGRATIONSOURCES AND THE POLICIES AND PROCESSES OF REMITTANCES IN TIMOR-LESTE AND THE DESTINATION COUNTRIES

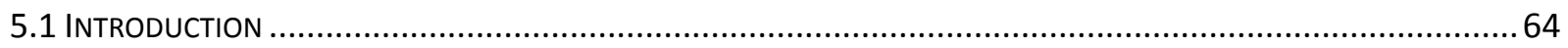

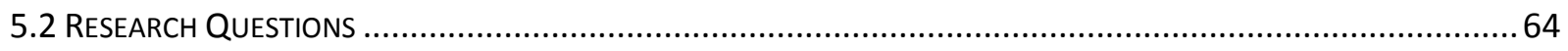

5.3 Migration Sources and Processes to the United Kingdom of Great Britain, Northern Ireland, South

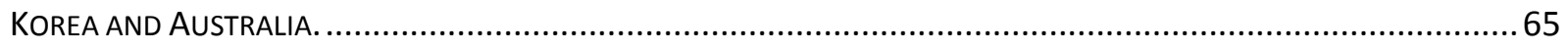

5.3.1 Migration Sources and Processes to South Korea and Australia. .........................................68

5.3.2 The Process of Labor Migration to United Kingdom of Great Britain and Northern Ireland via

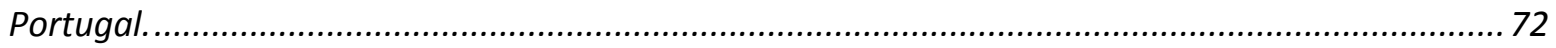

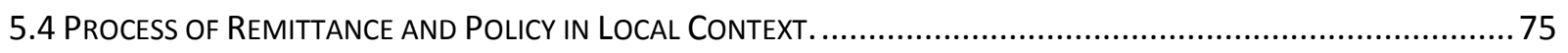

5.4.1 Remittance Process in the Commercial Bank and Business ............................................... 76

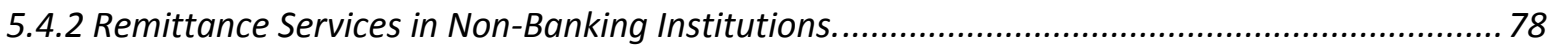

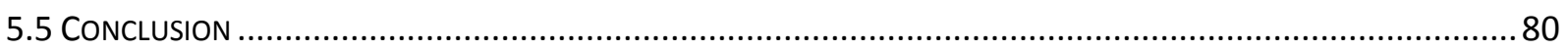

CHAPTER VI. RESULT TWO: UNPRODUCTIVE REMITTANCES - CONSUMPTION, PROPERTY INVESTMENT

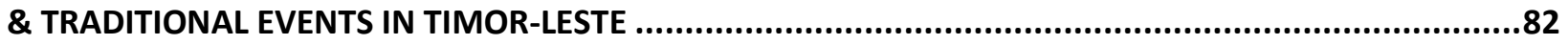

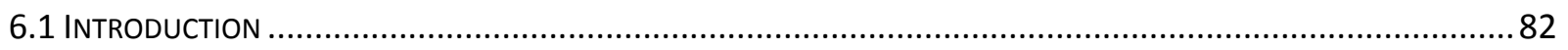

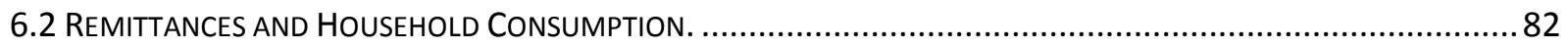


6.2.1 Remittances and Household Consumption on Unproductive, Non-Durable Purchases Goods such as Food, Clothes and Household Equipment.....................................................................84

6.2.2 Household Consumption on New Housing and Housing Equipment..................................... 86

6.3 Household CONSUMPTION ON Other EXPENSES (CULtURAL EXPENSES \& OtherS). .................................. 92

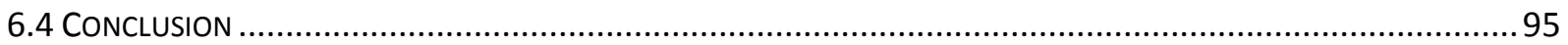

CHAPTER VII. RESULT THREE: PRODUCTIVE REMITTANCES: HUMAN CAPITAL INVESTMENT AND THESMALL-MEDIUM BUSINESS INVESTMENTIN TIMOR-LESTE. ................................................96

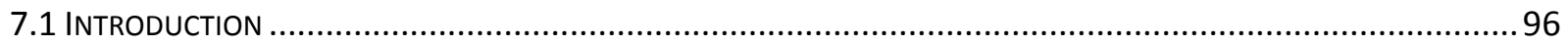

7.2 THE IMPACT OF REMITTANCES ON INVESTMENT IN HUMAN CAPITAL. ....................................................... 97

7.2.1 Remittance's Investment Enhances Human Capital at University Level ...............................97

7.2.2 Remittance Funds Support the Children's School Materials and Children's Health to Stay at School (Primary School to Senior High School).......................................................................... 102

7.2.3 Remittance Funds Support Youth in Vocational Training such as Language Training and

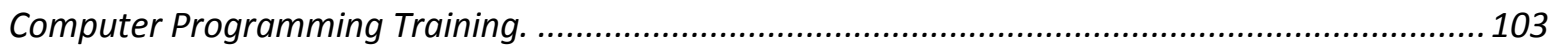

7.3 THE IMPACT OF REMITTANCES ON BUSINESS INVESTMENT .............................................................. 103

7.3.1 Remittance Fund Support Transportation Business Both in Rural and Urban Areas. ............. 104

7.3.2 Remittance Funds Support for Medium Businesses in Timor-Leste...................................... 109

7.3.3 Migrant Remittances Enhance Agricultural Production in Rural Areas. ............................... 112

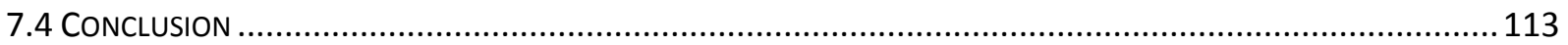

CHAPTER VIII; SUMMARY, LIMITATIONS AND RECOMMENDATIONS. ERROR! BOOKMARK NOT DEFINED.

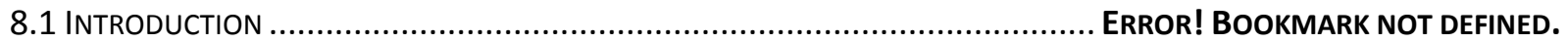

8.2 FINDINGS SUMMARY AND INFERENCES.................................................... ERROR! BOOKMARK NOT DEFINED.

8.2.1 Processes and Policies of Migration and Remittance Services in Local Context.Error! Bookmark not defined.

8.2.2 The Impact of Remittances on Durable and Non-Durable Consumption.Error! Bookmark not defined.

8.2.3 The Impact of Remittances on Human Capital Investment and Business Investment........ Error! Bookmark not defined.

8.3 CONTRIBUTIONS ERROR! BOOKMARK NOT DEFINED.

8.4 LIMITATIONS ERROR! BOOKMARK NOT DEFINED.

8.4.1 Sample Method and Data Collection Error! Bookmark not defined.

8.4 2 The Focus of The Study Error! Bookmark not defined.

8.5 RECOMMENDATIONS ERROR! BOOKMARK NOT DEFINED. 


\section{List of Figures}

Figure $1 \quad$ Map of Timor Leste.

Figure 2 The number of East Timorese migrant's workers in the United Kingdom of Great Britain (July, 2014).

Figure 3 The number of Timorese workers in South Korea by Sectors.

Figure 4 The number of East Timorese working in the seasonal program and the sector they work in, in Australia.

Figure 5 Labor Migration Processes to South Korea.

Figure 6 Labor Migration Processes to Australia.

Figure 7 The processes of Timorese people travelling to the United Kingdom of Great Britain and Northern Ireland.

Figure 8 Percentages of household consumption on food, clothes and house equipment purchase by location.

Figure 9 Household consumption on new house construction and the purchase of land by location.

Figure 10 Flowchart of household consumption on new housing and how these affects the local market in Timor-Leste.

Figure 11 New house built in rural, Covalima, Timor-Leste, by family who receive remittances from member overseas.

Figure 12 New house construction in urban Oecusse by labor worker who returned home in 2014.

Figure 13 New house construction, in rural area, built from remittances sent from a family member in the United Kingdom of Great Britain.

Figure 14 Household consumption on cultural event in a rural area of Timor-Leste.

Figure 15 traditional events in a rural area of Timor-Leste

Figure 16 Public Transportation - a Mikrolet purchase with remittances.

Figure 17 A truck purchases with remittances.

Figure 18 A small shop (Kios) run by the wife of diaspora working in Northern Ireland

Figure 19 A recent project using remittances\&workers on a recent project.

Figure 20 The participant shows the miler her family purchased with remittances. 


\section{List of Table}

Table 1 Timor-Leste critical industries

Table 2 Summary of overseas remittances by country of destinations

Table 3 Summary of remittances receivers by locations

Table 4 Numbers of labour migrants, their families and the channels used to send and received remittances

Table 5 Household information about the numbers of people in education supported by remittances

Table $6 \quad$ Household members attending private and public universities

Table 7 Participant information on business investment 


\section{List of Abbreviations}

\begin{tabular}{|c|c|}
\hline $\mathrm{ADB}$ & Asian Development Bank \\
\hline ANZ & Australia and New Zealand Bank \\
\hline ANDRA & Adventist Development and Relief Agency \\
\hline AusAID & Australian Aid \\
\hline BPA & Bank Payment Authority \\
\hline BMS & Border Management System \\
\hline BNU & Banku Nacional Ultramarino \\
\hline CCBA & Certification of complementary in Business Analysis \\
\hline CGD & CaixaGeraldoDeposito \\
\hline EPS & Employment Permit System \\
\hline GoTL & The Government of Timor-Leste \\
\hline GDP & Gross Domestic Product \\
\hline $\mathrm{G}$ to $\mathrm{G}$ & Government to government \\
\hline HRD & Human Resource Department \\
\hline HADEMER & HadiaDalan Ba MorisRasik \\
\hline ILO & International Labour Organization \\
\hline IOM & International Organization of Migration \\
\hline MTO & Money Transfer Operator \\
\hline $\mathrm{MoF}$ & Ministry of Finance \\
\hline MNEG & Ministry of Foreign Affairs \\
\hline MD & Ministry of Defense \\
\hline MNRI & Ministry of Natural Resoruce Institute \\
\hline NELM & New Economic of Labour Migration \\
\hline NSP & National Strategic Plan \\
\hline RDTL & $\begin{array}{l}\text { RepublicaDemocratica de Timor-Leste (The Democratic Republic Timor- } \\
\text { Leste. }\end{array}$ \\
\hline SEPFOPE & $\begin{array}{l}\text { The Secretariat of State for the Professional Training and the Employment } \\
\text { Policy }\end{array}$ \\
\hline TL & Timor-Leste \\
\hline TSDP & Timor-Leste Strategic Development Plan \\
\hline UNDP & United Nation Development Program \\
\hline UK & United Kingdom of Great Britain \\
\hline UNTL & Universidade Nacional de Timor-Leste \\
\hline UNPAZ & Universidad da Paz \\
\hline WU & Western Union \\
\hline
\end{tabular}




\section{Appendices}

$\begin{array}{lll}\text { Appendix I } & : & \text { Ethic Approval } \\ \text { Appendix II } & : & \text { Interview Guide } \\ \text { Appendix III } & : & \text { Preliminary Questioners (Tetum) } \\ \text { Appendix IV } & : & \text { Participants Information Sheet (Tetum) } \\ \text { Appendix V } & : & \text { Participants Information Sheet (English) } \\ \text { Appendix VI } & : & \text { The location of Study Field Research Held (MAP) }\end{array}$




\section{CHAPTER I.INTRODUCTION}

\subsection{Introduction}

I regularly received money from my husband who is working in Northern Ireland, I often, use it to buy food for my family, clothes for kids, pay some money for my sister education at university and build our house (Interview, 12 July 2014).

Two of my friends and I have started our construction company using remittances that we sent home and saved in the bank since we came back together from the United Kingdom of Great Britain in 2010 (Interview, 18 August 2014).

Do remittances contribute to the development of Timor-Leste? If so how and if not, why not? The above quotes illustrate the uses of remittances in Timor-Leste. The first tells of a wife who was sent money regularly by her husband and how she used it to cover basic family needs and to build a house. Although the expenditure on these essentials is regarded, by some as ${ }^{1}$ unproductive(Buruah, 2006; Burges, 2004; Rampel, et al. 1978; Massey, et al.1987; Adam, 2011; Pablo A. Costa,2007; Amuedo, et al. 2004; Singer, 2010; Bakardzhieva, et al. 2010; Sign, 2015; Chami, 2008; Miller, 2001; Yu, et al. 2014. Remittances are nevertheless essential to sustain households in Timor-Leste and other third world remittance receiving countries around the world. Many past studies on the impact of remittances on household consumption behaviour report that their use for household expenditure is positive(Yang, et al. 2005; Poirine, 1997; Lucas, et al. 1985;1988; Edward, 2003; Costa, 2006; Ratha, 2007; Cohen, 1998; Sugui, 2007; Rodrigues, 1998; Taylor, 1989; Adam, 1991; Haas, 2009; Adam, et al. 2005).For example, the study case of Albanian households where external remittances from migrant workers overseas, reported that the expenditure on durable and nondurable goods was higher than those households which did not receive remittances (Adriana Castaldo, 2007). This expenditure of remittances has similarities with Timor-Leste and although it is an illustration of, what some may define as unproductive remittances, I argue that the use of remittances has a positive contribution to the development of household participants' welfare.

\footnotetext{
${ }^{1}$ Unproductive refer to the used of remittances spent on durable and non durable goods such as consumptions and construction a new house or house renovation which has no income as return.
} 
The second quote illustrates what some regard as the productive ${ }^{2}$ impact of remittances. In this, it is shown that when they are invested in the local economy in general they also sustain household's economies in the long term through the growth of the business. The quote comes from a young man, who with his friends, worked overseas for several years. They returned to Timor-Leste and started their own business, using remittances they had saved in the National Bank at the origin country. This particular example shows that remittances are not only spent on consumption, but they have also been invested in human capital and business investment. A previous study by AusAid (2008) in Timor-Leste, found that, the flows of the money received are often used as contributions to improve living standards and financial security in many households as well as being invested in some small businesses (Shuaib, 2008). This supports my argument that remittances have a positive impact on receivers, as expenditure onnon-durable and durable goods immediately enhances all facets of people lives and when businesses are developed ensures their futures.

The above examples are only two of the cases from the many households whose relatives are working overseas. There are still many examples, that are presentedthroughoutthis thesis. These cases show that, remittances play a significant role in the development of participant households' economies. These quotes present productive and, as some believe, unproductive remittances on the local economy of Timor-Leste. To conclude, remittances from Timorese migrants overseas have a significantpositive impact on the development of the household welfare, human capital in education and investment in small and medium businesses. The value of remittances into Timor-Leste is significant.

In Timor-Leste, the total estimate of inward remittances, per year is US\$5 million which represents around 1.4 per cent of non-oil GDP. This figure also shows that labour is the country's second largest export after coffee (Shuaib, 2008 as cited by ACP, 2010). Both these facts are important to Timor-Leste and should be given more attention from the government. Further, in Timor-Leste as with other developing countries, these flows of money are often spent on education, starting new businesses, food, clothing, household improvements and they also increase monthly savings (Shuaib,2008). Shuaib's study also focuses on the financial institutions which provide remittance services inside the country but he used only secondary data from The World Bank and ADB. No

\footnotetext{
${ }^{2}$ Productiverefers to the used of remittances spent on business investment and human capital investment.
} 
primary research was carried out (ACP, 2010). Therefore, my study was designed, with a qualitative research method, to investigate the impact of remittances and focuses on the primary actors - the remitters who are sending money home and the remittance receivers in Timor-Leste. Given the lack of studies related to remittances in Timor-Leste, it is difficult to discern the gaps between migration and the reality of development. However, linking to the wider global literature, there have been many studies undertaken to see the how remittances contribute to the economic development in other country. The studies show a variety of results. For example, In Mexico Bougha-Hagbe (2004) finds that increased construction activity is correlated with remittances. In Philippines, remittances received through official channels amounted to $5.2 \%$ of the GDP in that year(2004). Tonga, a small archipelago country in the South Pacific, more than half of its population lives abroad and $28.7 \%$ of its GDP is made up of remittances. In terms of remittances as a percentage of GDP, Lesotho (26.1\%) and the Palestinian territories (23.7\%) rank third and fourth in the world, respectively(Hertlein, 2006).Therefore, the big question about the impact of remittances in Timor-Leste needs to be answered. This question is the central foundation of this thesis.

\subsection{The Purpose of the Study}

The purpose of this qualitative study is to understand the impact of remittances in Timor-Leste. In addition, this research also studies the challenges faced by remitters in sending money home, examines how the remittance receivers manage these challenges. The focus of the research is threefold:

1. To collect information about the total inflow of remittances to the country, their destination and their ultimate use.

2. To examine ways to help facilitate overseas work opportunities, grow the inward "3 3 migradollar" and reduce transaction costs faced by migrant workers and households that received remittances.

3. To measure the future plans of the households which receive the remittances; whether they are to be used for consumption only or if there are any plans to start small or medium enterprises.

The primary aim of this thesis is to explore the impact of remittances in Timor-Leste. According to Andrews (2013) there exist interconnections between the theoretical frameworks, the methodology, including the method used and the researcher's view of the epistemology. I have taken the new

\footnotetext{
${ }^{3}$ Migradolar is the dollar earned by migrant.
} 
economic of labour migration (NELM)point of view as the foundation to examine the impact of remittances on Timor-Leste and this study is complemented by my academic knowledge and positionality. To achieve the aim of this study the qualitative case study method is employed to gain a profound understanding of the impact of remittances in local contexts. Thirty (30) participants were chosen and the snowballing method was used to select these participants. This method has been used because of the lack of data about emigrants and their family members in Timor-Leste.

\subsection{Significance of The Study and How It Contributes New Findings.}

This study issignificant because it impacts on both practical and academic areas. Firstly, it contributes to new findings about remittances and development in Timor-Leste. There is currently one study on remittances in Timor-Leste. This is the second. The previous study mainly examined the channels of remittances and explored the significant role of financial institutions play in facilitating the transfer of remittances from the migrants overseas to Timor-Leste. In this research, I focused on the study of the ultimate uses of remittances, both productive and unproductive, by remittance receivers in both urban and rural areas in Timor-Leste.

Secondly, this study also contributes to the academic literature and research on remittances. In particular, it significantly benefits research and provides insights into the new economy labour migration (NELM). Further, this study shows that economic support for families is the main factor, which influences their decision to send a member overseas. The need for economic support for the people of Timor-Leste is a result of Timor-Leste beinga newly independent and post conflict country, still facing many challenges, including a high rate of unemployment among the youthabout 3.8 percent (SEPFOPE, 2010), a limited productive sector which results in little or no income for many householdswhich is $\$ 40$ per person or less per person per month (Ministry of Finance, 2011). I argue that this family supported migration is positive because by leaving the country the young people learn skills, widen their outlook and contribute to their families' finances.

Thirdly, this study will also be beneficial to the Timor-Leste Government because it comprises new information on migration and remittances and can be used to develop effective policies on these and on fiscal policies.In addition, it offers government institutions' suggestions about how to control and regulate the financial institutions which provide remittance transfer services as well as encouraging remittance receivers to invest in a productive sector such as education, agriculture and small 
and medium industry/business.

Lastly, this study will become one of the references for future academic researchers on the issues of remittances and development in Timor-Leste. My findings will be the base line for any future researcher to look at the subject of migration and development.

\subsection{Scope and Limitations}

This study covers the impact of remittances in economic, agriculture, tourism sectors, it will study and analyse the expenditure of remittance funds on durable and non-durable goods by participant households. It also presents the impact of remittance funds on human capital investment and business investment. In addition, it has drawn on wide descriptive information on the processes and policies of migration and remittances in the local context forTimor-Leste. This study does not cover the processes and policies of host countries receiving labour migrants and it has not explored the experiences of the diasporas in the host countries, including consumption behaviour and other related issues faced by the migrants.

\subsection{Overview of the Method}

In depth interviews, participant observations and document analysis studies are used as the data collection methods. The in depth interview method involves deep conversations between the researcher and the household participants. Conversation is the basis of human interaction, human beings talk to each other through conversations and get to know other people, learn about their experiences, feelings and hopes and the world they live in (Riikonen, 1997). Therefore, the in depth interviews, in the form of conversation, were based on a number of semi-structured questionnaires underpinned by the central question and were used to explore the opinions and experiences of both migrants and their families on the process and impact of remittances in Timor-Leste. Alongside the interviews, participants were observed to capture their reactions to things mentioned during the interviews including the psychology of building of new house, opening a small shop, the purchase of materials and other important items mentioned as the result of remittance funds. In addition, government policy documents related to migration, remittances and financial institution services were studied and analysed. Similarly, earlier research, personal records and the mass media, regarding the migration processes and their impact on Timor-Leste, were studied and analysed. 
These data were analysed using content analysis, where the data collected from the content of communication were divided into methodology and labelled in a qualitative form. Discourse analysis was also used in this study ${ }^{4}$. Further, relevant documents were studied and analysed to seek a comparison between the reality and the reports. Lastly, semiotic analysis was used particularly to analyse the wide range of material such as photographs.

\subsection{Overview of the Chapter}

This thesis is organized in the following way: chapter two presents the country context and the background of migration from Timor-Leste and is divided into two parts. Firstly, it presents the history of migration and looks deeply into the differences and changes between the past and the present, including current destinations and the causes and motives for migration. Secondly, it looks at how the remittances are used and their impact on Timor-Leste, and finally, it covers why and how remittances are important to the development of some vital sectors in Timor-Leste.

Chapter three outlines the review of the literature which has two distinctive parts. The first part draws on the theory of migration from, the developmentalist: neoclassical micro and macro theory. It then presents the historical and structural model of migration including the dual segmented market view, the dependency theory and the world system theory. Following this is the presentation of the network system model of migration and the chapter closes with the new approach to the economics of labour migration. The second part describes the theory of remittances and divides it into two major parts, the pessimistic point of view and the optimistic point of view. This chapter also presents a review of studies into migrant remittances in Timor-Leste and finally, the research questions and hypothesis are reiterated.

Chapter four outlines the methodologies employed in this study. These are epistemology and positionality. This chapter further provides the rationale for choosing the qualitative case study and the approaches to explore the processes and impacts of remittances in Timor-Leste. Details of the sampling recruitment and data collection method follow. This chapter closed with the data processing and data analysis phase of the research.

\footnotetext{
${ }^{4}$ Discourse analysis discussed the relationship between the text and the conversation during the interview.
} 
Chapter five, six and seven discuss the findings of this research. Chapter five focuses on the findings about the processes of migration and remittances in the local context. It provides descriptive information about these processes and policies and provides the findings of labour migrants' destinations, which include the United Kingdom of Great Britain, Northern Ireland, South Korea and Australia. The second section of chapter 5 focuses on the findings of the processes and policies pertaining to the remittances in Timor-Leste, including the services of the commercial banks and non-banking institutions. In addition, this chapter answers the sub questions of this thesis which are: who sends remittances and who receives them, what are the sources (information, processes and channels used by the migrants? which is the destination country they choose to go? why and how? and the last question is what are the informal and formal institutions and channels remittances travel through?

The focus of chapter six is on the findings, of what some say, are unproductive remittances, specifically on three different findings. Firstly, how they are used for household consumption. These uses are divided into consumption of non-durable goods such as foods, clothes and other household equipment. Secondly, the use of remittances for property investment and/or durable goods is explored and thirdly the findings report on the expenditure of remittances on traditional events and other areas.

Chapter seven discusses the findings of productive remittances. It has two different subject findings. The first is the ultimate use of remittances invested in human capital such as the education (formal and non-formal) of family members in Timor-Leste and the second discusses the findings of remittance funds used to invest in small and medium business in both urban and rural areas.

Chapter eight is the thesis' conclusion. It highlights the future prospects of the impact of remittances in Timor-Leste. In this chapter I present all the topics discussed, draw the main issues identified and link them back to the broader debates in the development studies area. I also have stressed the findings and their connection to the new economy of labour migration, which has a significant influence on migration decisions and the impact of these on the country. In this chapter, I again 
highlight the limitations of this research and provide some recommendations for the future research in the same area in Timor-Leste. 


\section{CHAPTER II.MIGRATION CHALLENGES AND DEVELOPMENTIN TIMOR-LESTE}

\subsection{Introduction}

In the introduction, I stated that the study of migration and remittances are important to the development of Timor-Leste. Firstly, I believe that remittances have a positive impact on the participant household welfare specifically, to support their economy and the education of their members. Remittances also have a significant and wider impact on the development of the country when it is invested in small and medium businesses. I agree with Ratha's (2007) opinion. He posits that workers' remittances have become a major source of external finance to many developing countries, including Timor-Leste. However, to see the impact of migration and remittances on this country, an understanding of the country's historical and socio economic conditions are important. For this reason, this chapter presents the country's profile, which includes an overview of Timor-Leste's migration and its impact on the development of households and, in particular on the development of the country in general. This chapter will structure the presentation as follows: firstly, I will present an overview of Timor-Leste's migration including its geographic location and the story of migration from the past to the present; secondly, I will point out the socio economic conditions, indicate the gaps remittances might fit in to; I will follow this with a discussion of the destinations of the Timorese migrants and lastly I will discuss the impact of remittances on the Timor-Lest emigration.

\subsection{Overview of Timor-Leste Migration.}

Figure 1. Map of Timor-Leste

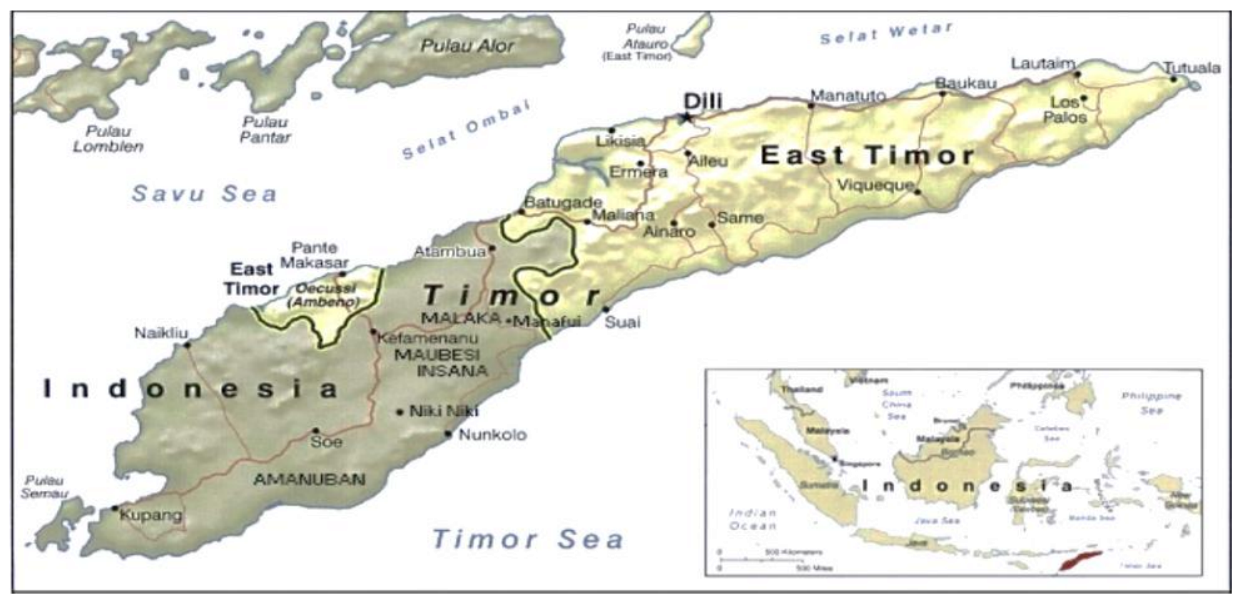

Source: Wikipedia, 2014 
The Democratic Republic of Timor-Leste officially gained independence from Indonesia in 2000. Look at the history, Timor-Leste was colonized by Portuguese for 400 years until 1975, Timor-Leste become one of Indonesia's province for 24 years. In the beginning of the new country was then run by the United Nations (UNTAET) who handed over power officially to TimorLeste in 2002.Timor Leste approximately 15.700 square kilometres in size include one island an enclave of Oecusse and is located in South East Asia, approximately 500 kilometres north of Darwin, the capital city of the Northern Territory of Australia, and is situated within the Lesser Sundae Islands at the eastern end of the Indonesia archipelago, the map of Timor-Leste can be seen in figure 1. Timor-Leste's independence from Indonesia was violent and destructive (The World Bank, 2014). The inhabitants of Timor are descended from three waves of migration. The first to settle the island were the Vedo-Australoid people related to the Sri Lankans, who arrived between 40,000 and 20,000 B.C. A second wave of people, from Melanesia, arrived around 3,000 B.C, and drove the earlier inhabitants (called Atoni) into the interior of Timor. Malay and Hakka people, from southern China, followed the Melanesians.

Migration is therefore not new for the people of Timor-Leste, however new patterns of emigration have emerged and these have changed because of political and economic motives. In the past, migration motives in Timor-Leste were purely caused by politics. For example, during World War II, when the Japanese arrived in Timor, many people escaped the country and became refugees in Australia. According to the data of Australia's refugee centre, 600 PortugueseTimorese arrived in 1945 and following the invasion by Indonesia in 1975, about 1,645 Portuguese -Timorese arrived in Darwin (Ribeiro, 2009). It is estimated that around 5,000 TimoresePortuguese have settled, predominantly in Darwin, and they still have strong links with families and businesses in Timor-Leste (Ibid). Other refugees from Timor-Leste who migrated to Portugal and Mozambique are not recorded.

In recent times, migration drives from Timor-Lest have not only been political but have been influenced by, very significant factor i.e. the economic situation of individuals and/or households. After independence, the rebuilding of the nation faced many different challenges. These included poverty and the weak social and economic conditions of many people in Timor-Leste. This situation has been deeply affected by the long history of colonization by the Portuguese through to the 
Indonesians from the 1600s-1999. The consequences of independence lingered, and in 2006 the country again faced turbulence (Brady, 2006). An outcome of this was that many disaffected youths made the decision to migrate to Portuguese speaking countries, Australia and fled to West Timor.

Since independence, Timor-Leste continues to face many challenges in developing its economy. The current population is about 1.2 million (The Department of Statistics, 2010). According to the World Bank (2013) the population growth is estimated at about 3.5 percent per year making it one of the countries with the highest population growth in the world and the fastest in Asia. In addition, Lundahl\&Sjoholm(2013) reported in 2009 that the percentage of people living in poverty was estimated to be around 41 percent. Another World Bank report (2006) presented the preliminary results of a household expenditure survey, which indicated that the national poverty line was formulated between US\$ 0.55/day/person. Timor-Leste has a lack of productive skills (including literacy). The human development index (HDI) states that Timor-Leste's literacy rate was 0.495 in 2010 and it increased slightly in two years to 0.576 in 2012 (UDNP), 2013 cited by Lundhal \& Sjoholm, 2013). The lack of, or inadequate access to, social and economic services (e.g. access to schooling is low) especially in the poorer districts, and rural residents have to walk, on average one and half hours to reach the nearest health facility; access to extension services are low and markets are difficult to access (Beck \& Araujo, 2013) but these are not the only challenges facing the people of Timor-Leste.

The lack of remunerative employment and unemployment are the country's biggest challenges. These conditions are linked to the population growth, and consequently it has increased the unemployment rate. SEPFOPE (2010) predicted the rate of unemployment has increased by about $3.6 \%$ since 2001. In this case, there is an unavoidable migration of rural youth from the poorest districts in rural areas to the capital from time to time (UNDP, 2012). In my opinion, this picture not only changes the pattern of internal migration but it has contributed to the increasing number of Timorese migrating to other countries to seek a job. This statement is supported by a previous study of migration and remittance channels (Suhaib, 2008) who indicated that the movement of Timorese people out of the country for the purpose of working overseas has increased from time to time. 


\subsection{Timor-Leste'sEconomic Situation}

The previous section described the economic conditions of the country as one of the causes for people to move over the border for the purpose of working. Ineffective and inadequate government policies to control all strategic planning implementation in productive sectors perpetuate poverty and as a result will contribute to the increasing numbers of migrants. However, the increasing numbers of emigrants positively contribute to the reduction of unemployment in TimorLeste and has also increased the flow of remittances into the country. Therefore, to see the impact of remittances on the development of the country it has to invest in the productive sector. According to the Timor-Leste's National Strategic Plan (NSP) 2011-2030, three sectors have been identified as the main income sources for the country. These are: agriculture, tourism and petroleum sectors. The Timor-LesteGovernment (GoTL) suggests that these three sectors will create more private sector companies and thus create more job opportunities for people. This is described in the quote below from the NSP 2011-2013:

Timor-Leste will build a modern, diversified economy based on agriculture, tourism and the petroleum industries which will underpin a flourishing private sector and create new opportunities for all our people (p. 57).

An analysis of the above statement, in the current situation for Timor-Leste, shows that, the tourism sector is very small and the Ministry of Tourism is still in the process of developing its strategic development plan and agriculture sector is in the progress of transforming from subsistence agriculture to the agriculture-based economy. Further, theproduction in the private sector is slow because of limited government annual spending on construction and trade (ADB, 2014). Moreover, imports outweigh exports (Trading Economic, 2015). The progress of the economy is still struggling to meet the targets. Therefore, remittances which are invested in the private sector, both small and medium, can contribute to the development of the three sectors mentioned. 
The table below, shows the details of each economic resource sector;

Table 1. Timor-Leste Critical Industries

\begin{tabular}{|c|c|c|}
\hline AGRICULTURE & TOURISM & PETROLEUM \\
\hline Food Crops & The Eastern Zone & Timor Gas \& Petroleum E.P. \\
\hline Cash Crops & The Central Zone & Tasi Mane \\
\hline Livestock & The Western Zone & South Coast \\
\hline Fisheries & & \\
\hline Forestry & & \\
\hline
\end{tabular}

Source; SDP 2011-2030

Table 1 shows the three areas the government identified as potential economic sources. Each sector illustrates the significant impact on development and the promising job opportunities theseoffer to many unemployed in the country. These sectors provide an important gap which could possibly be filled by remittances funds if household participants who regularly receive remittances or migrants who have saved their money at their country of origin, decide to investing businesses in these sectors. Following is information of the three sectors mentioned above and how remittances can fill the gap.

\subsubsection{Agriculture Sector}

Remittances could be invested in agriculture businesses. As noted the development of the agriculture sectors important because it guarantees the sustainability of Timor-Leste's economy after oil and gas as well as important for Timor-Leste to feed itself and reduce reliance on imported food such as rise. Timor-Leste's economy is agrarian and $80 \%$ of the population works in this area. However, little income is generated from the labor invested and when combined with aquaculture, does not support the economic livelihoods of the people. This is due to the lack of modern farming methods, access to markets or the cost of transport as the barrier and inadequate farming materials. For example, many farmers still farm using traditional systems or the sub- 
system farming method (Rogers, 2014). Similarly, the aquaculture sector faces the same problems as many of the fisheries still use the traditional way of fishing (Andrew, 2011).

Even though many arguments state that migration has caused the loss of household farm labor in some cases, with many family members unemployed, remittances from migrants have increased farming production as some are used to buy adequate farm materials to support farming activities.

\subsubsection{Petroleum Sectors}

Remittance funds might have little impact on this sector, because this sector owns dollar through Timorese off shore workers. However, remittance funds from other sectors could be invested in training for those who are interested in working in this sector. There is some evidence of how a remittance contributes to this sector, the petroleum sector is believed to be engaging more labor. Due to the problematic contracts between the government of Timor-Leste and international oil and gas companies the construction of the refinery and the sourcing of oil and gas have been slower than expected. As a result, there has not been the growth in jobs for the many unemployed. Data from the Ministry of Natural Resources Institute (2011) shows that the oil and gas sector is a major contributor to Timor-Leste's economy. Specifically, in 2009, 79\% of the country's GDP came from the petroleum sector and in $2011,89 \%$ of the Government's revenue was derived directly from petroleum revenue. Further, this sector is predicted to provide more job opportunities, especially in construction.

\subsubsection{Tourism Sector}

Some of the locations of this study are in some of the potential tourism destinations in TimorLeste and remittances have become an important source of investment in businesses, which support this sector. The beautiful scenery, long beaches, green mountains and unique, unspoiled cultural life are truly tourist attractions. Timor-Leste's National Strategic Development Plan (20112030) prioritized the tourism sector as the most promising sector to build the economy (The Government of Timor-Leste, 2011). However, to date, the lack of infrastructure and transportation has hindered the growth and it has yet to achieve its full potential. Other reasons for the slow development of tourism include indecision in selecting the best sites, building the infrastructure 
and training courses in hospitality. As a result, there are currently few job opportunities in this area.

To summarized, although the productive sectors discussed above promise great potential they have not as yet produced the expected job opportunities for Timor-Leste 's growing unemployed which is compounded by the country's burgeoning work force. The work force has grown by $35 \%$ between 2001 and 2010 representing 300,000 to 405,000 people respectively seeking or available for full time work (The Government of Timor-Leste, 2011). Few available jobs are provided by the private sector and the lack of opportunities has led to more and more people migrating to seek jobs and to make money overseas. The main destination of these migrants is the United Kingdom of Great Britain and Northern Ireland, and the workers fully support their families financially. Australia and South Korea are also destinations for migrants and these are fully supported by the government of Timor-Leste.

\subsection{New Settlement of Timorese in Northern Ireland, England, South Korea \&}

\section{Australia.}

The resettlement of Timorese overseas is influenced by political, social and economic factors. However, economic motives are the current trend for the increasing emigration (Mansor\&Qulin, 2006). Since Timor-Leste gained independence, the Timorese people have been able to connect with each other and share information. Further, the advances in technology including mobile phones and the social media enable a wide dissemination of information and communication. In addition, the cheaper cost of airfares and the flexibility of travel documents make overseas travel easier. These factors enable people to find information and communicate easily and those emigrating are able to keep in close contact with families at home.

Moreover, the changes in Timor-Leste's political environment, particularly relevant here, are the bilateral agreements with other countries. These give opportunities to Timorese people to seek work overseas. However, the principle reason for people emigrating is economic. 


\subsubsection{New Settlement in United Kingdom of Great Britain and Northern Ireland}

The recent settlement of Timorese people the United Kingdom of Great Britain and Northern Island is mainly influenced by the availability of jobs (McWilliams, 2011). However, the process of travelling to these countries is complex as the Timorese people have to go through Portugal. As a former colonial power in Timor-Leste, the Portuguese Government gives special dispensations, in Decree law no. 37/81, 3 October 1981, which stated that all territory under Portuguese administration in which their father or mother was born in 1975 has the right to Portuguese citizenship (Minitry of Foreing Affairs Timor Leste, 2011), (McWilliams, 2011). Consequently, many Timorese have used this citizenship as a corridor to the United Kingdom of Great Britain to search for job opportunities. Following are the numbers of migrants as recorded by SEPFOPE, 2014.

Figure2. The number of Timorese Origin Migrant Workers in the United Kingdom of Great Britain \& Northern Ireland (July, 2014)

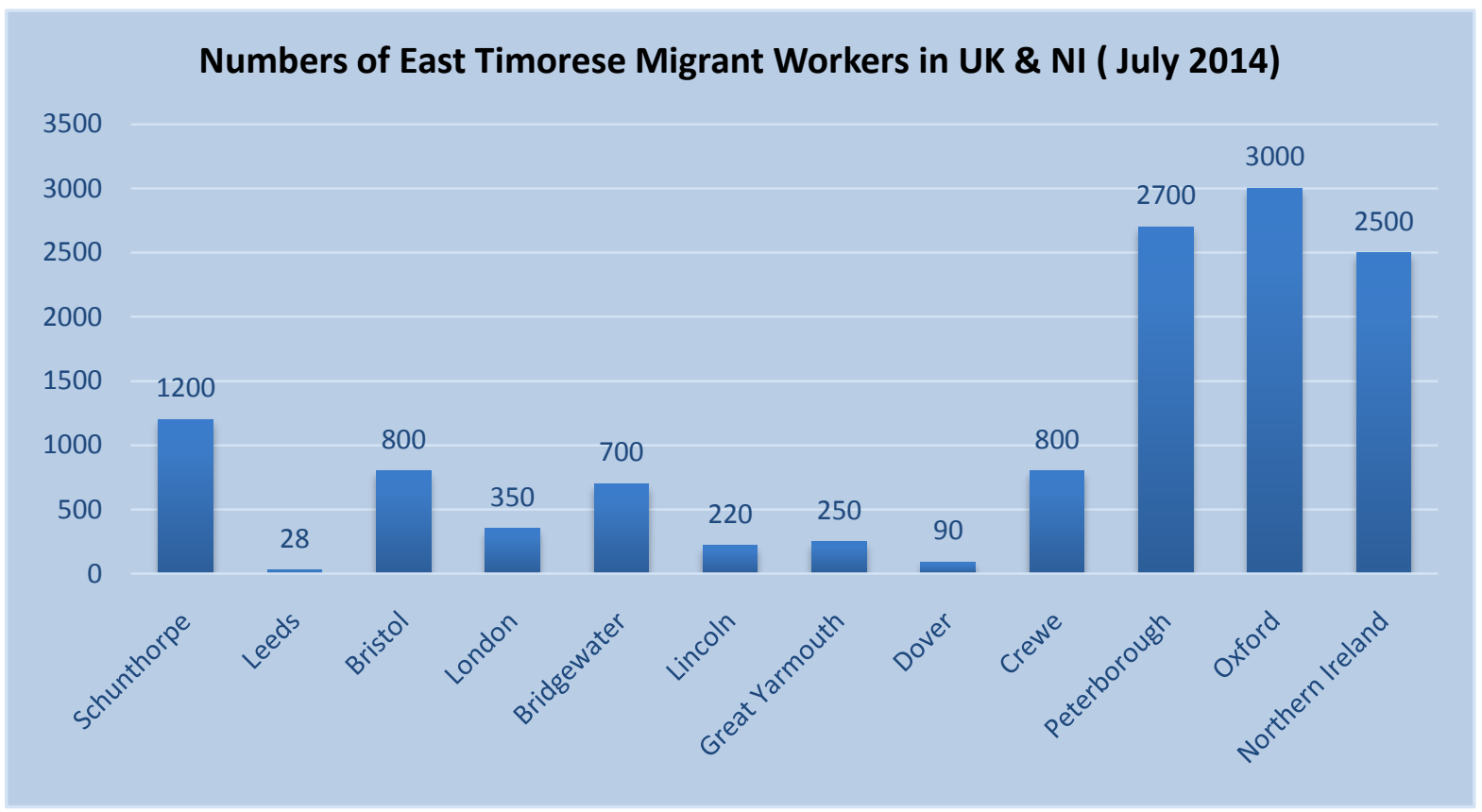

Source; SEPFOPE, 2014

According to the World Bank fact book 2011, the total migration out of Timor-Leste is about 16.8 thousand and the data in 2014 provided by SEPFOPE, showed around 15.18 thousand migrants are in the United Kingdom of Great Britain of and Northern Ireland, which mean that almost $90 \%$ of migrants reside and work in these countries. These large numbers of expatriates and 
the remittances they send home benefit thousands of families in Timor-Leste, however, the World Bank state at the moment that there is no available data on remittances sent to TimorLeste.

\subsubsection{New Settlement of Timorese Migrant Workers in South Korea\& Australia.}

The Independence of Timor-Leste has brought bilateral relationships with many countries in the world. Two examples are between Timor-Leste and the Australian and South Korean governments regarding overseas workers (SEPFOPE, 2014). The numbers of Timorese working in South Korea and the sectors they are employed in are shown in Figure 4 below:

Figure 3. Number of Timorese Workers in South Korea by Sectors.

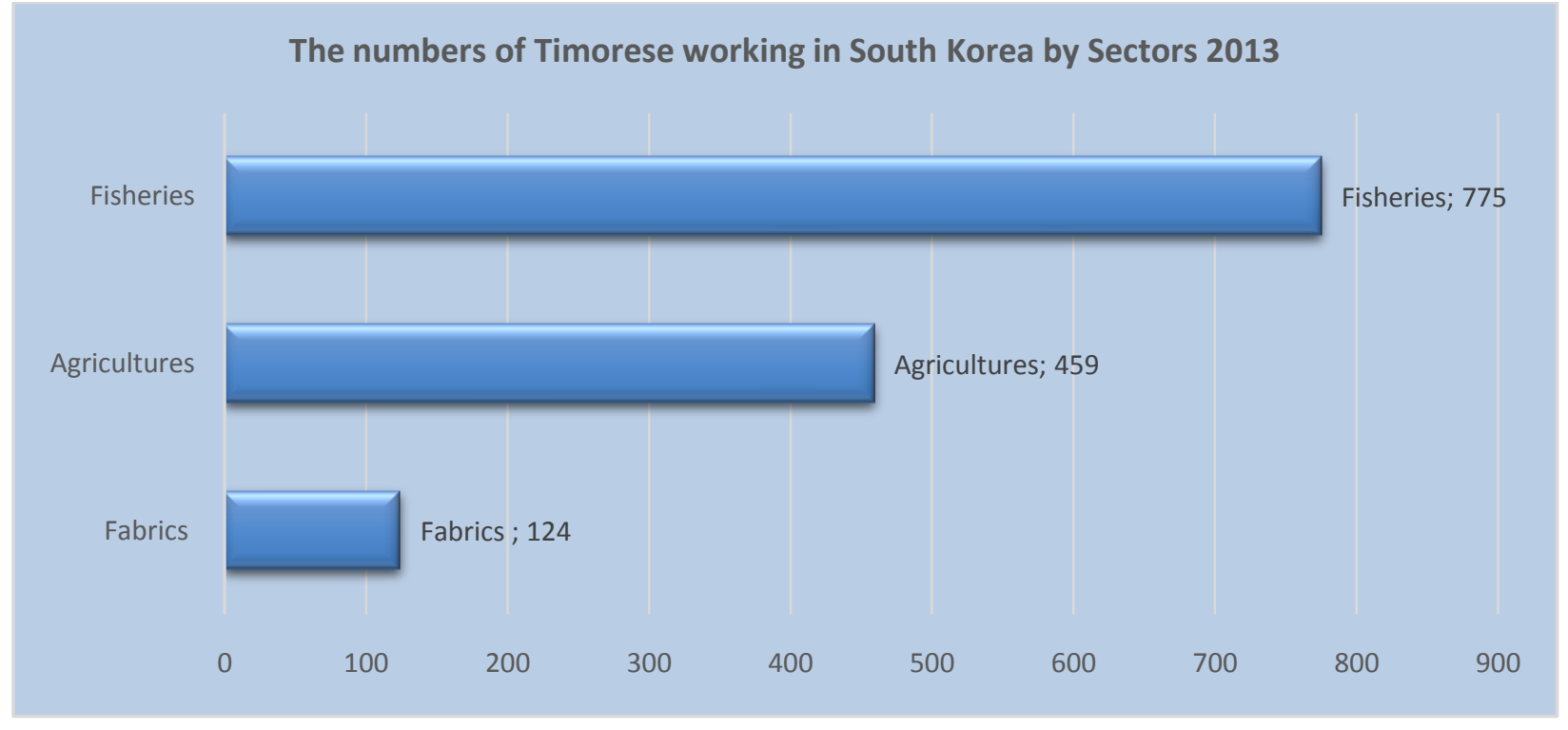

Source: SEPFOPE 2014

According to the data from the National Bank of Ultramarine (BNU) (2013) the transfer of monies from the Timorese workers in South Korea to their families is around US\$ 2,946,838.53 per annum. These remittances play a significant role in supporting many households in Timor-Leste.

On the other hand, the number of Timorese workers in Australia is fewer than, those in South Korea. This is because the programs for migrant workers to Australia are for seasonal workers, 
which offers job opportunities to a limited number of people for 3 to 6 months every year (Timor, 2012).

The numbers of seasonal Timorese workers in Australia and the sectors they work in are shown in figure 4 below:

Figure 4. The number of Timorese Workers in the Seasonal program and the sector they work in, in Australia.

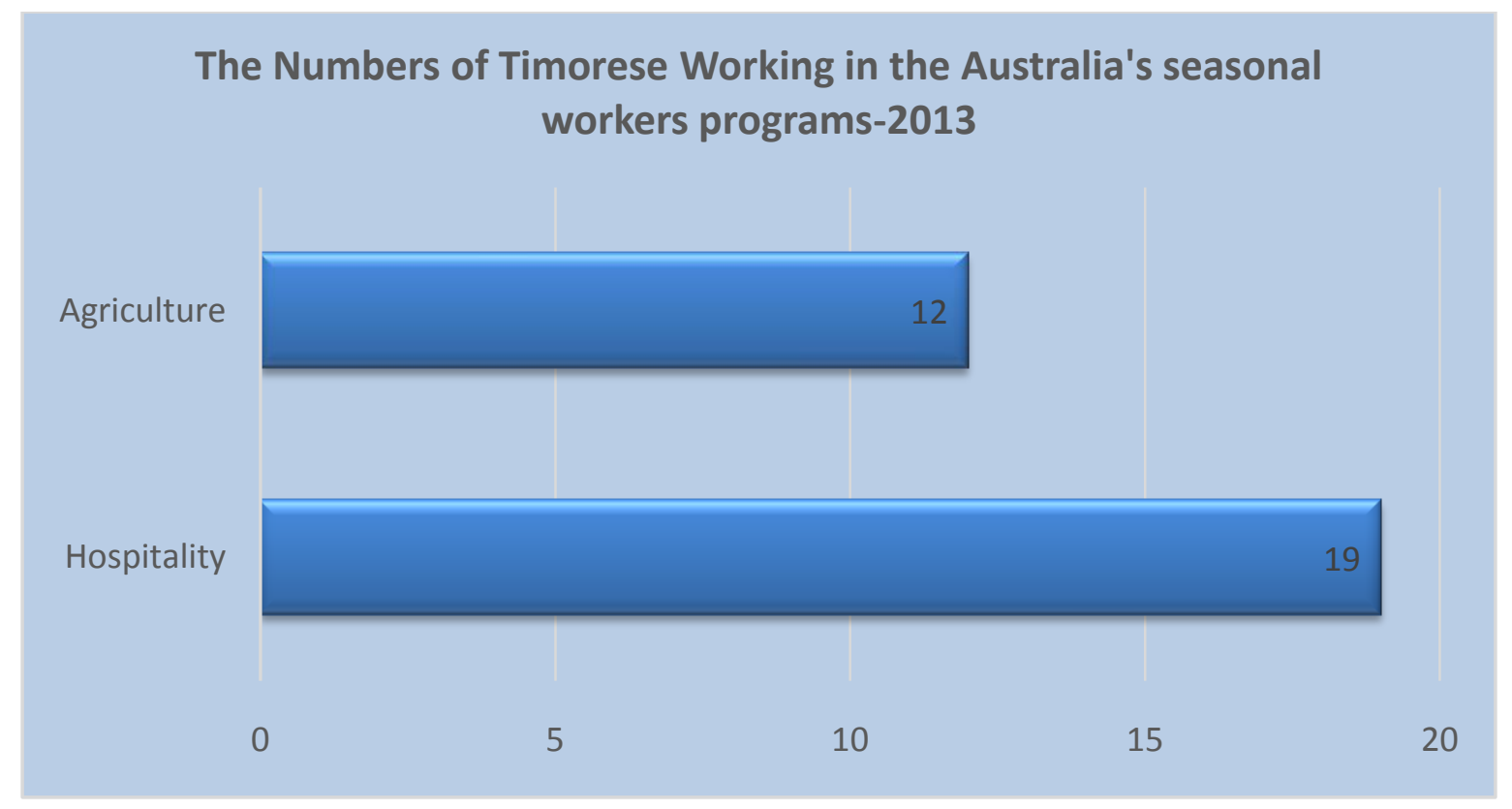

Source: SEPFOPE, 2014

\subsection{Conclusion}

To conclude, remittances are an important source of income to the many families of migrants around the world and in Timor-Leste. I believe that remittances have become one of the sources of income, whichhelpfulfil household basic needs such as consumption on durable and non- 
durable goods, including food, transportation and housing. They are also used to pay for family members' education and are invested in some small and medium business.

As a new country Timor-Leste is facing many challenges. Perhaps the foremost of these is the lack of job opportunities for many young Timorese as few jobs have been created by the three vital sectors of agriculture, tourism and petroleum. As a result, unemployment numbers are increasing, and so many families send their relatives overseas with the expectation of them finding jobs and making money. In addition, good political relationships with other countries, technology advances, cheap flights, reliable networking, and the availability of jobs with good incomes attract emigration to the current destination countries of the United Kingdom of Great Britain, Northern Ireland, South Korea and Australia.

Remittances then have become important sources of income to many developing countries in the world. Although some studies found that remittances have negative impacts on countries' development, there are many positive impacts of the contribution of remittances to the receiving households. The following chapter will present a review of literature and studies done in many other countries in relation to the positive and negative aspects of migration and remittances as well as to the cases of productive and unproductive remittance. 


\section{CHAPTER III: A THEORETICAL REVIEW}

\subsection{Introduction}

This chapter presents the literature review of a selection of available public documents on the topic of migration and development, specifically, unproductive and productive remittances. As mentioned in chapter two, there are virtually no studies to date, which have looked into in the long-term reliance on remittances and their impact on the development of a new country like Timor-Leste.

This chapter is important because it reviews information, ideas, data and evidence, from a particular standpoint and to fulfil certain aims and express certain views about this topic. In addition, this chapter reports on the investigation and effective evaluation of the above documents and evidence in relation to this research. The structure of the literature review is organized as follows. Firstly, it explores migration and development in the Timor-Leste context and highlights previous studies of migration and development in Timor-Leste. Secondly, it will explore the unproductive remittances. Thirdly, a review of productive remittances will be presented and this chapter concludes with a section on developing the research question and hypothesis.

\subsection{Relevant Migration Theories}

Broadly speaking the impact of the remittances of migration are important points to be understood. Migration impacts on the development of the origin country as well as on the host country. These are both positive and negative. The study of migration can be examined under the general rubric of migration theory with diverse conceptualizations from time to time, which present many different points of view about how and why migration emerges and how it correlates with different sectors, including culture, demographics, economics and political and social aspects. In this study, international migration is more relevant than internal migration, therefore to deeply understand the concept of international migration and its impact on the development of the country migrants leave it is important to review all the relevant theory which has a strong connection to the decision for moving from one country to another with the objective of looking for a better life or a job. The following are the different theories of migration and development, which lead to the remittances as the ultimate benefit to the country of origin. 


\subsubsection{Developmentalist; Neoclassical Views.}

The Developmentalist theory emerged in the 1960s and came with the neoclassical theory (Haas, 2007). The neoclassical or developmentlist theory argues that to rapidly drive the development of the economies of poor countries a large input of capital and industrialization are needed. This theory sees migration as the transfer of investment capital from the poor to the rich. Moreover, it presents that many developing countries actively encourage migration because it is seen as being instrumental to the promotion of national development (Kanu, 2015). From this point of view migrants are seen as agents of change, innovation and invention. Therefore, in relation to the local context of Timor-Leste, the government programs for overseas employment ${ }^{5}$ fully adopted this theory because it encourages emigration as it contributes to investment in human capital as well as capital flows from these labor migrants into Timor-Leste. In relation to migration and development, neoclassical theories are divided into two different paradigm schools of thought. These are neoclassical economics: macro theory and neoclassical economics and micro theory. Following are the reviews:

\subsubsection{Neoclassical Economics: Macro Views}

This theory explains that the main point of migration is a process of development (Douglas S. Massey et al, 1993). Its main focus is international migration which occurs as a result of geographic differences in the supply of, and the demand for, labour (ibid, 1993). Kureova (2011) argues that this theory centres on wages. It can be understood that beyond the assumption of full employment, it predicts a linear link between wage differentials and migration flows (Bauer and Zimmermann 1999; Massey et al. 1993; Aidemiret, al. 2007; Kurekova 2011). Further, according to Douglas S. Massey et al. (1993) who looked at the flows of migrants, he noted the migration from poor countries to rich countries and stated that this is a flow of capital and human investment as Douglas S. Massey et al. continue:

The movement of capital also includes human capital, with highly skilled workers moving from capital rich to capital poor countries in order to reap high returns on their skills in a human capital scarce environment, leading to parallel movement of managers, technicians and other skilled workers (p. 433).

\footnotetext{
${ }^{5}$ Overseas employment program is one of the program under National Employment Division of the Secretariat for Professional Training and Employment Policy of Timor-Leste.
} 
Analysing this quote, in the context of Timor-Leste, presents the reality of capital flows from rich to poor countries and vice versa. Moreover, a lack of skill in various levels of professional workers influenced the decision of many people to work overseas and when they left the country their positions were filled by experts from other countries. Although this system is effective in promoting international, migration the theory also provides some perspectives containing several implicit propositions and assumptions. For example, a common reason for people to migrate internationally is that wage rates differ from rich to poor countries (Douglas S. Massey et al, 1993). In reality, wages are not the only reason why migration numbers increase from time to time as there are several factors, which cause migration flows.

From a macro-economic point of view, a high rate of unemployment may be the reason for people to migrate. Therefore, the elimination of wage differentials will not end the movement of labor. Secondly, this theory's perspective on international migration is the transfer of human capital with high skills where it is different from the thought that people movement is caused by wage differentials (Ibid). In the case of Timor-Leste, to reduce the rate of unemployment inside the country, it is beneficial to the country to send more workers, who are categorized as unskilled labor, to work overseas. For example, a case study of overseas migrant workers from the Philippines identified 8.6 million people and the flow of capital, into the Philippines, as remittances, is about USD 17.3 billion which is about 10.8 per cent of the country's GDP (Cai, 2011). However, in other countries, the transfer not only of money but also human capital from rich countries flows into poor counties to fill the gaps in the professions in poor countries such as managers, technicians etc. As a result, remittances or capital, as mentioned, not only flows into poor countries but also much larger remittances flow out of poor countries. Another point is that, in many developing countries like Pakistan, Bangladesh, India, the Philippines and Sri Lanka, returning migrants have significantly higher rates of unemployment (Cohen, 2005).

To conclude, by applying this theory into the overseas employment program of the government of Timor-Leste we can consider some reasons presented above. Further, this theory may provide a way for governments to control migration flows by regulating or influencing labour markets in sending and receiving countries. 


\subsubsection{Neoclassical Economics: Micro Views}

This theory presents the model of individual choice (Sjaastad, 1962-Todaro, 1969, 1976, 1989; Todaro and Maruszko, 1987, Douglas S. Massey et all, 1993). This model presents:

Individual rational actors decide to migrate as a result of calculating the cost benefit and this leads them to expect a positive net return, usually monetary, from the movement (Douglas S. Massey et al: 434).

This quote refers to an individual who chooses to move to a place, which would provide good job opportunities, and financial rewards resulting in money being sent home as remittances.Towalde (2005) describes remittances as monetary and non-monetary items that migrants earn while working abroad and send back to their families. Moreover, according to Ratha (2007) remittances are the flow of money from migrants to their families and friends in their origin countries. However, the economic impact of remittances is dependent upon the prosperity of the recipient households and whether they consume or invest them (Englama, 2009).

\subsubsection{Historical-Structural Model}

This model is inspired by the Marxist interpretation of the development of the capitalism system, which structures the world economy. It included dual and segmented labour markets, the dependency theory and the world system theory of migration (King, 2012). The dual market and segmented labour market focuses on:

A primary labour market of secure well paid jobs for native workers. A secondary labour market of low skills, low-wages, insecure and generally unpleasant jobs in factories and the service sector which are filled by migrant workers because such jobs are shunned by local workers (Ibid. p16).

Gordon, (1995) who states that the dual or segmented theory divides migrant jobs into two styles supports this quote. These are organizational and technological. The organizational style includes the primary workers who have skills, knowledge and experience and tend to have more control 
over their work. The technological style is categorized by labour intensive jobs where workers lack power and are restricted to earning low wages. This comparison shows how different these workers' categories are and result in different treatment in every aspect of employment including wages andworkconditions. An example of a case study from New Zealand provides evidence on how workers are categorized into different segments (Easton, 1994). He stated that seasonal worker employment conditions are comparable to those in the secondary labour market and that woman and ethnic minorities appear more likely to be among this group (Ibid).

The second model of the historical and structural theory is the dependency theory. This theory explains how countries are divided into developing and underdeveloped countries. Sens, (2012) explains that the dependency theory divides the countries in the world into first, secondary and third world countries. This situation provides the opportunity to create an international division of labour to serve and benefit first world countries, which have resources and dominate industry, technology and capital investment from the third world countries, which are mostly dependent on agriculture, and provide cheap labour. Secondly, class distinction within countries between the rich and the working class.Sens further argues that the economic elite co-operate with one another that further exacerbate the divide and this co-operation extends globally and is known as liberalism where third world countries serve the economics of core countries (ibid.). Therefore, the flow of international migration is seen as the dependency of poor countries, which send their workers as cheap labour, to serve the economic interest of rich countries.

The last model of historical and structural theory is the world system theory. This theory emerged in the era of the dependency theory and links the relationship between colonial era ties of the past colonial powers and their former colonies, creating transport and communication infrastructure, administrative links, linguistic and cultural commonalities (King, 2012). According to Messy (1989), Douglas M. Massey (1993),

Migration is a natural outgrowth of disruption and dislocations that inevitably occur in the process of capitalist development. As capitalism has expanded outward from its core in Western Europe, North America, Oceania and Japan, ever larger portions of the globe and growing shares of the human populations have been incorporated into the world mar- 
ket economy. As land, raw materials and labour within peripheral regions come under the influence and control of markets, migration flows are inevitably generated, some of which have always moved abroad. (p. 445).

This quote explains that the whole process of migration is linked to the historical colonial relationships between the rich colonizing and poor colonized countries. Therefore, migration is not just based on wage differentials but is more related to the dependency system of colonization.

\subsubsection{System and Network Theory}

International migration movements are also related to systems and networks. This model is focused on structure, linkages and processes. Further, it has drawn from the general system theory, which is flexible in scale, ideology, internal urban migration, and is followed by the European labour migration to the global migration system or the world system theory (Mabogunje,1970, Poot, 1992, White and Woods 1980: 49-55, Kritz et al. 1992, Wellerstein 1979 cited by King 2012).

According to Douglas S. Massey et al (1993) migrant networks are created by the interpersonal ties between the migrant and former migrants and non-migrants in origin and destination countries through kinship, friendship and origin communities. For example, the case study of Mexican migrants in the United States of America shows the flows of migrants are related to the networks created between migrants in the destination and origin countries (Aysa, 2005). Another example is the case study of Chinese migrants who have spread to many countries using this system (Corrado Guilietti, 2014).

Further examples are the migration from the Philippines (Tacoli, 1999) and agricultural workers from Morocco, who rely on the social ties of family and friends to get work on the same farms in the south of Spain (Poros, 2011). The increasing movements to other countries are because of lower transport costs, less risk and the expected returns from the migrants. Therefore, the migratory flows between two countries are not only caused by wage differentials but other considerable factors like systems and networks. 


\subsubsection{The New Economic ofLabour Migration Theory (NELM)}

This particular research used the NELM theory as a foundation to study the impact of remittances on families left at the origin country. Alexander Abreu (2012) states that the NELM presented itself as a theoretical third way between Neoclassical and Historical Structural Approaches to migration and purported to reconcile agency and structure in a way previously not achieved by either of them. Oded Stark \& David E. Bloom (1985) defines that the New Economic of Labour migration is the theory which explainsmigration decisions are often made jointly by migrants and some groups of non-migrants. This theory suggests the view, that the empirical evidence seems to support that the pattern of remittances are better explained as an inter-temporal contractual arrangement between the migrants and their family (Bloom, 1985).

J. Edward Tylor (1999) describes the theory of new economic labour migration and has proposed two arguments. Firstly, that migration decisions are part of family strategies to raise income and as insurance against the risks of agricultural production. Secondly, remittances, or in some cases the consequences of potential remittances, set in motion a development dynamic by losing production and investment constraints faced by households in poor development countries.

There are some important points suggested by this theory related to the development aspect of migrant money. For example, Taylor (1999) argues that most migration research has viewed migrants in isolation from the family and community context. He believes that migration and remittances may have ignored migrants who send remittances through indirect channels, which were not included in the traditional research approach. He then noted that the true determinants of migration and remittances on development differ across locales. These are where the most impact of remittances depends on migrants, the use of remittances and on the economy such as market and economic policies.

To sum up, all migration models from those implicit in Lewis (1954) to Todaro (1969) and Harris \&Todaro (1970) have presented the view that migration decisions carried out by individuals are shaped by known or expected income differences between migrants' home and host countries. However, these models of migration theory, such as the historical and structural theory, which included dual segmented markets, the dependency theory and the world system theory, 
give different reasons about why the flow of migration increased from time to time. Similarly, other models such as the networks system theory where the movement of people is not based on wage differentials but is more likely to be the connections and strong networks, which ease the process for migrants to settle and get a job overseas. The last and the most important theory, which underpins this particular study sees the impact of migration at origin countries, is the new economics of labour migration.

\subsection{Remittance Theory}

As discussed in the section 3.2, the whole migration theories structured above are important and have relevance to this particular study. As the main object of this study remittance becomes a central debate, therefore the understanding of them needs to be defined. With reference to this BerhaneTowalde (2005) states that:

Remittances are monetary and non-monetary items that the migrants earn while working abroad and sent back to their families living in homeland.

Ratha (2003) argues that remittances are a migrant's capital transfer and are assets that a migrant brings into or takes out of a country. Similarly, The International Organization for Migration (IOM) 2006 defines remittances as the financial flows associated with migration. In other words, they are the personal cash transfers from migrant workers to their relatives in the country of origin. The International Labour Organization describes remittances as the portion of migrant workers' earnings sent back from the country of employment to the country of origin (Puri\&Ritzema 1999). Remittances play an important part in development in receiving countries but there are two different points of view on remittances, which form the backbone of remittance theories in the development aspect. These are the pessimistic and the optimistic points of view.

\subsubsection{Pessimistic View about Remittance Impact at Origin Country.}

The pessimistic point of view believes that remittances make a negative impact on the economy of the origin country. There are some important issues identified in this view. Firstly, remittances should not be encouraged because their ultimate use is invested in unproductive sectors, such as building a new house and buying land. Further, remittances are also viewed as detrimental to the 
growth and development of these recipient/receiving countries because they are mostly used for excessive consumption and they increase the importation of goods, which leads to dependency (Baruah, 2006). Burgess (2004) supports this view by evaluating the impact of remittances using the new labour migration economy as follows:

\begin{abstract}
Remittances lead to "excessive" consumption, import dependency, or "unproductive" investment in housing and land and are no longer tenable. The potential costs of remittances are now viewed as largely deriving from moral hazardous problems. Remittances could ease pressure on governments, faced with large external deficits, to engage in difficult structural reforms. They could also negatively influence labour efforts and savings and the investments of recipient households, even if the remittance sender wants the family to work hard and/or save and invest (P.234).
\end{abstract}

Moreover, Rampel and Lodbell (1978) indicate that remittances are mainly devoted to daily consumption needs. In support of this Massey et al. (1987) estimate that $68 \%$ to $86 \%$ of Mexican migrant remittances are used for consumption. From this point of view, the pessimists' analysis show that remittances are used only for consumption and, for many poor countries, the dependency on imported goods and services will definitely increase.

Adams (2011) reports that, migration and its remittances seem to increase inequality not only for international and internal migrants but also for non-migrants. These views more specifically explain the condition of local markets in countries of origin facing the changes in the price of goods and services in the local economy. One of the examples is the case study of Cape Verde where the remittances, used by the households at the origin country, contribute to the increase of local prices on goods and services inside the country. 
Another researcher who supports the pessimistic point of view is Pablo A. Acosta (2007). He believes remittances create the "Dutch disease ${ }^{6 "}$ which has a negative impact on the economics of origin countries. This pessimistic view argues that remittances lead to overshooting countries' exchange rates and are detrimental to their competitiveness. This phenomenon is known as Dutch disease 7 For example, the study of countries in the Caribbean and Latin America reported that a $100 \%$ rise in remittances affected the real exchange rate (Amuedo-Durantes, 2004). Singer (2010) conceded that the appreciation of the exchange rates caused by remittances is stronger among smaller developing countries. Bourdet\& Flack's (2006, cited by Bakardzhieva et, al. 2010) illustrate that remittances in Cape Verde have affected the country's competitiveness. Remittances are not only said to be disadvantageous to recipient countries' economies but are also considered to lead to moral problems.

Singh (2015) also supports the pessimistic point of view and posits that remittances create a moral hazard problem. In the macroeconomic viewpoint the moral hazard manifests itself in two ways. Firstly, recipients reduce their labour efforts and rely on remittances as single sources of income and secondly, recipients may become involved in risk investment such as gambling (Chami, 2008). This tendency is also reported by Miller, (2001), who found that, households in Thailand who are remittance receivers are more likely to gamble. He also noted that remitters are more likely to gamble than non-remitters are. He then suggests that remittance contact may induce risk-takingbehaviours in destination countries.

Lastly, another view of the pessimists stated by Yu et.al (2014) is that remittances are instrumental in causing human brain drains. In the case of the brain drain, remittances have led to countries losing professional workers who are highly qualified and skilled. The gaps left by these professionals are quickly filled by international experts who expect high salaries thus host countries' monetary resources are not only depleted but the money also flows out to the experts' home countries. Further, remittances also attract people to find legal as well as illegal ways to move

\footnotetext{
${ }^{6}$ Dutch Disease is the deindustrialization of a nation's economy that occurs when the discovery of a natural resources thevalue of that nation's currency, making manufactured goodslesscompetitive with other nations, increasing imports and decreasing exports
} 
from their origin country to a destination country with the objective is to work and produce more money.

In conclusion, the supporters of the negative impacts of remittances reflect the pessimist view as they consider remittances have a negative impact on development and should not be encouraged. Although this point of view has proven some negative aspects of migration and remittances in the origin countries, some scholars posit positive views of the impact of remittances on development. These hold the optimistic view.

\subsubsection{Optimistic View about Remittance Impact at Origin Country}

The ultimate use of remittances has become interesting to study. There are many assumptions about how they contribute to the development of local economies in the countries of origin. These studies provide academic explanations about the use of remittances from two differing views, those from the optimists and pessimists' perspectives. The optimists view the impact of remittances as positive on the recipient households and countries as, they posit, that they could alleviate poverty, promote economic development, ease pressure on governments faced with large external deficits and enable them to engage in difficult reforms. These aspects and others will be discussed in the following sections.

Firstly, Yang \& Choi (2005) consider remittances as positive and posited that they serve as insurance to households during economic downturns. Furthermore, Poirine (1997) states that remittances may represent the migrant's repayment to their family for the financial support they received when they decided to go overseas to work. In the education sector, remittances play a significant role in enhancing human capital. For example, evidence from Botswana shows that the education of recipient families' increase using migrants' remittances (Lucas \& Stark, 1985). This is also reflected in Cox Edward \&Ureta's (2003, cited by Costa, 2006) study which described the impact of remittances on education in El Salvador where school dropout rates have decreased. Another study in the Philippines by Yang (2005) found that remittances have resulted in more children gaining an education, a reduction in the incidence of child labour, higher educational expenditure in the migrant households and increased participation in entrepreneurial ac- 
tivities. Moreover, a study in Sri Lanka by Ratha (2007) observed that remittance flows improves the weight of children under five belonging to female-headed households.

On other sectors such as agriculture and business investment Lucas \& Stark $(1985 ; 1988)$ illustrate that remittances are higher during drought. This point demonstrates that migrants' remittances are important to support agricultural production during adverse weather conditions and therefore protect families in times of famine. Further, Conway and Cohen (1998) found that remittances have become a reliable source of capital when recipients invest them in the purchase of land and the development of small-scale enterprises or farming operations. There are also important findings by Jessaine Sugui Soraya, (2007) who reported that remittances are treated as a transitory income that prompt receiving households to invest in productive activities.

Secondly, remittances could alleviate poverty. Remittances are believed to raise the income per capita of recipient households (Rodriguez 1998), Stark and Taylor (1989) found that:

In Rural Mexico "relatively deprived" households are more likely to engage in international migration and are "better off" households (Pp, 12-14).

Moreover, Adam (1991, cited by Haas, 2009) estimated in his study in rural Egypt that:

The numbers of poor household's decline by $98 \%$ when household incomes include international remittances and they account for $14.7 \%$ of the total income of poor households (Pp73-74).

Although the findings of these past studies are limited due to their small sample sizes they have proven that remittances have little impact on reducing poverty in some cases (Adams \& Page, 2005).

Thirdly, remittances promote economic development, ease pressures on governments faced with external deficits, and enable them to engage in structural reforms. A real example of how remittances contribute positively to a country, when the local economy faces external deficit as well as 
the global economic crisis is presented by Yang (2005) who reports on Filipino household's responses to overseas members and economic shocks at home. He found that during the global financial crisis 1997-1998 many remitters sent money home to their families and as a result the households received increased remittances from overseas.

\subsection{The Migration Issues and Remittance Impact in Timor-Leste.}

\subsubsection{Migration and Remittance Data in Timor-Leste.}

Migration from Timor-Leste has a long history. However, since independence, there are two new factors, which have attracted policy makers, and researchers. The first is the new flow of migration especially immigration numbers and motives in Timor-Leste. Secondly, the topic of remittances and the impact of these on the country's economy have drawn attention. The first is the new flows of migration especially net emigration from Timor-Leste. There is currently no accurate data of migration flows in - out of the country. Estimations show that 16.8 thousand Timorese people become immigrants to other countries (World Bank, 2011). However, the data is vague because it fails to provide the numbers, which settle in destination countries and the purposes of this settlement. For example, the latest Fact Book of the World Bank showed that the top destination country of these Timorese migrants is Australia, Portugal, Philippines, Canada, New Zealand, Netherland, Japan, Republic of Bolivarian de Venezuela, The Czech Republic and Norway. In addition, the report by the migration observatory (2010) described Dili airport as the main gate for people to exit and enter the country, although to date there is no accurate data published by the government institution regarding numbers of emigrants or migrants through the government official website. Therefore, according to this resource there is no reliable data available to draw conclusions on migration flows and patterns in Timor-Leste (ACP, 2010).

Secondly, there is no accurate data on the total remittances in US dollars from different currencies, which produce by migrant in different countries, flowing into Timor-Leste. One of the reasons is that there is scarce research on the impact of remittances and another reason is the lack of empirical studies and poor data availability (Shuaib, 2008). However, an estimation of the amount of remittances, used in this study, shows that USM \$5 of remittances is believed to enter the country every year (Shuaib, 2008). In sum, this section has discussed the rationale behind the migration patterns and remittances in Timor-Leste, since this country achieved independence in 
2002. Moreover, it highlights the lack of a migration data system in Timor-Leste's Immigration Department and the poor availability of data from financial agencies inside the country.

\subsubsection{Migration and The Flow of Labour Migration from Timor-Leste to Destination Country} Overseas.

Traditionally, people movement in Timor-Leste has been caused by political situations. The study by McWilliams, 2011 found that Timor-Leste has experienced a new type of migration pattern. Significantly, his study provided two different findings: The first is there was a new flow of migration in Timor-Leste both inside and outside the country. The study discussed a new form of trans-national migration which included neighbourhood countries such as Indonesia and Malaysia but also well beyond to the destination in Western Europe, such as the United Kingdom of Great Britain and Portugal (Ibid, 2011). Lastly, McWilliams found that these processes included the complex interaction at work between local customs and nation building, mediated through relation of long distance migration (Ibid, 2011). McWilliams study significantly contributed to social science research focusing on migration and transnationalism by fully examining the history of migration patterns in one specific district or ethnicity in Timor-Leste. However, his paper did not provide information about migration development such as the focus on the sustainability of household investments. Specifically, whether remittances are used "now" or for future "productive investments" that positively contribute to the growth of the household economy and therefore will not rely on remittances in the long run.

Another study done by Shuaib, (2008) categorized as the first piece of analytical research work which sought to estimate the value of inward remittances and to assess these financial flows on the livelihood of the poor in Timor-Leste. His study provided a broad picture of how local channels such as banks and non-bank institutions provide services for the transfer of remittances in Timor-Leste. He argued that microfinance institutions in Timor-Leste have limited direct involvement in the flow of migrant workers' remittances (ibid, 2008). He also found that, households with one or more members who have migrated overseas to work and send home remittances are better off financially by many multiples than households pursuing employment in the local market and that the transaction costs faced by the Timor-Leste migrants sending and those receiving remittances are far above the international average. 
In order to reduce these transaction costs MFIs, need to explore their legal rights to be able to transact in foreign exchange. One suggestion is to form partnerships with those already licensed such as Western Union, with a view to serving clients in rural and remote locations.

1. Programs and initiatives to increase the skills base for Timor-Leste workers in order to promote continued access to labour markets in developed countries will be valuable.

2. Government programs to fund potential migrants' travel for overseas employment are necessary to drive the export of labour and grow remittance receipts. Further, the pre-departure and travel costs are a significant burden on migrant families and a policy is needed for governments seeking to promote remittances.

3. The Government's migrant worker program to South Korea should be evaluated in order to identify valuable lessons learnt, and a direction for scaling up its program to both South Korea and other labour receiving countries.

4. There is a need to investigate the outreach of financial services in urban and rural areas, with a view to broadening access to remittance services.

Although, Shuaib's findings focus only on the channels of remittance services in Timor-Leste these findings are really important for this particular study because some of his arguments supported the findings of chapter five of this thesis, which is the processes, and policies of migration and remittances in Timor-Leste.

\subsection{Research Questions \& Hypothesis}

Drawing from the perspective of different migration theoriesand different points of view on remittance theories, provided through extensive studies in other countries, has led to this current study to specify and examine the impact of remittances on Timor-Leste. Using the base line of migration and referring to the impact of remittances, from previous research and studies in Timor-Leste, this study has one key question i.e. what is the Impact of Remittances in TimorLeste? Considering the key question and the different relevant theories, presented above, this study argues one hypothesis, which is that remittances have a positive impact in Timor-Lesteas they are invested in productive sectors such as human capital and small and medium businesses. 


\subsection{Conclusion}

To conclude, this chapter has critically summarized the current knowledge about migration and remittances on the development of countries. The review of this literature also identified the strengths and weaknesses of previous works and related them to this current research. With regard to this objective, I think it is important to review all the theory related to migration and its impact on the development of countries. Therefore, this chapter presented the structural history of migration and led to remittances as the key point to answer the big question of this thesis.

The first point, this chapter presented was the history of migration such as the present views of migration theory from the Developmentalist neoclassical economics: macro and micro views to the historical and structural theories, which included the dual, segment theory, the dependency theory as well as the world system theory. These are important because they have relevance in answering some key questions in this chapter.

Secondly, this chapter reviews the key theories of remittances. The new economy of labour migration is applied as the fundamental theory to examine the impact of remittances to TimorLeste. In addition, the pessimists and optimists' views were reviewed. According to those who adhere to the pessimistic point of view, remittances should not be encouraged because they have negative impacts on development. This perspective has been proven correct by some case studies in different countries, which show that the ultimate use of remittances is in the unproductive sector such as increasing the consumption of durable and non-durable goods. However, the optimistic viewpoints found there are many positive impacts from remittances, as they contribute to the development of households in particular, and local economics in general.

Considering the theories of migration and remittances and a previous study of these in the same location as this one, I adhere to the optimistic view. I consider that remittances give a positive impact on many households in Timor-Leste. To prove this argument, I have formulated one big question to examine this argument i.e. what is the Impact of Remittances in Timor-Leste? 


\section{CHAPTER IV. RESEARCH DESIGN \& METHODOLOGY}

\subsection{Introduction}

This chapter presents the qualitative research methodology used in this study. As a broader discussion in the previous chapter, further study needs to be undertaken to justify more evidence of how the result of remittance impact influences the development of migration and transnationalism in one area. To examine my argument that remittances have a significant positive impact on Timor-Leste, I will demonstrate the appropriateness of the techniques used to gather data and the methodological approaches employed. Therefore, this chapter will initially discuss the epistemology and the standpoint of the basic knowledge used to conduct this research. Secondly, it describes my positionality and reflexivity. Further, this chapter explains various sections of the process and steps undertaken in this research undertaken i.e. research design; data management and data analysis including data limitation. In addition, this chapter will include the anticipation of ethical issues.

\subsection{Epistemology}

The understanding of epistemology is the key to the success of research. Epistemology as described by Soini et.al.(2011) as the nature of knowledge which is related to similar notions such as truth, belief and justification. Sumner (2006) explains that epistemology is the criteria for what counts as knowledge and provides the reference for its trust and the justification. Other than that, the basic assumption of the epistemological stance is to obtain phenomenological insights and revelations, to understand how social reality has been created, to map the context, to study the systems, processes and changes and to construct a positivist science. Therefore, I used the constructivist and feminist epistemology as the foundation of knowledge, which led me to conduct this research.

\subsubsection{Constructivist Epistemology}

Constructivist epistemology has influenced the whole process of my research. Constructivist epistemology is understood as the philosophy of learning and it is founded on the premises that reflecting on experiences, and constructing our own understanding of the world we live in (Saleh, 2006). According to constructivism, there is no single valid method in science but rather 
of diversity of useful methods. Therefore, this understanding led me to position myself as a researcher in social science, to remind me of how I used different theories to back up my findings and provided me with various understandings of different methods used to examine case studies.

\subsubsection{Feminist Epistemology}

The feminist standpoint in this research is complementary to the constructivist view. As stated by Rose (1983) the feminist approach is the relationship between women's positions in science and those of the patriarchal. Timor-Leste has a strong patriarchal system in which people often view subjects with emotion, attitude and interest. In this situation, I acknowledge that my position as a Timorese woman who has gained education in higher learning institutions overseas, as well as my position as a mother in this system, play a significant role as a subject and as an object to interact with participants in this research. This epistemology also stands to see the issues of inequality, the treatment of race-ethnicity, gender and class differences and discrimination are all relevant subjects in this study. As posited by Kitchen et al. (2000, cited by Longhurst, 2003) "Feminism is a political project seeking empowering and emancipator benefits for the research participants" (p.18). Therefore, using a feminist approach as complementary to this study to construct the understanding of conceptual frameworks.

Through the epistemological framework, I look, talk, listen and learn from my participants. I believe that this baseline will guide me to think and seek the truth and non-truth so that I can determine the proper method to evaluate my findings in this research.

\subsection{Positionality}

Understanding my position as a researcher, I have critically put myself as an instrument to experience (Guba\& Lincoln, 1981). The self as both inquirer and respondent, as teacher and learner has brought me to know myself within the research. Moreover, reflexivity gives an understanding that researchers not only deal with the research problem of choices or with whom the researcher engages for research purposes but it significantly influences selves and multiple identities that represent the fluid self in research settings (Alcoff\& Potter, 1993). 
Knowing the position of self as an individual is subjectivity and it is deeply connected to the social and political constructions in life as it shapes people's behaviour and experiences. I am an activist,working through different positions with different organizations in development areas, such as in $\mathrm{HADEMER}^{8}$ as a vice director, in ${ }^{9} \mathrm{CAUCUS} / \mathrm{IRI}$ as a trainer, in ILO as a district coordinator, in Peace Dividend Trust as a program associate, in The Asia Foundation as a planning analyst, in UNTL as a part time lecturer, and as a National Advisor to the Secretariat of State for Professional Training and Employment Policy. This extensive working experience gives me massive advantages to create networks in society and gives me the basic understanding of the developing world and its interferences, especially the world of people who I choose to study. In addition, as a young Timorese woman currently pursuing a Master's degree in the Development Studies at the Faculty at Victoria University, Wellington, New Zealand. Here, I have power among my fellow Timorese to be one of Timorese women researchers and conduct this research with single mindedness and self-confidence. Moreover, I am the mother of one child and I am perfectly healthy, able bodied with an active mind, which privileges me in society and frees me from various forms of discrimination.

As a women and wife who lives in a patriarchal society, I have always had to deal with gender roles, gender equality and domestic violence. This system does not benefit me and I am aware that I am not entirely free from discrimination, however, from the feminism standpoint as I mentioned in the epistemology framework, I have the power to understand and be aware of my positionality. I was born and grew up in a small family in a rural area of the Ermera district and I was privileged to engage in the society. Society is the idea of family construction (Richard, 2002 cited by Fry 2002). My life within my family taught me the values of unconditional love and I was also given active support and safety. In addition to my ethnicity and culture, being black and having similar skin tones to my Timorese fellows has given me extensive advantages as I am viewed as an insider and this gives me flexibility and opportunities to talk, listen and share with the community without concerns of discrimination. Having parents from both sides of the country, my mother is from east and my father is from the west of Timor-Leste, gives me a massive

\footnotetext{
${ }^{8}$ HADEMER is a woman organization working specifically to enhance women capacity in potential business in District.

${ }^{9}$ CAUCUS is an organization under International Republican of Institute working specifically on women participation in politic
} 
privilege and the value of belonging in both areas where my research was conducted. In terms of religion, I live in a society with strong Catholic affiliations. I am a pure Christian and this gives me another benefit because I share the same beliefs with the society of Timor-Leste and I have learned the value of respecting other people based on love and the principles of the God.

On the other hand, as a young woman who is actively involved in many organizations I also share views of and participate in politics. Being young, energetic with an active voice to share community ideas, such as community problems in public media, including local newspapers give me more advantages to deal with research participants in this study. This position has influence on my presence in the community where people are willing to share their ideas and tell the truth. However, I am also aware that this gives the community the high expectation that their voices will be shared in public and help will come from the government. Finally, growing up in a low class family where economic foundations were weak makes me understand living in poor conditions and how families always support each other by giving without thinking of receiving. This enables me to share the same values, ideas and understand why participants in my study, decided to send family members overseas for work. I love Timor-Leste; I take a huge inspiration from those who died for the independence of my country and thoughts of them encourage me to continue my battle to help my community by actively participating in the development of TimorLeste.

Reflecting on this and although the researcher has many identities to bring into the field there are only three categories of self such as research based self, broughtselves ${ }^{10}$ and situational created selves (Reinhardz,1997). I have a clear understanding that the research is not a project but a process. In addition, it uses every aspect of a researcher's position to learn by using different contextual frameworks to discover the subject and to discover self.

In short, the above explanation is not to explore my biases, however, I used it to ensure my values, assumptions and beliefs do not affect my research. I am mindful of how I construct myself, I also understand how other people view and construct me, and so I validate my distinctive truth

\footnotetext{
${ }^{10}$ The brought salve is the salve that historically, socially, and personally creates individual standpoints.
} 
with multiple subjectivities. From all of this I know that I cannot enforce my own experience on others. This is my positionality.

\subsection{Research Design}

\subsubsection{Method of Data Collection}

This study was carried out using a qualitative design method (Gorman \& Clayton, 2005) (Dezin \& Lincoln, 1994, Dezin \& Lincln, 2005) that assumes social constructions of reality. Dezin\& Lincoln (1998) positQualitative research is multi-method in focus involving an interpretive, naturalistic approach to its subject matter (p. 3).

Unlike a quantitative method where researchers rely on numbers and figures, a qualitative method is more focussed on how people feel, what their opinions are and why they decide to do something. The rationale behind using a qualitative method, in this specific study, is because it captures the trends and details of a situation as well as requiring a deep understanding of an issue. As a researcher, I tried to understand the complexity of life, living standards, pictures, word analysis, report details and views of my participants by conducting the study in a natural way. I took such understandings of the study of the impact of remittances from three different techniques of data collection, which are usually applied, in qualitative research such as in-depth interviews, document studies and participant observations. Application of these three techniques will help me answer the research question.

\subsubsection{In-Depth Interviews.}

Interviewing is used to collect information from people. According to Monete at, al. (1986:156) an interview involves an interviewer reading questions to respondents and recording their answers. Furthermore, according to Burns (1997:329) "an interview is a verbal interchange, often face to face, though the telephone maybe used in which an interviewer tries to elicit information". (p.45) In-depth interviews are used to glean the underlying motives of the interviewees' attitudes, behaviours and perceptions. Using this method is the most effective way to communicate with people. To support this Kvale (1999) remarks "conversation is the basis of human interaction. Human beings converse to get to know each other and learn about each other's experiences, feelings, hopes and the world they live in" (p. 5). Analysis of this statement reveals that 
relaxed conversations, with an experienced and flexible interviewer, gathers more insightful information. 30people were interviewed for this research and were asked the same questions ${ }^{11}$ about the impact of the remittances on their lives and the country.10 people were located in the urban areas such as the capital of the district and 10 people were in the rural areas mostly in villages. Another 10 interviews were conducted with the Timorese diaspora from United Kingdom of Great Britain, Northern Ireland and South Korea.

The interviews were between 1 and 1 and a half hours. Initially, the interviewer asked the participants to relate how they decided which members of the family would migrate. This was done to put the people at ease. The interviewer then asked basic research questions to focus the relatively homogenous participants on the topic as it would be expected, they would have shared experiences on the topic (Crabtree, 2006). Before each interview, the interviewer was ethically required to explain the purpose of the study, how the interview will be recorded, how the information will be stored and how it will be destroyed after analysis. In addition, the equipment and materials to be used were explained. These included a tape recorder to record conversations, a professional camera for photographs and paper and pens for making notes.

The interviews with the Timorese diaspora, as these people were living overseas, were conducted through Skype, utilising camera where possible. This was because Skype is universally known, offers face-to-face communication and is easy and cheap to use. To support this Cater et.al (2014) comments that individuals and companies around the world utilise Skype for personal communication, job interviews and travel information as it offers free international calls. Moreover, most of the Timorese diaspora use Skype to communicate with their families at home.

Besides interviewing members of households and many of the Timorese diaspora, researchers also interviewed government members from relevant departments and people from financial institutions (commercial banks and non-bank institutions) that operate in Timor-Leste. As with the other interviewees, these participants were given the same explanations including the equipment and processes. However, the objective of these interviews was to glean their opinions about the remittances from the Timorese diaspora.

\footnotetext{
${ }^{11}$ Unstructured Questionnaires (preliminary Questioners) can be seen in Appendix III
} 


\subsubsection{Document Study}

A document study is another method of qualitative research used in this study. According to Olson (2013) a document study is the source of verities data such as paper, letters, information on the daily activities of people and departments relating to the study. Olson (2013) further mentioned that the analysis of the verities documents provides a window into historical, political, social, economic and personal dimensions of the case beyond the immediacy of the interviews and observations. Beside the primary source of data collected, secondary data such as government or semi-government publications, earlier research, personal records and mass media (Kumar, 2011) play a significant role in this study.

In this study, I have collected government documents relating to the policies and services of migration and the remittance processes in Timor-Leste. These data include the guide or handbook of remittance policies and processes, data from the 3 month report of remittances in and out of Timor-Leste provided by the central bank of Timor-Leste; the revenue report which is included in the GDP annual report provided by the Ministry of Finance; the Portuguese citizenship permits provided by the Ministry of Foreign Affair of Timor-Leste; the policies and processes of immigration provided by the Department of Immigration Timor-Leste and finally the processes and policies of labour migration to South Korea and Australia complete with their report of remittances in to the country provided by the Secretariat of State for Professional Training and Employment Policy. In addition, this study also used various online publications from the government of Timor-Leste and other sources. For example, census data from the Department of Statistics which publishes online, the National Strategic Plan 2011-2030 of the Government of Timor-Leste and the constitution of the republic of Timor-Leste.

Earlier research studies on related topics in Timor-Lestewere also chosen to be one of the materials to complement data needed. These documents provided me with some information I needed to develop this particular study. In this section, I have collected some studies by the ACP (2010), the Leveraging Remittance with Microfinance: The Timor-Leste country report by Shuaib (2008) and The East Timor: Old Migration Challenges in the new Worlds' Newest Country (2004). Fur- 
thermore, I included some reports from the World Bank and other sources, which reported information, relating to migration and remittances in Timor-Leste. Personal records obtained as information were provided by Portugal Embassy regarding some data related to migration, which has not yet been published including the numbers of Timorese labour migrants who are currently working in Northern Ireland. I also used some reports that are published by national and international newspapers and some related information I found on the internet. For example, information about the Timorese labour migrants in Northern Ireland, theUnited Kingdom of Great Britain, South Korea and Australia.

Although these documents are useful and important to include in this study, there are some important issues that need to be considered before using this data as there are some problems with the availability, format and quality of the data. From all the data I have mentioned above, I have found that some have no validity and reliability. Other information from personal diaries and newspapers may have problems with personal biases and lack the rigour and objectivity I expect in this research report. In terms of availability of data, I have experienced that not all institutions can provide data needed because of issues of confidentiality and their interests, especially data related to financial issues. For example, I provided a formal letter to one of the commercial banks in Timor-Leste to acquire some data but my request was rejected because they have no interest in my study. Another case is the data I wanted to collect from the Money Transfer Operators in Timor-Leste, again my request was refused as the regulations of this institution prohibit researchers receiving data. Although I was unable to collect information from these financial institutions, banks and non-banks I have gathered reliable data provided by government institutions regarding the total amount of remittances that come into the country.

\subsubsection{Participant Observations \& Visual Methods}

Participant observation is the third method of data collection, used in this study, to view household uses of remittance money. As posited by Kumar (2011)

"Observation is a purposeful, systematic and selective way of watching and listening to an interaction or phenomenon at it takes place" (p.140). 
This method allows me to randomly observe the conditions of the participants lives. For example, to learn about and ascertain the functions performed by a worker or to study behaviour. In many ways participant observation appears simple and straightforward which means that it could be seen merely as an intention of how you engage with the world around you (Daniel Hammett, et al, 2015).

Observation may take many forms and is at once the most primitive and the most modern of research techniques (Goode \& Hatt, 1952). Realising that each model of data collection has its own advantages and disadvantages, I acknowledge that the participant observations, I chose in this study, also faced the same things. The advantage of this method is that data is independent of people's self-presentation and biases: data on situational, contextual effects rich data on hard-tomeasure topics ${ }^{12}$, and the data yields new insights of hypothesis (Leonard Bickman, 2008). On the other hand, the disadvantages of this method are varied such as constraints on accessing the data; cost; time; observer bias, low reliability which may affect the behaviour of those observed: hard to analyse and report: less rigorous and may be seen to be unscientific. In this particular study, I also wrote down what I observed during the interview with the participant household.

In addition, the visual method is also used as another method in this study. According to Denzin \& Lincoln (1994) the visual method usually uses film, video and photography as means of recording and documenting social life. This method is often called a memory, as it provides realistic information. Therefore, in this study, I used photographs to capture the social changes around the participants. The foci of these observations are the living conditions, including housing, household furnishings and effects, vehicles, television sets and other items as evidence of the receipt of remittances. The camera recorded these under the ethical agreement between the researcher and the participant.

\subsubsection{Forms of Question}

The form and wording of questions used in an interview is extremely important (Kumar, 2011). Therefore, the questions for this study were designed using open-ended questions of different variables to determine the impact of the remittances and demographic questions, which are de-

\footnotetext{
${ }^{12}$ Hard-to-measure means topics refers to emergent behavior or culture
} 
signed to provide distinctive points of information required. Further, the focus of the questions is to provide information relating to the ultimate use of remittances and information about the migrants including: how they adjust to their employment, their income and the regularity of sending remittances to their families. As well as knowledge of the process of their migration, it also involves the process of entering a new job, information about yearly incomes, regularity of sending money to family and channels used to send money home. The questions are structured based on the central question and sub questions. The questionnaires are seeking information on the different levels of participants. These are set at three levels of participants with different questionnaires (1) Remitters and Receivers' households. (2) Relevant government institutions. (3) Financial institutions public and private, which provide the remittance services.

\subsubsection{Sampling}

Lack of data about Timorese labour migrants and their families at home made me decide to use non-random sampling in this study. This is useful because the number of elements in a population cannot be individually identified. The household participants were selected by using the non-random design of snowball sampling. Snowball sampling is the method of selecting a sample by using a network (Kumar, 2011). It is a non-probability sampling technique where the numbers of participants are difficult to locate

The saturation point of this study is 30 household participants including the labour migrants overseas. To start using this technique, I interviewed the first participant from Dili, the capital of Timor-Leste. From his networking, I expanded the interview out of the capital to the eastern part of the country in the districts of Lospalos, Baucau and Viqueque and later to the centre of the country in the Ainaro district and in the west the district of Covalima and the special territory of Oeccusse. To gather information from labour migrants overseas, I started by selecting participants using Facebook. Through this networking, I conducted interviews with migrants residing in Northern Ireland, England and South Korea using Skype. 
Table 2. Summary of remitter's overseas participants by country of destination

Country of destination

\begin{tabular}{|l|c|}
\hline Northern Ireland & 5 \\
\hline United Kingdom of Great Britain & 3 \\
\hline South Korea & 2 \\
\hline Total Participants & 10 \\
\hline
\end{tabular}

Source: Brigida Soares, 2014.

Table 3. Summary of remitter's receiver participants by location

\begin{tabular}{|l|c|c|}
\hline \multicolumn{1}{|c|}{ District } & Urban & Rural \\
\hline Dili & 2 & 0 \\
\hline Lospalos & 3 & 7 \\
\hline Baucau & 3 & 1 \\
\hline Ainaro & 0 & 1 \\
\hline Covalima & 1 & 0 \\
\hline Oecusse & 1 & 10 \\
\hline Total Participants & 10 & 10 \\
\hline
\end{tabular}

Source: Brigida Soares, 2014.

\subsection{Data Processing and Analysing.}

\subsubsection{Data Processing}

The steps taken in data processing is the important part after data collection. In this study the data processing is as follows:

\subsubsection{Editing}

From the raw material gathered in the interviews, I transcribed the original conversations of the 30 participants in the original language into word documents. To ensure that the data was clean after being transcribed, I edited it, which I did by scrutinizing the completed research instruments to identify and minimize possible errors, incompleteness, misclassification and gaps in the information obtained from the respondent (Kumar, 2011 p. 255). 


\subsubsection{Coding}

After cleaning the data, the following step is coding. To do this I manually coded the result of the interviews based on each sub question from the main research question using Microsoft Excel. For this, I used free format data entry (Kumar, 2011). I then divided each sub question into an excel column with the different categories and filled the column with, first the personal information of the participant of my study at the category such as location, name, age, status/ relation to the diaspora and job status. Further, I filled each column created with the main answer of each sub question. For example, the process of migration and the process of receiving remittances, what channel was used, was it easy or difficult and continued in the same style until all the sub questions were recorded in the spread sheet.

Each excel spread sheet has a column and row for each data category. The first spreadsheet consists of columns and raw data. The first data entry is the coding of the migration processes and the remittances' processes in Timor-Leste. Each participant household has its column and the raw data to maintain the information gathered from the row of data after the transcribing. The second data entry is the coding of participant households' expenditure on the consumption of durable and non-durable goods and services, using remittances. The last data entry is the coding of the participant households' expenditure to support a productive sector such as human capital and business investment. Similar to the coding in participant households' interviews, the data from government papers are transferred to separate spreadsheets by category based on the subquestions of this research. The aim of recording this data is to make it easier when analysing and quoting the argument or document, related to the issues discussed in this research.

The data from the notes during observations were also transferred into a separate spreadsheet as complementary to the main data entry from the interview. Some pictures, also captured during the interview, and used as an example of comparison to the statement from remitters family economic conditions. 


\subsection{Data Analysis}

This study used 4 different methods of analysis to explain the research findings. These methods are content analysis, discourse analysis/analysing talk and text, document study and visual data semiotic analysis.

\subsubsection{Content Analysis}

This study used content analysis as one of the methods to explain the findings of the research. Content Analysis is the way to examine forms of communication used to objectively document patterns (Lisa M. Given,2008). Early definitions of content analysis cited by Melissa Harly\&Bryman (2004) are as follow; "The content known as content analysis attempts to characterize the meanings in a given body of discourse in a systematic and quantitative fashion" (Kaplan, 1993:230). In addition, content analysis is the techniques of analysing data from the content of communication into a systematic, objective and it describes it, in a quantitative form (Barelson, 1952: p.8), (Cartwright, 1953: 424).

Given the understanding of these definitions, I have chosen this method to analyse all the data I collected. I used the most common approaches of content analysis i.e. a thematic analysis, where the coding scheme is based on categories designed to capture the dominant themes present in a text. In accordance with this, I divided the main research questions into categories. This way is similar to the opinion of Melissa\&Bryman (2004) who describe content analysis as "Content Analysis resorts to designing different coding schemes for different research questions applied in different types of text" (p. 550). To produce a quantitative form, I chose to use manual coding to identify the common/ similarities of words or opinions from the participant households based on the question categories. A pattern of this coding can be categorized by similarity ${ }^{13}$, differences ${ }^{14}$, frequency $^{15}$, sequence ${ }^{16}$, correspondence $^{17}$ and causation ${ }^{18}$. I chose to do it manually because of the way a participant household describes or answers to the questions, whether simple words are used, whether there is a mix of languages in one sentence such as using Indonesian and Portu-

\footnotetext{
${ }^{13}$ Similarity refers to things happened in the same way

${ }^{14}$ Differences refers to things happened in predictable different way.

${ }^{15}$ Frequency refers to things happened regularly or seldom

${ }^{16}$ Sequence refers to the things that happening in a certain order

${ }^{17}$ Correspondence refers to the things that happening in relation to other activities or event,

${ }^{18}$ Causation refers to the things happening one appears to cause another.
} 
guese languages and whether these are sometimes mixed with the local dialects are difficult to read using an automatic system like Nvivo.

To do this manually, I used open coding to divide the data already collected into segments and then I scrutinized them for the commonalities, which reflect the categories or themes. In order to make it easy to analyse, I maintained the open coding in a Microsoft excel spreadsheet ${ }^{19}$, designed each file with research sub-questions and put each participant's answers into the excel column. To make it quantitative, I used a Pivot ${ }^{20}$ system of the Microsoft excel advanced program to count the household participant's opinions. In this particular way, I created a column to put a code like consumption, school, business, process, difficult, easy and so on. This code then transforms the data in to numbers. For example, how many participants used remittances for consumption, how many participant use remittances to pay school fees and so on.

\subsubsection{Discourse Analysis.}

This study also used discourse analysis as one of the methods to discuss the relationship between the text and the conversation during the interview. Discourse analysis is analysis using written, spoken and sign language as the object, which has comprised a large unit such as conversation and the interrelationships between language and society (Lisa M, Given, 2008). Another point of view presented by Greener (2011) is that critical discourse analysis has a strong relationship between texts and talk, which has a reflective and reflexive approach. Although a deep and extensive understanding of linguistic theory is required, my study used conversations transcribed from the recordings of the in-depth interviews to link and locate these within the wider discourses present within society. For example, in this study I used quotes of the opinions from participant households to link and locate them to the wider discourses of migration and the impact of remittances in Timor-Leste.

\subsubsection{Document Study}

The last method used to analyse these research findings is document analysis. Document analysis is the study of written texts and takes into account the document's physical condition (Lisa M.

\footnotetext{
${ }^{19}$ The Microsoft spreadsheets that build in this research can be seen in the appendix.

${ }^{20}$ Pivot System is one of the Excel's most powerful features. A pivot system allow user to extract the significance from a large, detailed data set.
} 
Given, 2008). In this particular study, I collected some physical documents such as: migration policy papers; the Law of Citizenship which is regulated by the Government of Portugal and from the Timor-Leste Ministry of Foreign Affairs; some documents related to the processes and policies of labour migration from the relevant ministries like the Secretariat of State for Professional Training and Employment Policy; the policy document regarding the remittance services in Timor-Leste from the Central Bank; some physical data related to people's names; numbers of people and the amounts of USDs transferred from some of the commercial banks in TimorLeste

\subsubsection{Visual Data: Semiotic Analysis}

The last method used to analyse this study is semiotic analysis. Semiotic analysis is the analysis of a wide range of materials including visual data such as photographs and magazine advertisements (Matt Henn, 2006). In this study, I have used photographs, taken during the research, to analyse the difference between past and present of these participant households. For example, the condition of houses before any of the participant relatives went overseas to work were built with the triplex and now, after a relative has worked overseas the house construction may have changed from triplex to concrete block.

\subsection{Research Ethics}

Ethics is the science of morality: those who engage in the study of it determine values for the regulation of human behaviour Homan, (1991), Mark Israel \& Lain Hay, (2006). Ethics consideration is an important part of collecting raw material in the qualitative research method, which involves humans as the object of study. According to this, the Victoria University of Wellington requires students who are undertaking research with human subjects, to seek and obtain its ethical approval before starting the fieldwork. I gained ethics approval from the Victoria University Human Ethics Committee prior to beginning my fieldwork. I precisely followed the code of ethics provided by the university for all students conducting field research with human participants. In addition, I acquired written consent from each of the research participants. I also described what the research was about and why I needed to obtain the information. I explained the information sheet, which had been approved by the Ethics Committee. 


\subsection{Limitations of the Data}

I was unable to obtain data about remittances from commercial banks such as the National Bank of Ultramarine (BNU), The Mandiri Bank and other data regarding the transfer of remittances from non-bank institutions such as the Western Union and Money Gram. Nevertheless, I was able to gather data from SEPFOPE regarding remittance receiving which showed the amount of money sent by Timorese migrant workers from South Korea. Therefore, in my analysis, I was not able to present the comparison of how much money was received by each remittance service channel in Timor-Leste.

\subsection{Conclusion}

In conclusion, I am sure that these methods are appropriate to investigate the impact of remittances on Timor-Leste. To support my argument that remittances have a positive impact to Timor-Leste, these three techniques used to collect the raw data, such as in-depth interviews, the study of documents and participant observations are sufficient. As noted in this chapter, the lack of information about migrants and their family addresses, make a snowball sampling the right method use to find the participants. In addition, I focused the study in two specific areas: the urban and rural areas in Timor-Leste.

The sample, from the snow balling method, resulted in 30 interviewees, 20 from the receiving households, both in rural and urban Timor Leste. The remaining 10 were Timorese migrant workers living and working abroad in Northern Ireland, England and South Korea were interviewed. A seconds group interviewed included people from relevant government institutions such as the Ministry of Foreign Affairs, the Ministry of Defence, the Secretariat of State for Professional Training and Employment Policy and the Ministry of Finance. Financial institutions were also targeted including commercial banks and non-bank institutions. The commercial banks were the Central Bank of Timor-Leste BPA, BNU, ANZ and the Bank Mandiri. The non-bank institutions interviewed were the Western Union and Money Gram. Finally, NGOs were also involved in this study. These are the International Organization of Migrants (IOM), The International Labour Organization (ILO) and the World Bank. 
The methodology used in this study is appropriate to examine the issues, of 3 months of data collection in Timor-Leste. The following chapters will present the results using these particular methods. 


\section{CHAPTER V. RESULT ONE: MIGRATION SOURCES AND THE POLICIES AND PROCESSES OF REMITTANCES IN TIMOR-LESTE AND THE DESTINATION COUNTRIES}

\subsection{Introduction}

This chapter discusses the findings of the study, specifically, the process and policies of migration from and remittances to Timor-Leste. In addition, it is has drawn on perspectives from different sources, including, urban and rural participants, the diaspora, the government department that deals with the processes, sources of information and the channels the labour migrants use to go overseas. Further, it discusses the channels of the remittances and the policies pertaining to these both within Timor-Leste and outside the country.

I have summarized all the information regarding labour migrants and remittances. The data I collected is from participants and observations. I have also included the frustrations I experienced in endeavouring to gain information about the policies and procedures of migration and the remittances in Timor-Leste and the destination countries. I interviewed one staff member from the Ministry of Defence (MD), the Ministry of Foreign Affairs (MNEG), the Secretary of State for Professional Training and Employment Policy (SEPFOPE) and the Ministry of Finance (MoF). In addition, I interviewed one staff member from the Central Bank of Timor-Leste (BPA), and one from the ANZ bank. Further, I conducted in-depth interviews with all participant families as stated.

\subsection{Research Questions}

This research specifically looked at the processes and policies of migration and remittances' services in Timor-Leste. The aim was to explore and gain an understanding of government intervention in financial service institution. For example, the policy to regulate the banks, which provide receiver and transfer services and the Government's policy on the emigration, issues to protect the Timorese workers overseas. This chapter answers the questions of thethesis, which is who, sends remittances and who receives them? 
The financial institutions, both formal and informal, play a significant role in the remittance services in Timor-Leste. The research done by AusAID (2008) fully recommended that future research should examine the ways to facilitate access to overseas work, grow inward remittance flows and reduce the transaction costs faced by migrant workers and the remittance receiving households (Shuaib, Laveraging Remittances with Microfinances: Timor Leste Country Report, 2008). Moreover, this thesis explores all the processes of the workers' migration, including those supported by the government and those privately supported by the families. The reason for this is the need for Timor-Leste to find an alternative policy to support labour migration and facilitate the flow of remittances into the country. Shuaib (2008) further stated, "The future labour migration among the young Timorese people may increase the remittances to the region" (p.200). Hence, this primary research complements other academic research related to the transnationalism and development of Timor-Leste, especially with regard to the impact of remittances to the country. A discussion on the migration of the Timorese people follows.

\subsection{Migration Sources and Processes to the United Kingdom of Great Britain, Northern} Ireland, South Korea and Australia.

Migration involves movement from one country or place to another. It depends on many motives and reasons (BICC, 2006). The Geographic (2005), agrees and reported that people move for numerous reasons. These are political, social/cultural, economic and environmental factors. Economic conditions are often the motivation for many in search of better jobs and the promise of a better life (IOM, 2011). A significant point of view is presented by the migration system theory which argues that migration has the links existing between the sending and receiving countries based on colonization, political influence, trade, investment, social and the other factors (S Castles, 2006). In brief, the case of Timor-Leste'smigration is not far from the reasons mentioned.

In this case, study, the reasons of Timorese searching for work in Northern Ireland, the United Kingdom of Great Britain, Australia and South Korea are based on economic factors. Further, colonialization, politics and modernization ${ }^{21}$ have substantial influences and play a significant role in motivating these migrants from Timor-Lesteto migrate, via Portugal, as the former colo-

\footnotetext{
${ }^{21}$ Modernization refers to the advances in social media have contributed significantly to migration. This technology has enabled people to see the lifestyles of the diaspora and the advantages of remittances to families.
} 
nial power in Timor-Leste, to the United Kingdom of Great Britain and Northern Ireland. Thesereasons can be linked backto the structural theory, which focuses on the world system theory as already stated in the literature review.

In addition, Inter Government relationships between Timor-Leste and other countries, in particular Australia and South Korea has created advantages for all. Despite the fact that these relationships support migration from Timor-Leste, little attention has been paid to the process of migration including gathering data about those Timorese migrants who are privately supported by their families to the United Kingdom of Great Britain.

To investigate this, I interviewed one of the directors from the Ministry of Foreign Affairs, he said that:

Timor-Leste has bilateral relationships with other countries regarding labour migration. For example, the agreement between the Government of TimorLesteand South Korea and Australia through The secretariat of State for the Professional Training and Employment policy (SEPFOPE ${ }^{22}$ ). Also, numerous young Timorese flew over to the United Kingdom of Great Britain using Portuguese citizenship which is supported by regulation which exist in the Portuguese constitution $^{23}$. Therefore, the Timor-Leste Government has nothing to do with them. For example, if something happens to them it is the responsibility of the Government of Portugal. (Interview, June 24, 2014).

I also interviewed the director of the Immigration Department in his office regarding the data of young Timorese flying to the United Kingdom of Great Britain. He mentioned that they do not have any data about peoples' purposes for movement. Even though they have the Border Management System (BMS) to record people's movements, it is difficult to detect people's last destination and their purpose for travelling out of Timor-Leste. The following is his statement:

\footnotetext{
${ }^{22}$ SEPFOPE is abbreviation of Secretaria do Estado Para a Politica de Formação Professional e Emprego.

${ }^{23}$ The Portuguese constitution can be seen in the Appendix.
} 
Our system cannot detect peoples' destination countries. They all put Indonesia as the place they visit but when they arrive in Indonesia, they fly to other countries and we don't know that because we do not record their next flight overseas (Interview, June 25, 2015).

He added that people movements for the purpose of work is not their duty to record and suggested that to get information of young Timorese flight's overseas to the United Kingdom of Great Britain and Northern Ireland, the place to ask is the Portuguese embassy in Dili as they have the complete data. In contrast, he said that regarding labour migration to South Korea and Australia, they have maintained data because they have good coordination with the relevant institution, which sends Timorese youth overseas to work. His statement follows:

If you talk about people movement for work purpose, SEPFOPE is the right institution to ask. We coordinate with this institution to get data about how many people are travelling to Australia and South Korea (Interview, June 25, 2014).

His response indicated that there is no adequate system in the government database, to record the reasons people travel. This highlights that everyone who travels overseas has equal status and there are no differences in their reasons to travel. Briefly, the relevant department has paid little attention to the migration issues including data, particularly for the labour migration to the United Kingdom of Great Britain and Northern Ireland using Portuguese Passports. This has a significant effect on a study of migration in Timor-Leste. For example, there are no figures on the numbers of Timorese who have left the country as labour migrants. It is also difficult to control young Timorese who are employed with overseas companies and it is difficult to support them when they face problems such as, smugglers, drugs, murders or other violations of their rights in the host country. In related to this, I interviewed a Timorese diaspora who participated in this study and he said:

We faced many problems here. Timorese gang fighting, murders, and unseen sexual harassment. Many have not been captured and published in the news but many have been published with the statement "Timorese people". Even al- 
though we used Portuguese passport we are not Portuguese, our blood and our heart is Timorese and we expect that the Timorese Government can look after us here (interview, August 5, 2014).

He added that the government of Timor-Leste has only paid attention to the young Timorese who are working overseas in South Korea and Australia but not to those who are now in Northern Ireland or the United Kingdom of Great Britain. He also suggested that the Government of TimorLeste should have a look at this issue because it is a national issue and added "If we are involved in a crime the news will not mention "Portuguese people" but they will always refer to us as "Timorese people". In my observation, his opinion is factual, as in some cases in Northern Ireland or the United Kingdom of Great Britain the news always mentions immigrants from TimorLeste $^{24}$. These findings support the theory of the structural model, whichis more related to the dependency theory, where the classification of poor countries creates a gap in the international division of labour to serve as benefits of rich countries. While the origin countries have weak systems of miniaturization to these youth, diasporas overseas it will be difficult to help these youths in developing their rights as worker in host countries.

\subsubsection{Migration Sources and Processes to South Korea and Australia.}

Whereas little attention is given to the migration process particularly to the United Kingdom of Great Britain and Northern Ireland, the process oflabour migration to South Korea and Australia has a clear systematic process. The procedures for labour migration movements are explained below.

As noted in the dependency theory, the poor country will dependent on the rich country, South Korea becomes one of the good examplesof adestination for labour migrants from Timor-Leste. According to my interviews and observational data, the recruitment of labour migrants, which is facilitated by the government of Timor-Leste, is systematic and well managed. The followingfigures is the sequence of the migration recruitment process to South Korea.

\footnotetext{
${ }^{24}$ Immigrant from Timor-Leste in UK \& Northern Ireland news check the following link. http://www.theguardian.com/uk/2011/jul/16/east-timor-immigrants-fled-northern-ireland-violence, http://www.stepni.org/news.asp?newsid=35, http://www.belfasttelegraph.co.uk/debateni/blogs/hardworkingrespectful-and-warm-we-could-learn-from-our-timorese-guests-30377313.html,
} 


\section{Figure 5. Labour migration processes to South Korea.}

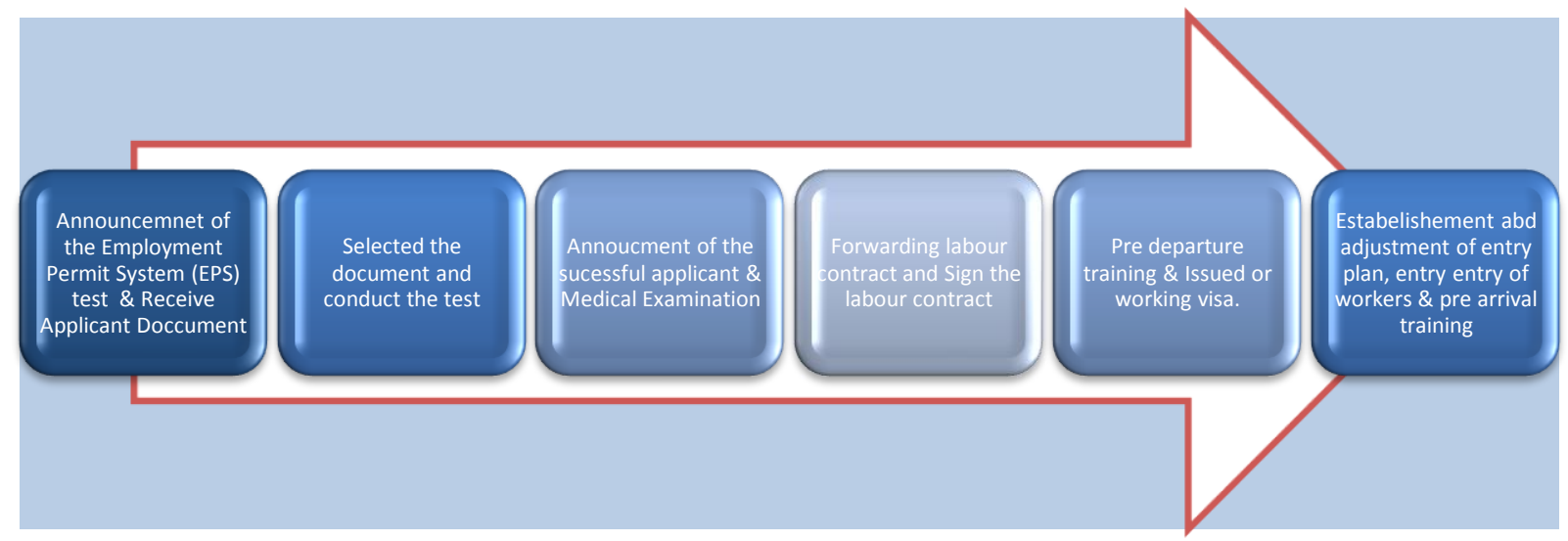

Source: SEPFOPE, 2014

I interviewed the director of the Employment Program from SEPFOPE, Mr. Paul Alves, he explained that the recruitment process to South Korea and Australia are governed by the official government to government agreement ( $\mathrm{G}$ to $\mathrm{G}$ ). In relation to labour migration to South Korea he said that:

The government of Timor-Leste has signed a memorandum of understanding with the South Korean government in relation to their program called the employment permit system. This program started in 2008 and our department had given training to 800 Timorese youth but only 500 have been selected to work in South Korea. The process of our recruitment is that these candidates attend the Korean language training that we provide for effectively 6 months. After sitting and passing, the test we send their names to the Korean system we called $\mathrm{CCBA}^{25}$. Once they approve they send us the contract and we call the selected candidates to sign the contract. The medical examination and we provide them pre departure training and at the end we send them to South Korea based on the quota from the company in South Korea in the Fisheries, Agriculture and Industry Sectors (Paulo Alves, Interview 15 July 2014).

\footnotetext{
${ }^{25} \mathrm{CCBA}$ abbreviation of Certification of Competency in Business Analysis.
} 
He continued and explained that the government has focused on labour migrants sent by it in terms of the worker's protection. He added that to control and look after these workers in South Korea, SEPFOPE has one Attaché and an assistant attaché in the host country. The above details the processes and the policies of the recruitment system to South Korea and shows that this is well managed. It also shows that the government of South Korea plays a significant role in supporting the Timor-Leste Government though their Employment Permit System (EPS). The EPS manages the recruitment of low-skilled foreign workers into small and medium firms in Korea and its principles are responsive to the current situation in underdeveloped countries, which have high unemployment among low skilled workers. There are 4 key principles in this system. They are:

- Complementary - a focus to transfer low skilled labour into small and medium sized industries in the host country

- Transparency - this prevents corruption and possible nepotism in the recruitment process

- Temporary migration - this encourages the temporary workers to return home at the end of their contracts and,

- Discrimination - which ensures foreign workers receive four social/labour-protectionrelated insurances during their employment and a lump-sum pension pay out at the termination of their employment (Yi, 2013).

These principles not only apply to Timor-Leste but also to other less developed countries, which have a bilateral agreement with the South Korea Government.

As seen above, in my observation the system is well documented in terms of recruitment, discrimination, and safety. However, it is limited in scope and other areas of importance are omitted by both governments. The government of South Korea, through its HRD, recruits' workers by examining only their health and language skills. They do not investigate the skills or physical fitness nor does the Government of Timor-Leste, through SEPFOPE. For example, the ability to swim and understand the language of fishing is not checked. 
Despite the agreement between the Timor-Leste and South Korean Governments, including the protection of workers in the EPS, there are many illegal Timorese workers in South Korea. Recently, a local newspaper in Timor-Leste reported that there are many illegal Timorese workers in South Korea because they are not working under the conditions they were contracted at the time they departed from Timor-Leste (Suara Timor Lorosae, 2014). This has occurred because the EPS lacks control over the firms, which recruit the workers and the attache of the TimorLeste Government who is responsible for looking after the labour migrants, does not have control of, nor up-to-date information, on these workers once they settle in South Korea.A similar process of agreement between the Australian and Timor-Leste governments known as "The Work Ready Pool System" " is presented in figure 6 below:

Figure 6. Labour migration processes to Australia.

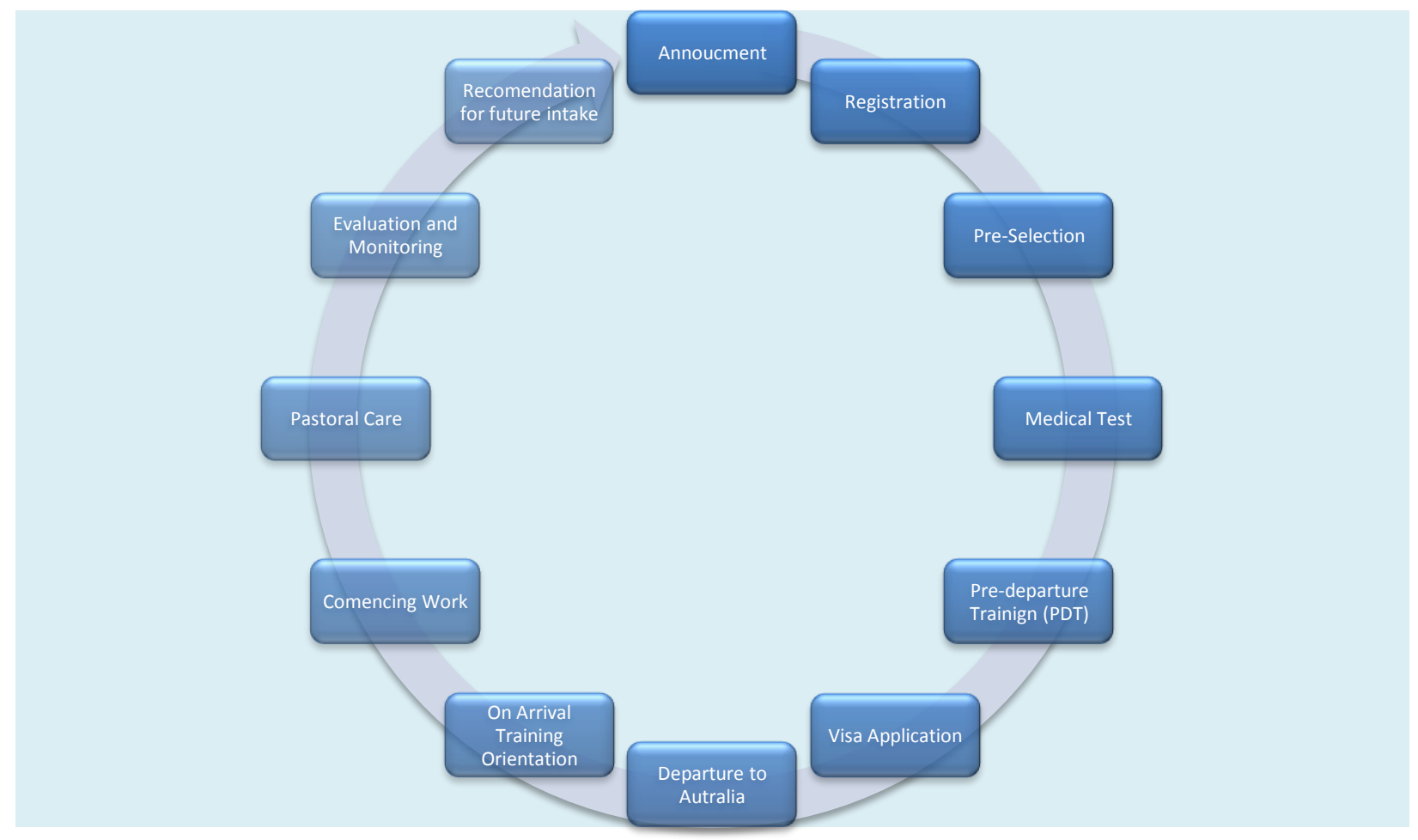

Source: SEPFOPE, 2014

The flow chart shows the process of "The Work Ready Pool System" for short work contracts from 3 to 6 months in Australia. It is also noted that little attention is given to training. Although this information is obtained from the Department of SEPFOPE Employment Program, this insti- 
tutions staff informed me that this program is specifically for members of Pacific countries, which is known as the Pacific Seasonal Work Program. However, the Timor-Leste's Government approach was to apply the same programs South Korea's overseas employment program to the Australian Program.Consideringthe bilateral relations with Timor-Leste, the government of Australia considered this requested and changed the name of this program in 2012. It became the seasonal work program and included Timor-Leste.

We signed a memorandum of understanding with the government of Australia in 2011 and in the first contract we have been offered 30 people to follow the training in the hospitality sector however we only sent 12 people because of their lack of English language as it is the main language of communication (Interview, $17^{\text {th }}$ June 2014).

In my observations, the labour migration program, which is approved by the Australian government, is effective as it gives many employment opportunities to Timorese youth. However, the numbers are limited as are training opportunities. Moreover, there are also a lack of government programs to provide free English courses to all the candidates compared to the Korean language courses provided to those who apply to the South Korea workers program.

\subsubsection{The Process of Labour Migration to United Kingdom of Great Britain and Northern Ireland} via Portugal.

In general, the process of labour migration to Northern Ireland and England is different from that to South Korea and Australia. The Timorese migration to South Korea and Australia is managed, fully supported and facilitated by the governments. However, the Timorese labour migrants, who aim to go to England and Northern Ireland, have to be privately supported by their family, friends and relatives. In accordance to this, I interviewed one of the diaspora via Skype who is currently is in United Kingdom of Great Britain as follow:

I am here almost 10 years. I was travelling from Timor-Leste with travel documents to Lisbon with all the documents required such as my birth certificate and the marriage certificate of my parents to process the citizenship of 
Portugal. After one week, I got my Portugal passport and arranged the flight to come here to the United Kingdom of Great Britain (Interview, 15 ${ }^{\text {th }}$ June 2014).

The differences in the processes of travelling to Northern Ireland and England are not only funding support, but they also take extra time to arrange the necessary documentation. As previously discussed, the Portuguese constitution recognizesTimor-Leste as a previously administrative territory, which gives Timorese people the right to apply for citizenship. This has resulted in a significant increase of Timorese labour migrants to Northern Ireland and England using their European Union citizenship.The processes required when travelling to England and Northern Ireland from Timor-Leste are described in figure 7 below:

\section{Figure 7. The process of Timorese people travelling to United Kingdom of Great Britain and Northern Ireland.}

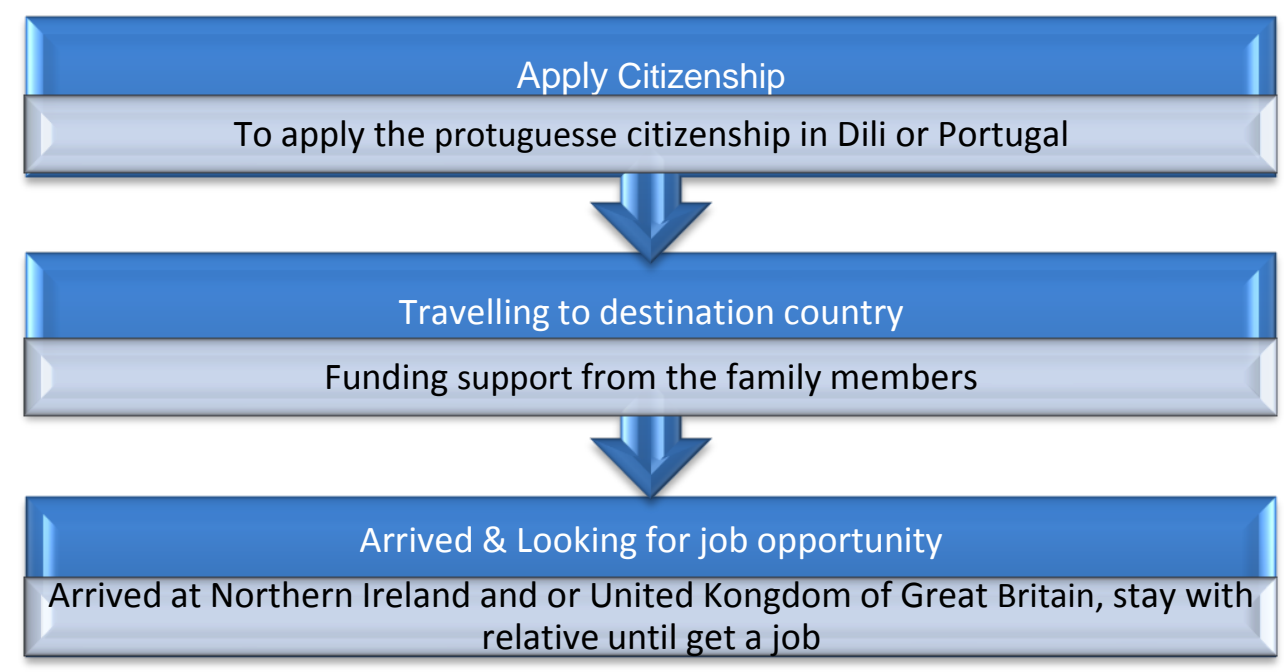

Source: Brigida Soares, 2014

This process can be linked to the theory of system and network theory Douglas S. Massey et al (1993), figure 7,Illustrates the processes the Timorese labour migrants must follow to gain access to countries in Europe. Once citizenship has been gained friends and family gather to discuss the second step - the funding needed. This study found this to be a unique process as it also involves community organizations and a high cultural commitment for the person seeking support. For example, in the village of Ira Ara, the community has a committee which has created an effective system to fund and support prospective migrants. These include, money to arrange for the docu- 
ments, the purchase of the air ticket, accommodation and assistance until the person finds a job. In return, the migrant will refund the monies and act as a supporter, within the same process, for another from the village who wishes to migrate to England or Northern Ireland. Further, interviews with people, from this village, established the fact that this process has been in train since 1999 and 200 households from the area have settled in Oxford, England. The final step is activated once the person arrives in England or Northern Ireland. Again this is organized by the committee at home which arranges for the new migrant to make contact with those already living and working in the destination country. For example, in Northern Ireland, many Timorese are working in low skilled jobs in Moy Park, a chicken factory, and a position is arranged for the new comer. Jobs are readily available in this factory for Timorese labour migrants as they have an excellent reputation for being disciplined, hardworking and work well with people from other countries working in the factory (Neiil, 2014).

The process of arranging all the citizenship documents varies between 1-3 months in Portugal but approximately 1-3 years in Timor-Leste via the Portuguese Embassy. The reason for this difference is the system between the two countries. Therefore, it is more efficient and less costly for prospective migrants to travel to Portugal and arrange their citizenship there. However, the data related to the numbers of Timorese people who migrated to the United Kingdom of Great Britain and Northern Ireland are not accurately recorded in the immigration data base of Timor-Leste. The immigration officers said:

We have a system we call Border Management System (BMS). This system records all the information on people movements however, this system cannot detect the last destination of people. We only have the records of arrival and departure. We check their travel documents such as passports, visas etc. to see if they are valid (Interview $25^{\text {th }}$ June 2014).

My observation is that the system may be effective to protect the security of the country for the purpose of controlling and recording the movement of people. However, to fulfil other purposes such as the compilation of data by the Department of Statistics on the numbers of Timorese emigrants the system is lacking. 


\subsection{Process of Remittance and Policy in Local Context.}

The Bank Payment Authority (BPA) is the central bank of Timor-Leste. The functions of this central bank are described in the law no. 5/2011, which says that the BPA is the central bank, which conducts the monetary policy with the objective of maintaining price stability necessary for the growth and economic development of the country. In addition, the BPA is given the power to regulate and control the currency and financial market and license and supervise the financial institutions established in the country (The Central Bank of Timor Leste, 2011). A BPA officer said that:

With the function that we have, we have also set up a policy on the remittance services in the country (Interview $20^{\text {th }}$ June 2014).

He further stated that, there are four commercial banks operating in Timor-Leste, three of these are identified as international banks and one as the Domestic Commercial Bank in Timor-Leste.

The three international banks trading in Timor-Leste are the Australia and New Zealand Bank (ANZ); the CaixaGeral do Deposito (CGD) or Banku National do Ultramarino (BNU) from Portugal and the Bank Mandiri from Indonesia. The domestic Commercial Bankis the Banku National de Comercio de Timor-Leste that is well known as the Central Bank of Timor-Leste and the Bank of Payment Authority (BPA). The official from the BPA mentioned that:

The banks are the super sale banks or power banks in Timor-Leste and they are the ones, which provide the remittance services. However, the other commercial banks also the have opportunity to provide this service because we provide a guideline for the MTOs licence (Interview, 20 ${ }^{\text {th }}$ June 2014).

Through a study of the BPA's documents, I found one, which sets out the guidelines of the Money Transfer Operators (MTOs). This states that "The Guidelines shall apply to persons or business entitles providing Remittance Services in Timor-Leste including agents of a MTO, their Administrators and Principal Shareholders" (Central Bank Timor-Leste, 2014). In my observa- 
tion of this document, I found it provided a good resource, for the Timor-Leste households of the diaspora, to use when receiving remittances. Even though it contains valuable information, I consider some of it complicated, in particular, the process to facilitate the transfer of remittances, the cost of administration and the process time. These services need to be reviewed and made more efficient. The Banks and other organizations, which provide remittance services, are discussed below.

\subsubsection{Remittance Process in the Commercial Bank and Business}

According to the result of the interview, I provide the channels used most by the diaspora and their families in Timor-Leste.

\section{Table 4}

Numbers of Labour migrants, their families and the channels used to send and receive remittances.

\section{Column Labels}

\begin{tabular}{|c|c|c|c|c|c|}
\hline \multirow[b]{3}{*}{ Location } & \multicolumn{5}{|c|}{ Column Labels } \\
\hline & \multicolumn{5}{|c|}{ Channel used in receiving money at Timor-Leste } \\
\hline & $\begin{array}{c}\text { Banku National } \\
\text { Ultramarino } \\
\text { /BNU }\end{array}$ & $\begin{array}{c}\text { Mandiri } \\
\text { Bank }\end{array}$ & N/A & $\begin{array}{c}\text { Western } \\
\text { Union }\end{array}$ & $\begin{array}{c}\text { Grand } \\
\text { Total }\end{array}$ \\
\hline Total of Diaspora & 1 & $\mathbf{0}$ & 1 & 8 & 10 \\
\hline Northern Ireland & 0 & 0 & & 7 & 7 \\
\hline South Korea & 1 & 0 & & 0 & 1 \\
\hline United Kingdom of Great Britain & 0 & 0 & 1 & 1 & 2 \\
\hline Total of Rural & 5 & 1 & & 4 & 10 \\
\hline South Korea & 5 & 1 & 0 & 0 & 6 \\
\hline United Kingdom of Great Britain & 0 & 0 & 0 & 4 & 5 \\
\hline Total of Urban & 5 & 1 & & 4 & 10 \\
\hline South Korea & 5 & 0 & 0 & 0 & 5 \\
\hline United Kingdom of Great Britain & 0 & 1 & 0 & 4 & 5 \\
\hline Grand Total & 11 & 2 & 1 & 16 & 30 \\
\hline
\end{tabular}

Source: Brigida Soares, 2014

This data I collected, provided information about the numbers of channels that provide a remittance service with the numbers of people using these services. From the data I found that West- 
ern Union is the preferred channel used by these participants, with 53\%using this service. The second preference is the commercial bank BankuNacionalUltramarino, and the third is the Bank Mandiri. The last preference is to send money by a friend. In regards to this, I interviewed participants from the diaspora and from urban and rural areas and used their quotes to explain why they chose these channels and what the advantages and disadvantages of the remittance services in Timor-Leste are.

Table 4, shows that of the 30 participant migrants, from various areas in Timor-Leste, sixteen uses Western Union as the channel to send money home to their families. According to those interviewed, there are different reasons why remitters use Western Union. For instance, one of the diaspora said:

I don't know any channels that can be used to send money from here to TimorLeste. When I arrived here, last time my friend told me to use Western Union so until now I often send money home using Western Union (Interview $26^{\text {th }}$ June 2014).

Others, from rural areas, offered their reasons for using Western Union.From this statement I have concluded that the lack of information become one of the big problems faced by many diasporas who are working overseas, especially the labour migrants to the United Kingdom of Great Britain and Northern Ireland. Interviewees gave different opinions from rural areas:

My brother is in the United Kingdom of Great Britain. He often sends money through Western Union to my parents and because we are here in Suai, he always calls one of my nephews, who studies in Dili, to take it and bring it here (Interview $8^{\text {th }}$ August 2014).

Another interviewee from an urban area said:

My husband always sends money through Western Union. I like to use Western Union because it is not complicated. For example, he sends me money to- 
day I can go and pick it up on the today after. The problem we have is to make sure that the receivers' and senders' names are spelt correctly (Interview $25^{\text {th }}$ June 2014).

From the interviews with the officer from BPA, a migrant and the wife of a migrant, who lives in Timor-Leste, I observed the many difficulties faced by both receivers and senders. The senders do not know how to find the best channel, which costs less and is efficient. This is due to the lack of information about the different MTOs and Commercial Banks, which may offer good prices. However, the receivers face lots of challenges such as the distances between the MTOs and their homes. This adds further costs as it may incur extra costs to get the money, which includes travel and accommodation because they may have to stay one or two days before they are able to gain access to the money. For example, Western Union is located in Dili and the district of Baucau, which is some distance from many remittance receivers.

\subsubsection{Remittance Services in Non-Banking Institutions.}

The second channel, which services a significant number of remittances, is the Banku National Ultramarino (BNU). About ten of the 30 participants, most of whom are labour migrants who work in South Korea, use BNU to transfer money to their families. The reason they often use the BNU is because they have accounts there and can get loans so they get cheaper rates. As explained by one of the government officers from the SEPFOPE "When youth apply to work in South Korea and have passed the test we often ask them, if they have money to buy a ticket and pay insurance and other costs. They often reply either that they have paid themselves or they need government help. Most need government help so we facilitate them to get a loan from BNU for the air ticket, insurance and others costs". He continued saying:

The amount needed is about US\$2,000. When they send money home to their families it will be easier and cheaper because they often share an account with their families like wife/husband and parents" (Interview $15^{\text {th }}$ July 2014).

One of the rural participants said "My brother sends money using BNU and now, as you see, we are building a house". "(Interview $8^{\text {th }}$ August 2014), He also has an agreement with the shop 
down the road about the materials we need, when we call him to inform him that we have run out of materials for the construction of the house he will call the boss of the shop to provide us the materials and I know that he also pays for all the materials through BNU to the shop "(Interview $8^{\text {th }}$ August 2014). My conclusion, gleaned from observation of these cases, is that the government has to provide more options and explain more details to the labour migrants under their program. These includes, sending remittances efficiently and cost effectively, managing them and the advantages of opening accounts with the MTOs.

This research found that one migrant did not use a formal channel to send money. He used family members or friends, who are travelling back to visit their families or to holiday in TimorLeste. This rural participant said, "No I don't use any of the agencies like my other friends. It was expensive so I often send money twice a year through friends of my family who are going back to Timor-Leste. I often send about US\$2,000 to US\$3,000. It is better via a friend or family member than through agencies, which cost me money "(Interview $12^{\text {th }}$ July 2014). In my view, this is dangerous with regard to security as carrying cash creates two possibilities. This is the possibility of it being stolen and the temptation to spend it. The rural participant proved this by saying, "I lost US\$1,500 I was taking home for my family, when I was in transit in Denpasar" (Interview $12^{\text {th }}$ July 2014). While this migrant is able to use families and friends, despite some disadvantages, to deliver his remittances others' choices are restricted.

In general, many participants have no option but to use another channel inside the country to send money back to their families. There are some commercial banks, which provide very cheap remittance fees in Timor-Leste. One of these is the ANZ Bank, which has the lowest fees for remittances if senders and receivers have accounts at the ANZ. This was clearly explained by one of the ANZ officers as follows, "Yes we provide remittance services with very low fees. The fees we charge to send money to Timor depends on the currency used to send the remittances. If they send USDs, the transfer fee is US\$12 and if they transfer money using other currencies the fee is USD\$10. These fees are applied to all the monies sent by the sender whether small or big amounts" (Interview $24^{\text {th }}$ June 2014). Lack of information and socialization from the commercial banks, the Government and the MTOs results in many remitters and their family having no op- 
tions and only use one MTO despite high transfer fees. There are many ways the Government can offer to encourage remitters to send money back. These are discussed in chapter eight.

\subsection{Conclusion}

To conclude, the processes and policies of the migration system in Timor-Leste and the destination countries have faced challenges even though governments support it. It is clearly indicated that migration movements have become interesting programs for many developing countries. Besides the benefit of investment in human capital through the vocational training programs, remittances are another important source of income, which has a significant positive impact on the development of labour migrants' households, in particular, and the country in general.

Although there are positive impacts of migration and remittances to Timor-Leste there are weaknesses in the government of Timor-Leste in terms of recording data on emigrant numbers as the Border Management System only records the valid travel documents and the numbers of people moving in and out of the country. Further information, such as the final destination and purpose of these people is unknown. Moreover, many Timorese travelling to European countries, using Portuguese citizenship makes it more difficult to record the data. On the contrary, labour migration to South Korea and Australia is well managed and protected by the governments. For example, they are insured to cover their safety and the numbers of these labour migrants are well recorded so their movements are easy to control. Therefore, the Immigration office and the SEPFOPE need to implement a system to record the movement of people so the government of Timor-Leste has data about the numbers of migrants and their destinations. Although there is a dearth of information about the people leaving the country the remittances they return is well documented.

The policies and processes of the remittance services are well recorded. The remittance services' policies are regulated by the BPA, which provides the guidelines and licenses to commercial banks, and the MTOs. Despite these, the remittance services in Timor-Leste are quite competitive. The four super sale banks provide remittance services as do the 3 big MTOs such as Western Union and Money Gram that also provide these services. However, there is a lack of information and socialization to the remitters and their families about the advantages and disadvan- 
tages of using these channels and as a consequence, the competitive remittance market is not effective in reducing the fees of the remittance services in Timor-Leste. The direct impact of remittances on development will be discussed in the next chapters. 


\section{CHAPTER VI. RESULT TWO: UNPRODUCTIVE REMITTANCES - CONSUMPTION, PROPERTY INVESTMENT \& TRADITIONAL EVENTS IN TIMOR-LESTE}

\subsection{Introduction}

In chapter five I offered a broad explanation of the processes and policies of migration and remittances which answer the three sub questions of this research. This chapter focuses on the impact of these on the remittance recipient households and will answer question number four. How are the remittances spent? How do the remittances effectively develop the economies of the families and the community in general? The answers to these will support my stance that remittances to Timor-Leste are not all used for the consumption of non-durable goods ${ }^{26}$ but are also spent on durable goods ${ }^{27}$. The study also found that household participants used remittances for cultural events such as funerals, dowries etc. Even though some argue that remittance consumption on food, basic necessities and housing are considered unproductive. This study found that there are some positive and productive impacts of these in local contexts.

\subsection{Remittances and Household Consumption.}

To seek an answer to the above question, it was necessary to understand the socio- economic characteristics of the participant households in Timor-Leste. The most recent data suggests that $80 \%$ of households in Timor-Leste rely on agricultural activity as a major source of income. Although this is the main source of income for many, the vast majority of agriculture activity is small scale, self-sufficient or subsistence farms, which make only a slight contribution to local communities as a consequence of very low harvests. Therefore, in relation to household income there is very little, from this sector, to support householdconsumptionfor durable and basic nondurable needs.Most of the participant householders in rural and urban areas, in this study, explained that it is very difficult to improve their incomes as farmers. This situation is one of the reasons for them to send their members overseas to make more money to maintain their families' economies. I interviewed Afonso Martins about his decision to send his son to work in the United Kingdom of Great Britain. He replied as follows:

\footnotetext{
${ }^{26}$ Non-durable goods is refers to food and clothing

${ }^{27}$ Durable goods refers to housing, land, transportation or other hard goods
} 
I don't have a permanent job, I am only a farmer who cultivates corn and peanuts every season. My wife and I don't get much money out of every harvest time. Therefore, I decided to send my son to the United Kingdom of Great Britain to work and send money home to support the family economy (Interview, $11^{\text {th }}$ July 2014).

Lack of income and the composition of people in one household have a significant effect on the consumption of durableand non-durable goods. As the theory of consumption proffers "consumption can increase significantly when the economy does not offer full employment (Rischard W. Kopcke, 2013). The more people who live in one house, with most unemployed, the need for non-durable goods increases resulting in greater expenditure on consumption. Another participant I interviewed also mentioned this:

I have five children and 2 sisters who live here with my husband and me. We do not have any jobs and our economic condition is very weak. Therefore, one of my uncles who went to Northern Ireland a long time ago, supported my husband to follow him so he can work like other people and send us money (Interview, 11thJuly 2014).

Remittances from the Timorese diaspora have played a significant role on receiving households' consumption. As a single source of income, for many of these households, the remittances have been used mainly for the purchase of basic family necessities. This behaviour is linked to the pessimistic point of view of Rampel and Lodbell (1978) which indicates that remittances are mainly devoted to daily consumption needs. However, other families spend the remittances on building new houses, purchasing a vehicle for family activities such as a motor bike, buying furniture and other household equipment or buying land as a future investment. These are considered unproductive uses of remittances. The following section will describe the details of household consumption in these three categories. 


\subsubsection{Remittances and Household Consumption on Unproductive, Non-Durable Purchases Goods}

such as Food, Clothes and Household Equipment.

Remittances play a significant role in supporting recipient target families' basic needs in rural and urban areas of Timor-Leste. Almost 100\% of household participants informed me that this fund was spent on household consumption such as food, clothes and household equipment. However, due to the regularity of receiving these payments, from family members overseas, there is often excess for expenditure on durable goods such as building a new house, renovating an old one or buying land. Figure 8 below, describes the expenditure on non-durable goods according to the information gathered through the in-depth interviews in this study.

Figure 8. Percentages of household consumption on food, clothes and house equipment by location.

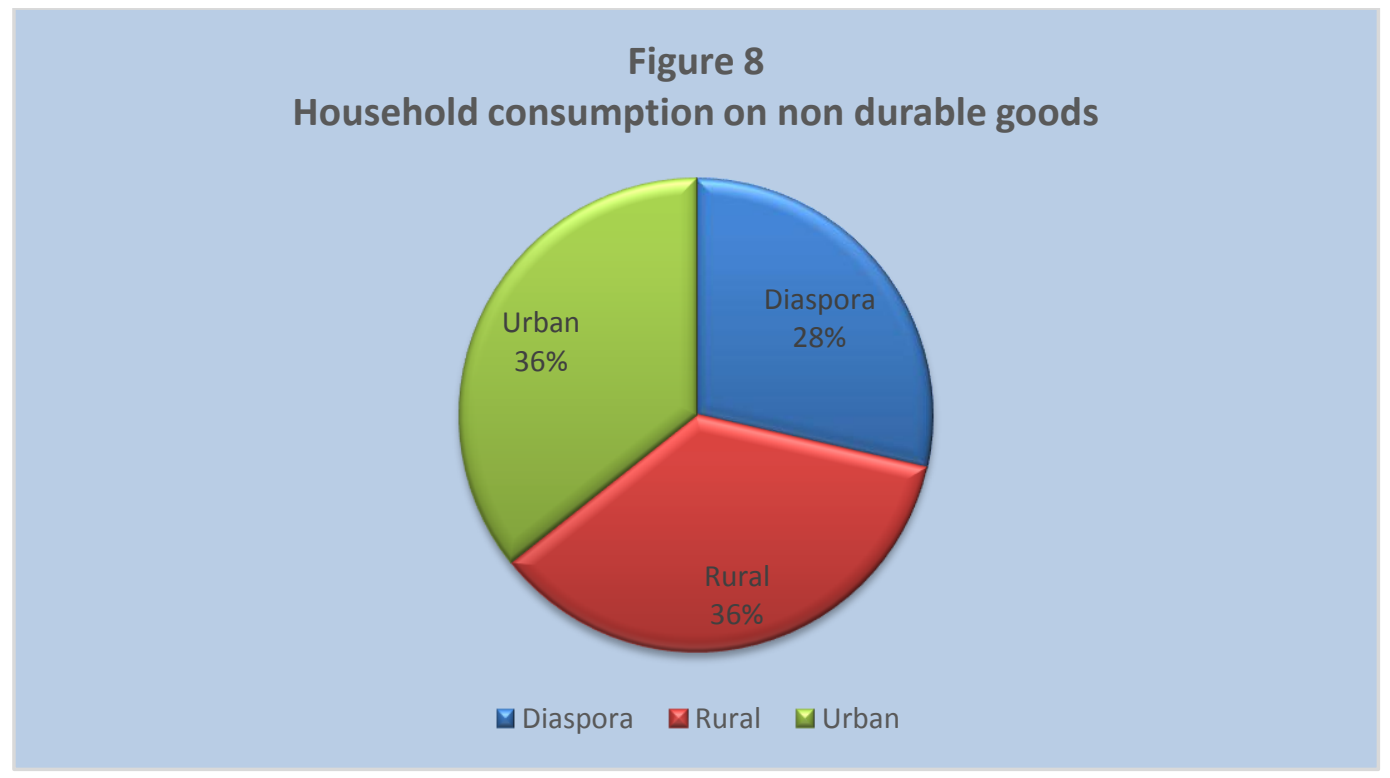

Source; Brigida Soares, 2014

Figure 8, shows that both urban and rural areas spend about the same percentage of remittances on non-durable goods, followed by the diaspora participants.

The following quotes from participants from rural and urban areas describe how they use remittance: 
The money I receive, I always spend some to buy food and clothes and sometimes I buy household equipment such as a TV, a refrigerator or other kitchen tools. But our focus is to finish our house (Interview, urban areas, $20^{\text {th }}$ July 2014).

We spent the remittances to build our house but I also spend some money to buy daily food and other materials for the household. Firstly, I do not have a job or other source of income to buy food, secondly as you see I have four kids and there are also my two younger brothers who stay with us here. My husband is now in Northern Ireland working to support our family here (Interview, rural area, 8thAugust 2014).

In addition to this, $28 \%$ of the diaspora participants stated that the money they send home to their families is first to support their families' daily needs such as food, clothes for the kids and other household equipment. However, to build a new house for the family is also a priority. This is stated in the following quote by one of the diaspora participants:

I send money home to support my family. My parents have no permanent jobs and they rely on agriculture products, which create insufficient funds to support the family for the whole year. Therefore, money I send home is to help them buy food, clothes and housing equipment when they are needed. My first priority is to renovate the family house and I will invest in another business when I go back (Interview $6^{\text {th }}$ July 2014).

The information above shows remittance funds are indeed used for consumption on basic household needs however, not all the money is for these. Other types of consumption include building a new house. Adams' (2006) study, found that a smaller share of the income of remittancerecipient households is used for food and other non-durable goods and the larger share is for housing, education and healthcare financing. Timor-Leste is a new country and its economy and systems are still weak, vulnerable and dependent. The lack of job opportunities has resulted in 
many unemployed and therefore many households have no income. Besides this, there are no social benefits' program such as unemployment benefits, assistance for widows or for single parents to support their children. Therefore, the remittances play a significant role in filling the gaps to support daily necessities for households.

The first key point is the irregular or lack of permanent income for households. In Timor-Leste, according to the data from the National Statistics, 3.6\% of unemployment is caused by the scarcity of industry in the country. This situation is one of the factors why people choose to migrate overseas to look for jobs to support the economies of their families. This is further supported by the theory of the new economy of labour migration (NELM) which states that "migration decisions are a part of family strategies to raise income, obtain funds to invest in new activities and insure against income and production risks and remittances consequently set in motion a development dynamic by losing production and investment constraints faced by households in developing countries". In conclusion, migration overseas for job purposes enhances the economies of families at home in the short term and drives the circulation of income inside the country. The second key point is that Timor-Leste has no government social programmes as discussed. There is however, a public payment every year but this is limited to pensions.

\subsubsection{Household Consumption on New Housing and Housing Equipment.}

New house construction is a significant feature of unproductive consumption in this study as most participants informed me that their remittance funds are spent on building a new house. As illustrated in table 6.1 the highest numbers of new houses are built by urban participants using their remittances. Table 6.1 also shows information from fourteen participants, seven from each household, including the members of the diaspora of these families. From the total of thirty participants six spent their remittance funds on other consumption, which does not include house construction or the purchase of land. The complete data of new house construction and land purchased by location can be seen in Figure 9. 


\section{Figure 9.}

\section{Household consumption on new house construction and the purchase of land by location.}

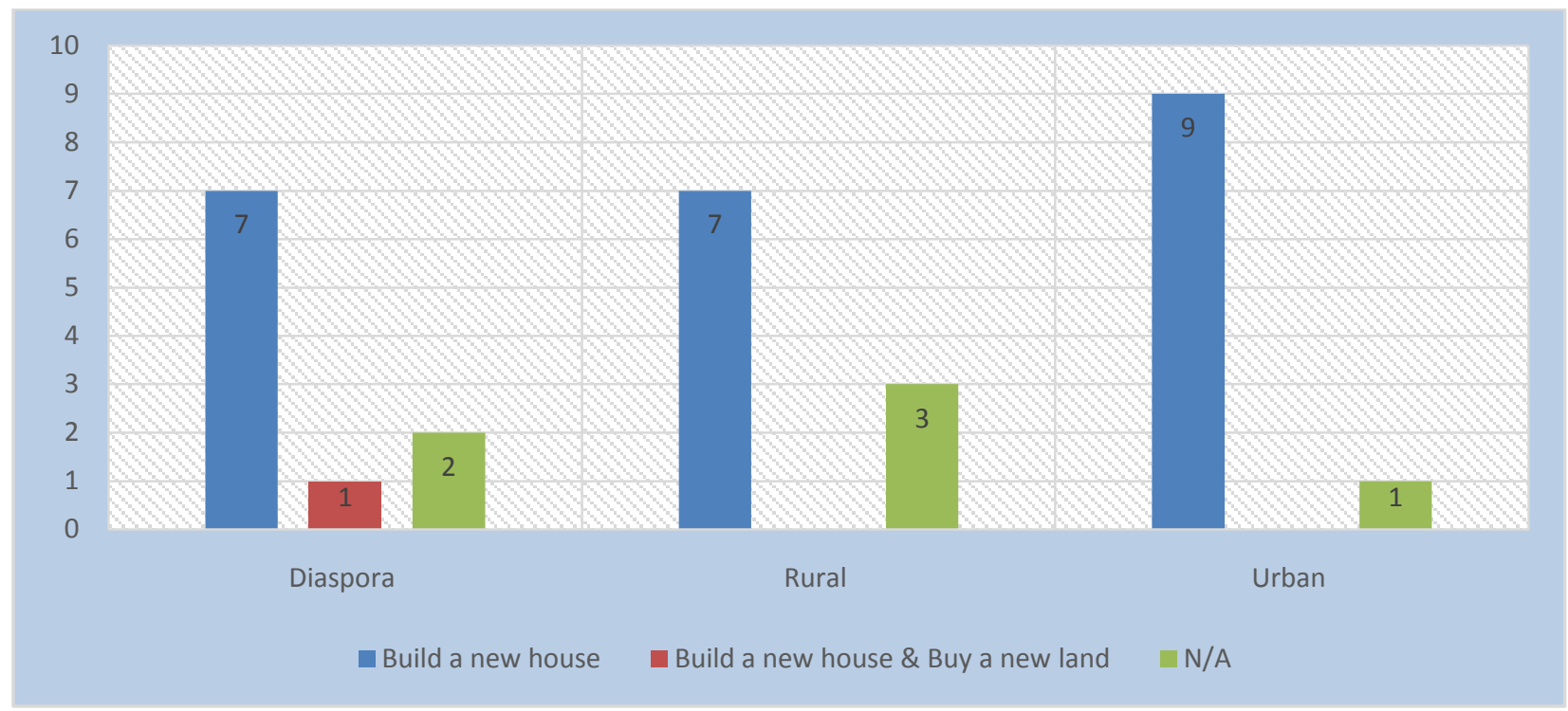

Source; Brigida Soares, 2014.

From the data provided, the consumption behaviour of these urban and rural participants varies. The first variation is the geographic location. In Timor-Leste the business centres are in the urban areas where many shops and businesses are located and this makes it easier for households to purchase all the construction materials at lower costs. These also include cheaper transportation and labour costs. This is supported by one of the urban participants who said:

I live in town, which is a good location for my family. When my son sends me money it only takes 10 minutes from my place to collect the money from Western Union. Now you see this house is complete because everything is easy and cheap for us. If we want to buy materials, we just go to the shop and their car is ready to deliver here free. If I want to buy a concrete block I call them and they send it and I pay for it here. How easy things are now days (Interview $24^{\text {th }}$ June 2014).

On the contrary, a number of participants from rural areas reported that it is expensive for people to build a new house or buy land in their areas because of previous ownership complications dating back to the Indonesian occupation. A participant continued saying that the cost of transport is 
high,as he has to rent a truck to carry building materials to his village. The following quote explains the situation:

My village is far away from the district town. I have used the money sent by my son to build a family house, but the construction is still not finished because everything is expensive from my village. I have to rent a car from Dili or Baucau to bring the materials here and it costs a lot of money (Interview 23th July 2014).

Another varying factor between families receiving remittances is the difference in jobs and income of their overseas families as well as the amount of money they can send home. For example, some of the overseas families earn from 250 pounds to 300 pounds a week if they work overtime (Interview 11 July 2014). Another diaspora participant mentioned that he made around 1200 pounds every month, which is equivalent to USD 1800 per month (Interview 24 June 2014). These incomes are more than those of public servants in Timor-Leste and therefore a family receiving money from overseas is able to build a new house. Some migrants send money home with this as the priority objective as mentioned by one of the participants:

My first priority as head of the family is to build a proper house to accommodate my family, I have many kids and I want them to have their own rooms, besides they are gown up now, therefore my wife and I set our priority to build a new house rather than spend on other consumption (Interview 12 July 2014).

The final factor influencing the migrants to send money home is their willingness to do so. Altruism and obligations are often the reasons for this as illustrated in the following quote:

I am the older son. My parents do not have jobs, which have permanent incomes. They are both agriculture workers but we have no agriculture products we can rely on all year. As a first son I have the responsibility to support my parents and look after my younger brother and sisters, therefore I need to send them money regularly to support the family (Interview 14 June 2014). 
Apart from these differences, this study found that many of the participants spend remittances on not onlyfood, clothes and other non-durable goods but most send money, to build or renovate a house or buy land as an investment for the future. This is similar to studies in other countries. For example, a case study of remittances and housing in Nigeria, found that older migrants and those with higher incomes are more likely to invest in housing. If they receive more income by working overtime, which often increases their wages by $10 \%$, investing in housing can improve their investment by $3 \%$. From the standpoint of migrants, this remittance expenditure on housing represents an important form of local investment (Osili, 2006). Following is the sequence of how household consumption can produce multiplying effects in the local markets.

Figure 10. Flowchart of How Household Consumption on New Housing Affects the Local Markets in Timor-Leste.

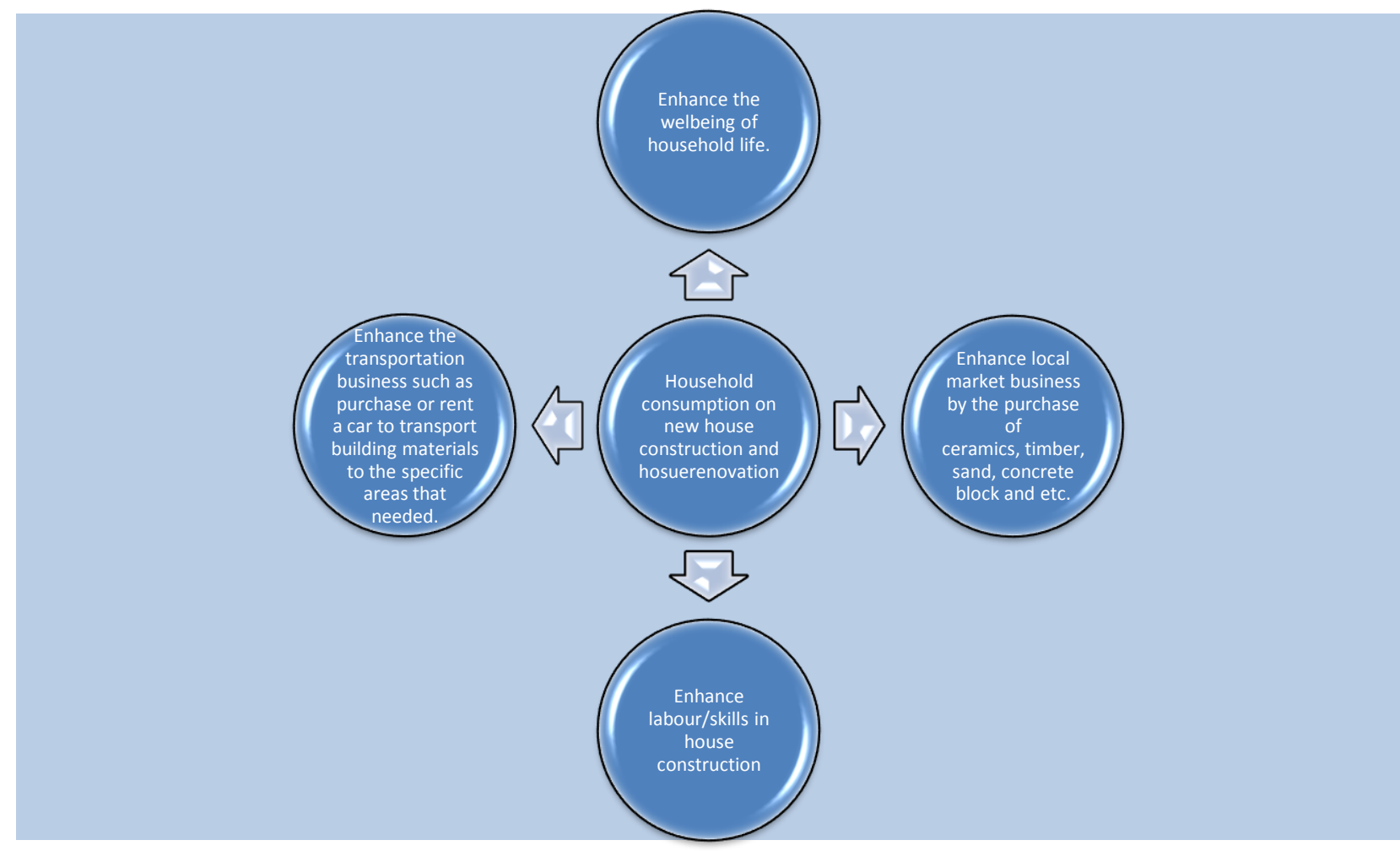

Source: Brigida Soares

The chart above shows that household consumption on building a new or renovating an old house or buying land for the family generally has the widest impact. Firstly, household consump- 
tion on new house construction or renovation will enhance the wellbeing of the family by having a proper kitchen, an inside toilet and children are able to have their own rooms. Secondly, new house construction sustains local businesses such as timber, concrete block businesses, collection and delivery, by locals, of sand stone from nearby rivers, the production of ceramics and so on. From the purchase of these materials locally, the remittances also bring a positive impact to local markets. Thirdly, household spending on house construction or renovation develop and enhance the skills of the temporary labour force, many of whom have unsuccessfully sought work in Dili, the capital city. Therefore, working on construction in their home areas builds their skills while being paid with money from the remittances. Lastly, house construction and renovation also increases the income of those who have transport businesses and enables them to hire staff. In general, this explanation relates to Magnusson's (2010) ideas, which include:

Remittances allow households to purchase goods they would otherwise need to produce which increases the market for even basic household goods and the available labour supply, as individuals are able to focus on outside employment rather than household production (p 6).

Few people in Timor-Leste can afford to build a new house. Those who are public servants can obtain bank loans, those agriculture workers who have regular incomes, business owners and people who regularly receive remittances from their relatives working overseas. The following picture shows a house built from remittance funds, which improved the householder's living conditions. 
Figure 11. A new house built in rural, Covalima, Timor-Leste, by a family who receive remittances from overseas.

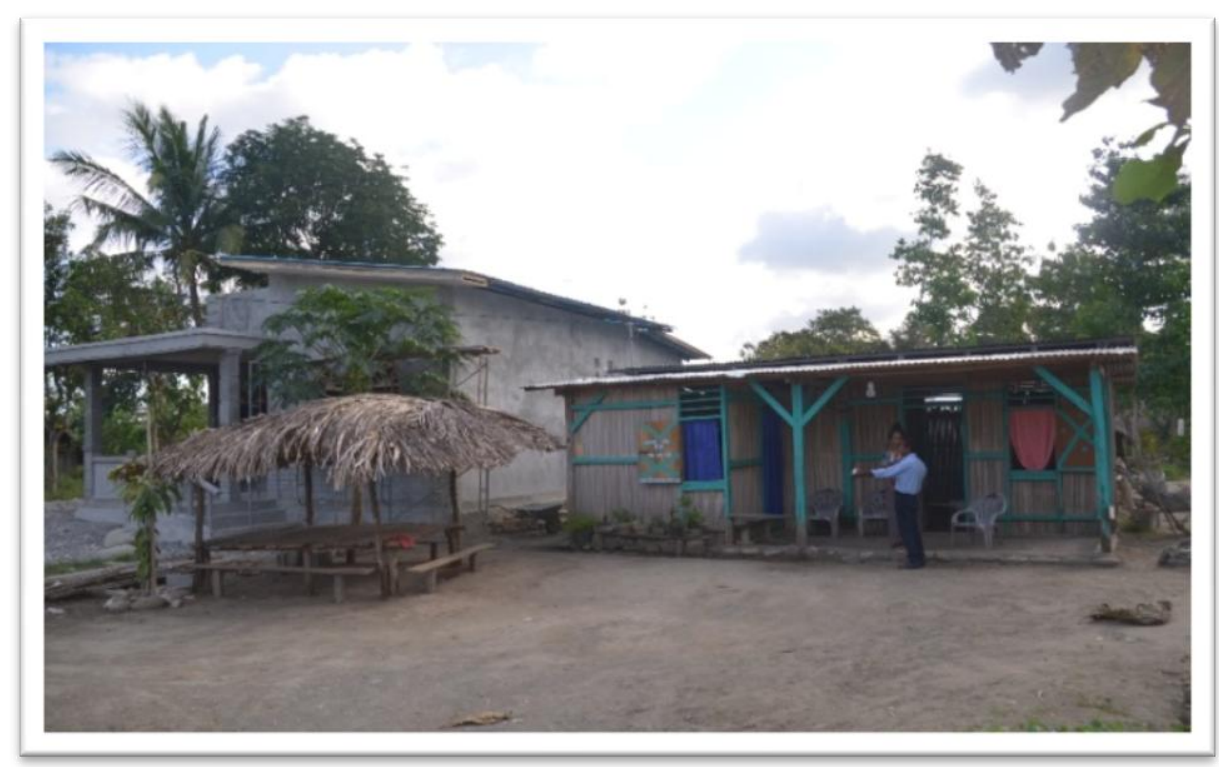

Photo by Brigida Soares, 2014

Figure 12.New house construction in Urban Oeccuse by a labour worker who returned home in 2014.

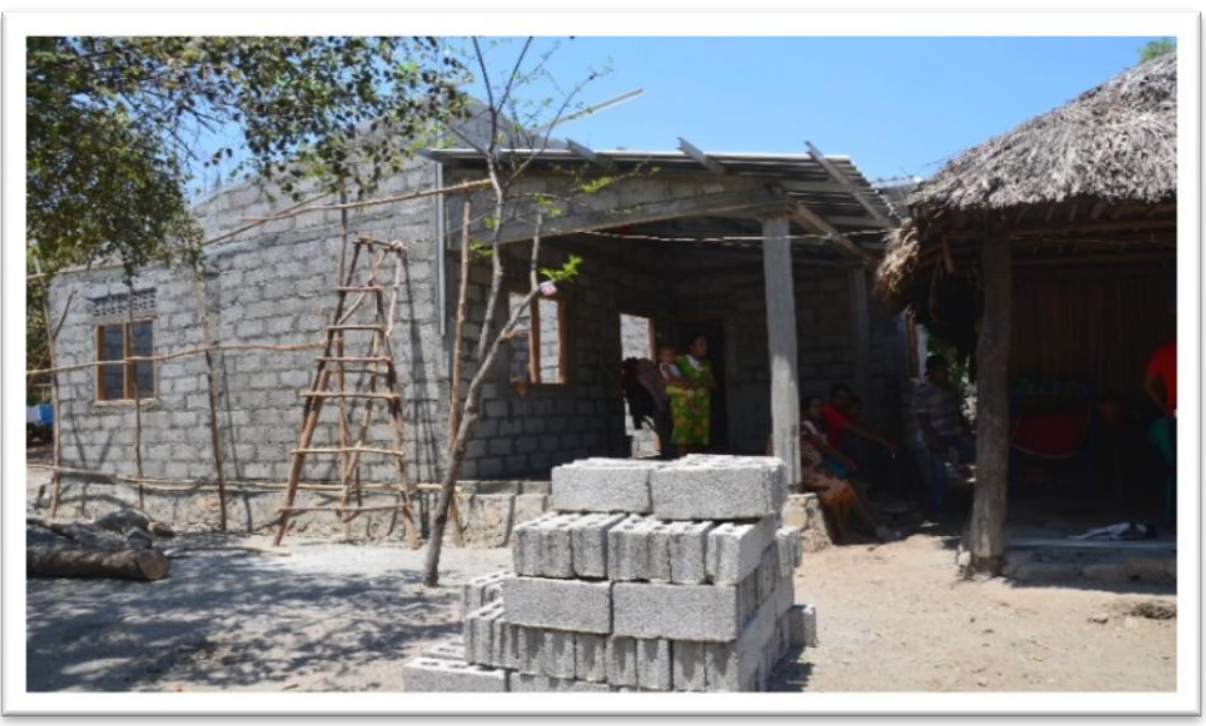

Photo by Brigida Soares, 2014 


\section{Figure 13.New House Construction, in a Rural Area, builtfrom Remittances Sent from a Family Member in the United Kingdom of Great Britain.}

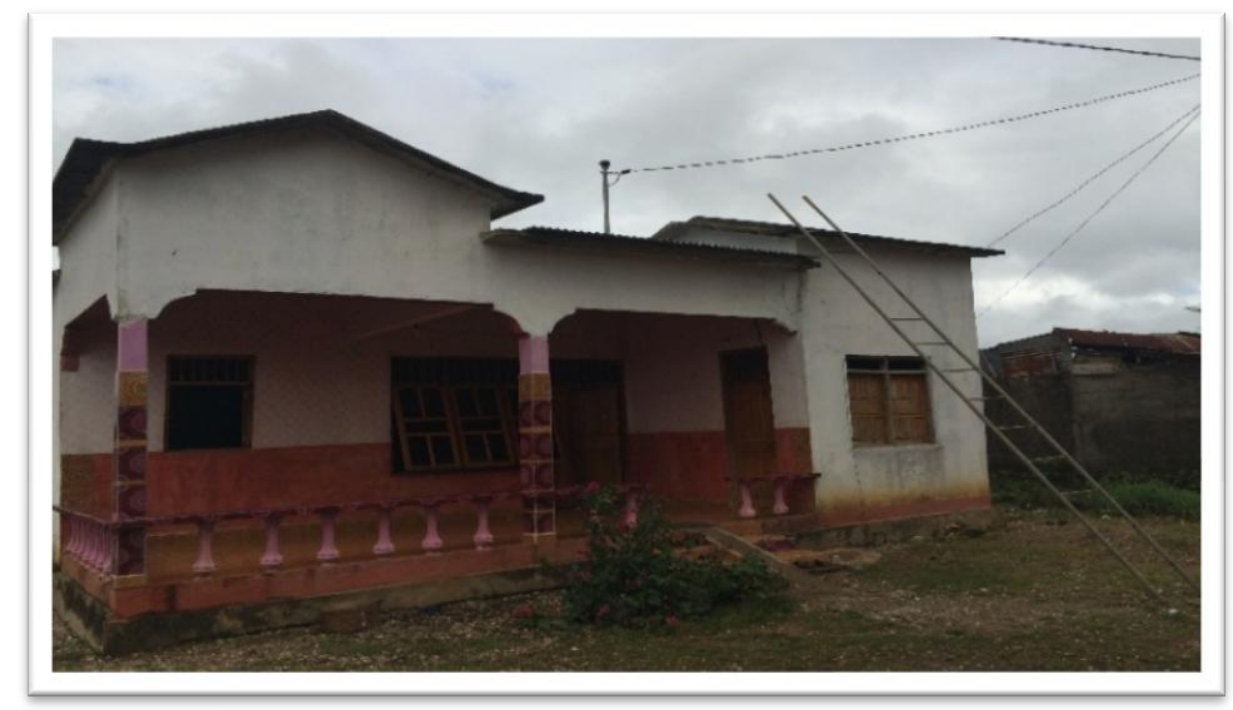

Photo by Brigida Soares, 2014

These pictures of house construction prove that remittances, received by participants, in this study, are not only spent on food, clothes and other housing equipment but also on building houses. Urban and rural participants and members of the diaspora mentioned that the most important priority is to build a proper house to accommodate their families. After building a house, the remittances can be used by the overseas family members to invest in productive businesses when they return home as they know they will still have to sustain their families. The above also creates the negative aspect of class inequality as consumption on building new houses highlights differences between rich and poor and produces discrete classes in society.

\subsection{Household Consumption on Other Expenses (Cultural Expenses \& Others).}

Cultural expenditure plays a significant role in rural areas. About fifty-four percent of the ten rural participants reported that they spend half of their remittance funds on cultural events. These include funerals, traditional house building, weddings, birthdays, baptisms and other related events. Thirty-eight percent of the ten-diaspora participants commented similarly. Whereas, only eight percent of those who live in urban areas spend their remittances on cultural events. The data collected on household consumption by district and location can be seen in figure 14 below. 


\section{Figure 14. Household Consumption on Cultural Expenses by Districts and Location.}

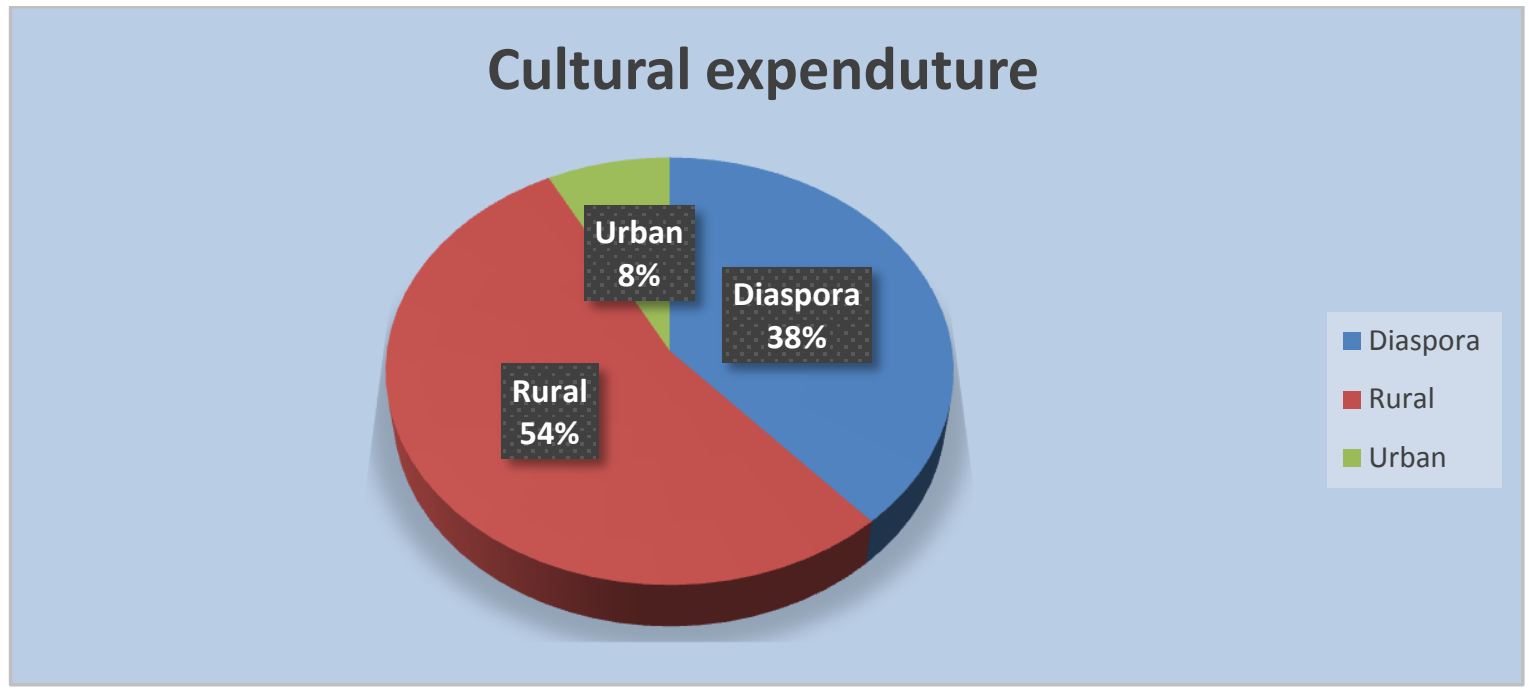

Source: Brigida Soares 2014

Timor-Leste has a high number of cultural activities such as funerals, second funerals, weddings, birthdays and baptism ceremonies. The above data, from this study, show that rural remittance recipients in Timor-Leste spend more on these than those in other districts and locations. This is supported by the World Bank (2013) which reported that $70 \%$ of the population of Timor-Leste live in rural areas and have strong connections between communities, with the environment, history and cultural traditions. This connectedness was also reported by Molnar (2005) who stated that connectedness makes families in rural areas believe cultural traditions are important events to adhere to as they sustain the relationships between community, family and the environment. Moreover, Timorese people share a common set of beliefs and values linked to a sense of belonging to a certain place, an 'Uma Lulik' (Sacred house). Therefore, the expenditure on traditional cultural events, often paid for by members of the diaspora, is important to people in rural areas as mentioned by the following participant:

My sister sends us money to support building our traditional house (sacred house) because we believe that our ancestors (Matebian) helped her to find the way to go overseas and get a good job. Therefore, she sends money to support this cultural traditional event (Interview $8^{\text {th }}$ August 2014). 
As discussed earlier, most of the overseas families who come from rural areas have strong family connections to cultural traditions. This is illustrated by $38 \%$ of the migrant participants who commented that they sent more money home when events such as traditional cultural celebrations were held in their families. One of these participants reported on this and stated:

I regularly send money home, however I will send more money when there is a traditional cultural event held by my family specifically, "Lia-Mate" funeral of relatives and "Lia-Moris" weddings, baptism, birthdays etc. I thank my "Matebian" (family or relatives who died in the past) they show me the way and help save my family and I have an obligation to support this cultural event when my family asks for it (Interview 12 $2^{\text {th }}$ une 2014).

Figure 15.Traditional Event in A Rural Area of Timor-Leste.

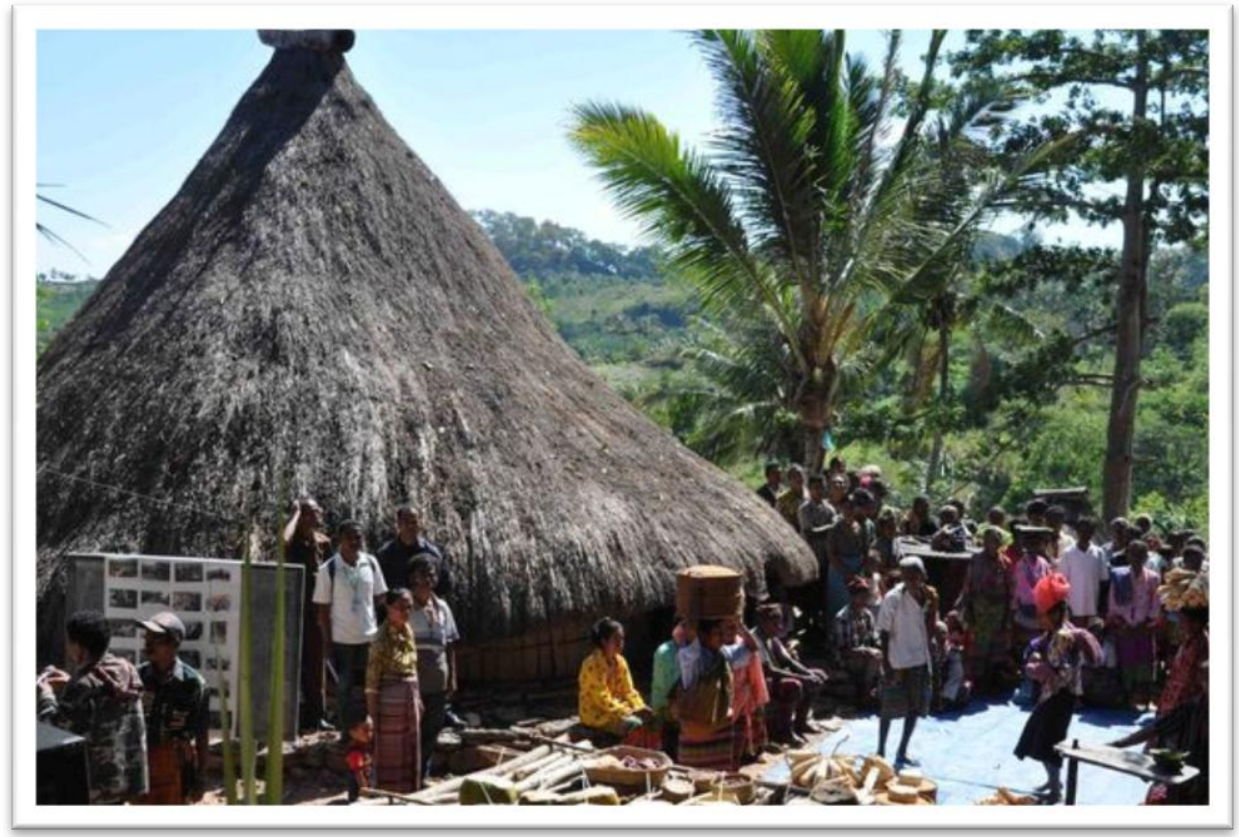

Photo by Brigida Soares 2014

Figure15 above, shows a traditional event in the countryside. There is fewer adherences to traditional cultural ceremonies in urban areas and so fewer are held in the towns. However, some money is expended on cultural traditions such as weddings, funerals, baptisms, birthdays, etc. Some people believe that celebrating cultural events is important because they bring them luck and their ancestors help to protect them from bad luck. To conclude, expenditure on this type of 
consumption is categorized as an unproductive use of remittances because there is no return on the money. However, these activities enhance the strong connections between community development and the environment.

\subsection{Conclusion}

To conclude, this study found that consumption on food and household equipment has positive impacts on local businesses such as agricultural food products, small shops (kios) ${ }^{28}$ and transport businesses within communities where households receive remittances. The other positive impact of the remittance funds is that they contribute to filling gaps where there are no government programs. This is particularly relevant when a country has high unemployment and there are no social welfare programs like unemployment benefits and social welfare. The remittance funds fill these gaps for many households. Moreover, new housing projects or renovating old houses and investments in land and jewellery give temporary jobs for some and opportunities for learning skills. For example, transport companies can hire more people to deliver construction materials and construction companies hire people to make ceramics and other businesses.

Although remittances used in these areas offer only short-term opportunities they are significant to new countries like Timor-Leste. On the other hand, this study also found that the most unproductive remittance funds' expenditure is on traditional cultural events and these are one of the significant negative uses of remittances. Further, it was also found that expenditure on traditional cultural events is highest in the rural areas of Timor-Leste and they have no economic benefits to the community in general and specifically to the households of the targeted participants in this research. An in-depth exploration of the unproductive sectors was presented in this chapter. The following chapter will discuss the investment of remittances in another productive sector.

\footnotetext{
${ }^{28} \mathrm{Kios}$ is a small shop which sells groceries.
} 


\section{CHAPTER VII. RESULT THREE:PRODUCTIVE REMITTANCES: HUMAN CAPITAL INVESTMENT AND THESMALL-MEDIUM BUSINESS INVESTMENTIN TIMOR- LESTE.}

\subsection{Introduction}

The previous chapter shows how remittances are used for the consumption of durable and nondurable goods. It concludes that remittances have a significant positive impact on household welfare such as fulfilling basic household needs and being used for household's emergencies. Although unproductive remittances have also been identified, I have shown that they still have a significant positive impact on many of migrant households in Timor-Leste. This chapter focuses on the discussion of the productive uses of remittances such as human capital and investment in small to medium businesses.

This chapter reports on the findings, which answer question; do migrant's remittances contribute to human development investment? Do remittances promote entrepreneurial activity and business investment? It also supports the validity of my argument that remittances positively contribute to the development of Timor-Leste by showing two benefits in the productive sector. These are the education and the economic and trade sectors. In the education sector, remittances enhance human capital by supporting students in primary and high school, university and vocational training in computing and languages. In the economic and trade sectors, the remittances also support students and have positive impacts on enhancing agriculture production in rural areas. They also enhance small and medium businesses such as grocery shops and transportation in both rural and urban areas.

Within the New Economic Labour Migration theory, the decision of families to send their members to work overseas is valid as a percentage of their remittances are invested in the productive sectors. As stated, these funds support many children at school and provide the equipment necessary for their education. Although studies have focused on school students none has explored how remittances support youth who have the capacity to continue their studies at tertiary level. This study offers an explanation of and information about how remittance funds support human 
capital investment. First, I provide an overview of the education and economic sectors in TimorLeste.

There has been a real change in the education and economy sectors since Timor-Leste achieved independence in 2002. Enrolment rates of children in primary school to junior high school have increased every year and the numbers of local businesses have increased significantly. Nevertheless, with these achievements have come new challenges and opportunities. These are illustrated in the education sector where although formal education from primary school to senior high school is free there are costs incurred, by parents, who are required to supply school materials such as notebooks, pencils, or pens, school uniforms etc.

\subsection{The Impact of Remittances on Investment in Human Capital.}

There are many positive impacts of the investment of remittances in human capital investments. In Timor-Leste's case, this study provides examples of the positive impacts of remittances on the development of human capital on different levels of educational programs as discussed above. They also support school dropouts to migrate overseas to work and enhance their skills.

\subsubsection{Remittance's Investment Enhances Human Capital at University Level}

My research found that, remittances from the Timorese diasporas contribute positively to the development of human capital especially at tertiary level. The first finding in this section is that remittances have supported many family members at tertiary level education.

Table 5. Household Information about The Number of People in Education, Supported by a Remittance Fund.

\begin{tabular}{|l|r|r|r|r|}
\hline & Diaspora & Gran \\
Description & Participant & $\begin{array}{l}\text { Rural Household Par- } \\
\text { ticipant }\end{array}$ & $\begin{array}{l}\text { Urban Household } \\
\text { Participant }\end{array}$ & $\begin{array}{l}\text { Total } \\
\text { Primary School }\end{array}$ \\
\hline Junior High School & 1 & 1 & 2 \\
\hline Senior High School & 9 & 2 & 3 \\
\hline University Level & & 5 & 4 \\
\hline
\end{tabular}




\begin{tabular}{|l|r|r|r|r|}
\hline $\begin{array}{l}\text { Vocational Training (computer learning } \\
\text { program, language program etc.) }\end{array}$ & & & 1 & 1 \\
\hline Grand Total & $\mathbf{1 0}$ & $\mathbf{1 0}$ & $\mathbf{1 0}$ & $\mathbf{3 0}$ \\
\hline
\end{tabular}

Source: Brigida Soares, 2014

According to table 5 above, 30 participants from households in urban and rural areas and members of the diaspora support one or two of their family members to continue studying. Analysis of the figures shows the investment of remittances on human capital is significant and continues to university level. The information shows that 20 participants from urban, rural and members of the emigrant put tertiary education as the priority. However, if we focus on the participants and their specific locations, it is evident that members of the diaspora support the most significant number of family members, about 9 , to continue their studies at university. The second category shows that urban people support 6 participants and 5 are supported from rural areas. Further analysis of the numbers of migrants or labour migrants overseas revealed they consider a high level education as important. The changes in social life, the environment and culture combined with their overseas experience have given them a new perspective on life. This way of thinking is linked to transnationalism ${ }^{29}$, as posited by Joachim Schroeder (2009) "In the perspectives of transnationalism, migration becomes a new key dimension into human existence, providing a sociological diagnosis ${ }^{30}$ of current social transformation". The understanding of this sentence is that members of the diaspora have a new perspective on life after living in a new culture. As a result, they are positively changing their opinions on social, cultural, economics and education. A tangible result of this is shown by the high numbers of migrants, in this study, who fully support their relatives to continue studying at university level.

Although the transnationalism aspect has changed migrants' lenses of life, they are also concerned about the dependence on remittances by their families at home. According to interviews with these migrants, they regard their investment in human capital in their families as important as it should reduce their family members' reliance on remittances. The following quote is the comment of one diaspora participant regarding this issue;

\footnotetext{
${ }^{29}$ Micro Process refers to internal process

${ }^{30}$ Sociological diagnosis is diagnosing of the individual which dealing with social questions, or problems, especially focusing on cultural and environmental factors rather than on psychological or personal characteristic. (Dictionary.com)
} 
At that time, I was thinking that it is good for the people like me, who have not had enough grades in school to continue study at the university level; I look for a better job than what I have done and use the money to support my brother who has the capacity to continue studying. The reason is that I cannot stand forever to support my family with the temporary job that I had and I know that one day I will come back to Timor-Leste. My brother who studied accountancy in Indonesia finished his study last year and now he has a permanent job and he helps me to run a loan business using the remittances that I have saved during my work period in UK (Interview, $11^{\text {th }}$ July 2014).

The second findings also demonstrate that support from remittances allow many participants to continue their study in public and private universities inside the country. The number of young Timorese who enter university is very high. Every year, about 1000-3000 student graduates from senior high school all over the country want to continue their study at university. There is only one public university in Timor-Leste, the National University of Timor-Leste (UNTL) ${ }^{31}$. Others are private accredited universities ${ }^{32}$. However, there is a significant difference between public and private universities in terms of the tuition fees. Compared to the private universities, UNTL has the lowest tuition fees because it is funded by the government. Therefore, itis the preferred university in the country. However, it can only accommodate 1000-2000 students each year. The rest of the candidates, if they can afford it, go to a private university either inside or outside the country, attend vocational training programs or look for job opportunities inside the country.

Table 6.Shows The Data from Households About Their Members Attending The Private and Public Universities in Timor-Leste and Overseas.

\footnotetext{
${ }^{31}$ The national University of Timor-Leste is well known as UniversidadeNacional de Timor Lorosa'e been legally created by the decree-law n. 21/2006 of 22 November, The Organic of the Ministry of Education (MEC) as a teaching Academic Institution Technical and higher whose purpose is human, cultural, scientific, ethical and technical coffering degrees. This public university fully funded by the government of Timor-Leste which is every year has received the total of $\$ 14,446$ thousand American dollar ( (Ministry of Finance, 2014)

${ }^{32}$ The other accredited universities which recently get the licensing and initial accreditation in Timor-Lesteis the University of Dili $^{32}$ and the Timor Larose'e Eastern University ${ }^{32}$ (Council Of Minister, 2013).
} 


\begin{tabular}{|l|r|r|r|r|}
\hline Description & Diaspora & \multicolumn{1}{|l|}{ Rural } & Urban & Grand Total \\
\hline Timor-Leste & $\mathbf{6}$ & $\mathbf{4}$ & $\mathbf{4}$ & $\mathbf{1 4}$ \\
\hline Private university & 5 & 3 & 1 & 9 \\
\hline Public university & 1 & 1 & 3 & 5 \\
\hline Indonesia & $\mathbf{3}$ & $\mathbf{1}$ & $\mathbf{2}$ & $\mathbf{6}$ \\
\hline Private university & 3 & 1 & 2 & 6 \\
\hline N/A & $\mathbf{1}$ & $\mathbf{5}$ & $\mathbf{4}$ & $\mathbf{1 0}$ \\
\hline Grand Total & $\mathbf{1 0}$ & $\mathbf{1 0}$ & $\mathbf{1 0}$ & $\mathbf{3 0}$ \\
\hline
\end{tabular}

Source: Brigida Soares, 2014

According to the data from table 6,9participants from the diaspora, from both urban and rural areas, informed me that they have used remittance funds to support members of their family to continue their study in a private university in Timor-Leste. Moreover, 5 participants' remittances have been used to support some of their families to continue study in the public university. From a deep analysis of the remittances, it is evident that many are used to support family members to continue studying. This is a significant contribution to the household as the tuition fees are expensive, in the private universities, but there is no other option as the competition for the public university is high. The following quote explains the situation;

I have sent money to my two brothers in Dili, to pay their tuition fees, every semester. Both of them had applied for UNTL but they failed and I saw that they had a big interest to continue their study so I worked to help them continue their study in the private university. One of them will graduate next year. I am so proud of his achievement (Interview $25^{\text {th }}$ June 2014).

From this statement, a remittance fund effectively supports two youths, who were not successful in the public university's entrance assessments. Remittance funds also support members of other families who do not have a permanent income and lack funding to support their members studding at the private universities, for-example, farmers. The following quote illustrates how remittances play its role to fill the gaps:

I am a farmer; I couldn't make more money from the production of agriculture that was produced every year. My oldest son is now in Northern Ireland and he 
is the one who is responsible to pay the tuition fees of his brother in the private, UNPAZ (Interview, $8^{\text {th }}$ July 2014).

Remittance funds not only support tuition fees, sometimes they are used to buy books, for photocopying, printing and living costs for the students. Following are quotes from two participants, from the diaspora, which demonstrate the situation:

I have two kids, who are going to the university in Dili, one is studying at the National University of Timor-Leste (UNTL) and another studies at the Universidade da Paz (UNPAZ) ${ }^{33}$ I am the one who supports them with the money I get here. I usually send the money to both of them separately every two months to buy books, photocopy, and print and support their basic necessities as students. Once a year I send money to my oldest son who studies at the private university to pay the tuition fees (Interview $13^{\text {th }}$ August 2014).

Another migrant commented similarly and also mentioned his remittances are also used to pay for his sister's transport.

I have also supported one of my sister's study in the IOB in the department of Accounting. Once a year I send her money for the tuition fees and every month I send USD 100 to support the transportation, photocopy, printing etc. (Interview $10^{\text {th }}$ August, 2015).

The final finding in this section explores the use of remittances to fund support for household members who study overseas. A noticeable fact is that Indonesia is the preferred destinations to study.The reasons for this are the cultural familiarities and the ease of communicating in the language. According to the data 5000 Timorese are in Indonesia studying at universities and technical colleges in Jakarta, (Yogyakarta and Bali (Bexley, 2011). From the data collected, in this study, 6 householders informed me that they send their members to study in various universities

${ }^{33} \mathrm{UNPAZ}$ is another private university in Timor-Leste, where 
in Indonesia. The following quote illustrates how remittance funds significantly contribute to the numbers of household members who are currently studying in university overseas.

I have supported two of my nieces to continue their study in Yogyakarta,Indonesia. I have worked very hard and pay for their tuition fees. I am also responsible to provide their tickets and housing as well as accommoda-

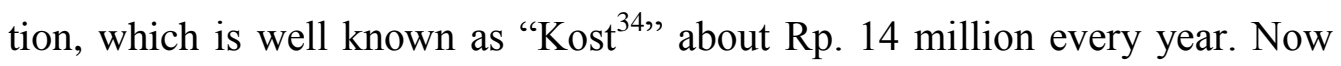
every month I regularly send 1 million rupiahs for their food and transportation. I do that because of my responsibility to the family. I believe that after they graduate from the school they will get a good job and will continue to support my child (Interview, $7^{\text {th }}$ June 2014).

\subsubsection{Remittance Funds Support the Children's School Materials and Children's Health to Stay at School (Primary School to Senior High School)}

According to table 6, numbers of householders informed me that the remittance funds are often used to buy children's materials such as school uniforms, books, pencils, shoes etc. According to the data collected, there are 9 households which use remittance funds to buy school materials for their children. Following is a quote to illustrate this:

I have used money that my husband sends to build this house and also to buy our kids school materials and pay for the medicine if the children are sick (Interview $25^{\text {th }}$ June 2014).

In my observation, even though, the school fees from primary school to the senior high school are free ${ }^{35}$ the school materials are the responsibility of the parents.

\footnotetext{
${ }^{34}$ Kost refers to the room rented for student.

${ }^{35}$ The free schooling is refers to abolition of school fees which resulted an extraordinary progress where within the two years period, the primary school enrolment rate had raised to $70 \%$.
} 


\subsubsection{Remittance Funds Support Youth in Vocational Training such as Language Training and}

Computer Programming Training.

In some other cases, remittances are used not only to fund youths' university study, but also to enhance their skills in vocational training while they study at university. The following quote proves that remittances have double uses - to invest in human capital, academic knowledge, as well as skills. Following is the opinion of a household participant in Timor-Leste.

My husband sends money home every month. Beside I have to spend to build this house, I also use some money to support my sister and my husband's sister to continue their English course and computer course. My husband and I told them that, now we still build this house, once it is done, we would pay for you both to continue study in University (Interview, 12 ${ }^{\text {th }}$ July 2014).

A similar opinion is offered by a participant who is currently working overseas

I have supported one of my brother's sons since he started university until he graduated last year from the private university (UNPAZ). During his period of study in university, I also supported him to attended training courses such as English language and computer training. I feel happy because now he has a job as a PNTL member (Interview, 14 ${ }^{\text {th }}$ June 2014).

\subsection{The Impact of Remittances on Business Investment}

The answer to the question "do remittances promote business activity and business investment?" asked in this study will be explored here. The findings found there is a definite correlation. According to the data, collected five types of businesses exist because of support from remittances. These are in: agriculture, public transport, construction, groceries and loans. Further, the data showed that transport has the most businesses with 6 operating in both the rural and urban areas. Next was the grocery business with 5 stores owned by families who receive remittances. Construction companies were third with 3 companies and businesses in loans, agriculture, and savings comprised 1 each. 11 participants had not ventured into business. 
Table 7. Participant Information on Business Investment Using Remittances, 2014

\begin{tabular}{|c|c|c|c|c|}
\hline \multirow{2}{*}{$\begin{array}{l}\text { Item } \\
\text { Business Description }\end{array}$} & \multicolumn{3}{|c|}{ Participants } & \multirow{2}{*}{$\begin{array}{l} \\
\text { Grand } \\
\text { Total }\end{array}$} \\
\hline & Diaspora & Rural & Urban & \\
\hline Transportation businesses & 1 & 2 & 3 & 6 \\
\hline Groceries Businesses (Small \& medium groceries shop) & 1 & 3 & 1 & 5 \\
\hline Construction Company & 2 & 1 & & 3 \\
\hline Agriculture \& Transportation Businesses. & & & 1 & 1 \\
\hline $\begin{array}{l}\text { Loan business, Groceries business \& Transportation busi- } \\
\text { ness }\end{array}$ & & 1 & & 1 \\
\hline Saving & 1 & & & 1 \\
\hline N/A & 5 & 3 & 5 & 13 \\
\hline Grand Total & 10 & 10 & 10 & 30 \\
\hline
\end{tabular}

Source: Brigida Soares, 2014

Figure 7.3 shows that remittance funds are well spent on establishing different businesses in rural and urban areas in Timor-Leste. These businesses are creating significant self-employment to these households and in the wider view are creating job opportunities for others. Sheehan, Riosmena (2013), who said that "business investment has a multiplier effect on the migrants, their families, their hometowns and the country at large" (p. 11), supports this argument. The following section presents a detailed explanation of the impact of remittances on the different business categories, found in this research.

\subsubsection{Remittance Fund Support Transportation Business Both in Rural and Urban Areas.}

According to figure 7.3 above, the public transport business is the primary business invested in by members of the diaspora and their families. 7 households mentioned establishing business in this sector. Through my observations, public transport was chosen as the source of income to replace the dependency on remittances from overseas. This business includes small buses ${ }^{36}$, mikorlets ${ }^{37}$, Taxis $^{38}$ and dump trucks ${ }^{39}$. These are used mostly for public transport by people to travel

\footnotetext{
${ }^{36}$ Small buses connect several of the main ccities like Baucau, Suai, Dili, Maliana and Los Palos. The buses are generally overcrowded and poorly maintained.

${ }^{37}$ Mikorlet refers to a Mini vans adapted for passenger travel are used extensively for getting around Timor-Leste. These vans are called Mikrolets and charge very reasonable rates
} 
around town and from one district to another. Some participants expressed their reasons for choosing public transport to invest in. One participant said:

My husband and I decided to buy a mini bus because transportation is important to us as we plan to open grocery shops. Beside this we can carry passengers every day and we can also use it sometimes when our shop needs to transport our materials to sell and we often use it for private matters such as a holiday and we can use this transportation to go somewhere with family (Interview, $14^{\text {th }}$ August 2014).

From this statement, it is clear that the transport business provides a regular income because many people travel and secondly, the vehicle can be used for other business requirements and family outings.Another participant explained the following:

My brother works in South Korea and he bought a mikrolet. Now our car is operating in Dili. He told us that with our minibus/mikrolet we can have a daily income and will not ask him to send us money every month. He said that he has to save some money, so when he comes back he will start a new and big business (Interview $28^{\text {th }}$ of August 2014).

It is clear, from the above, that establishing a new business can replace remittance funds as the only incomes of the families and establishing a new business reduces the dependency on remittances in the long run. This statement also shows that families can provide more opportunities for their family members overseas to save more money for their future use. From the data, it is also clear that the impact of remittances on transportation businesses gives more job opportunities to other people in the town. For example, the 7 households which have public transport businesses employ 14 people permanently as drivers and co drivers

\footnotetext{
${ }^{38}$ Taxis are one of the best means of transport in Timor-Leste. Fares are not very steep and taxis are the best option for visiting a few out of the way places

${ }^{39}$ Dump Truck usually hired to transport construction materials and other materials that cannot carry by Mikrolets or Small Bus.
} 


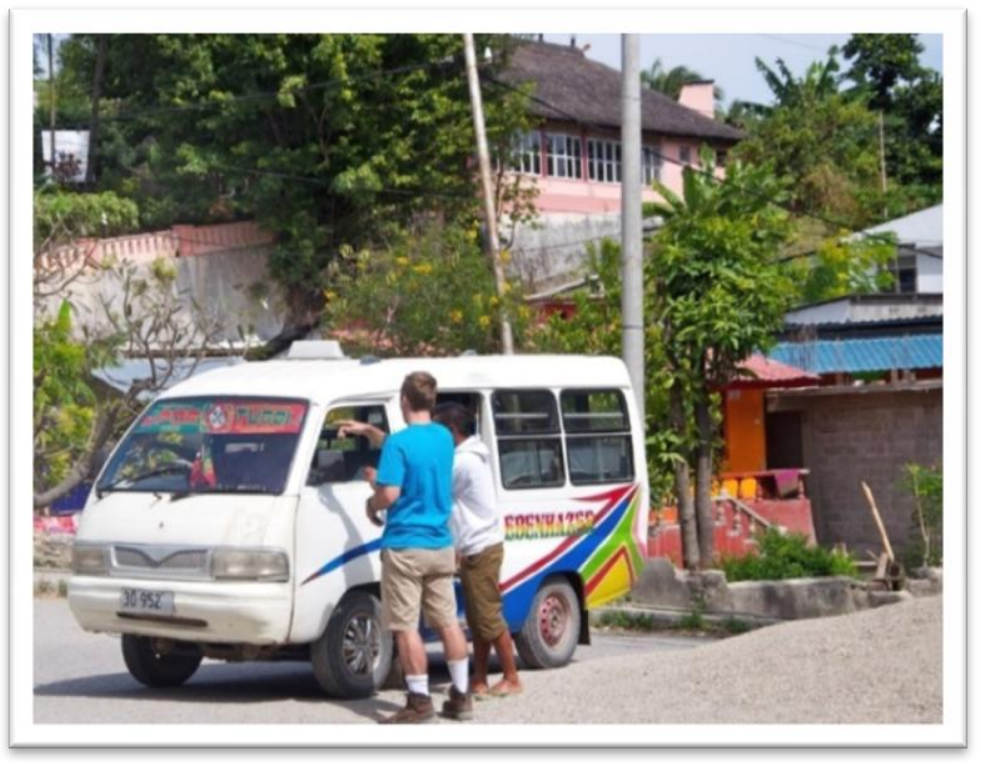

Figure 16.

A Mikrolet ${ }^{40}$ is a public transport vehicle, which can carry passengers between districts. This is one of the types of vehicles operated by many households in this research. It also has other advantages including being affordable and the maintenance is very affordable.

Photo by Brigida Soares, 2014

Figure 17.

This truck is used to transport heavy materials and is preferred by Timorese householders and their relatives overseas but they are very expensive. However, they are of high quality and therefore have a long working life.

Photo by Brigida Soares, 2014

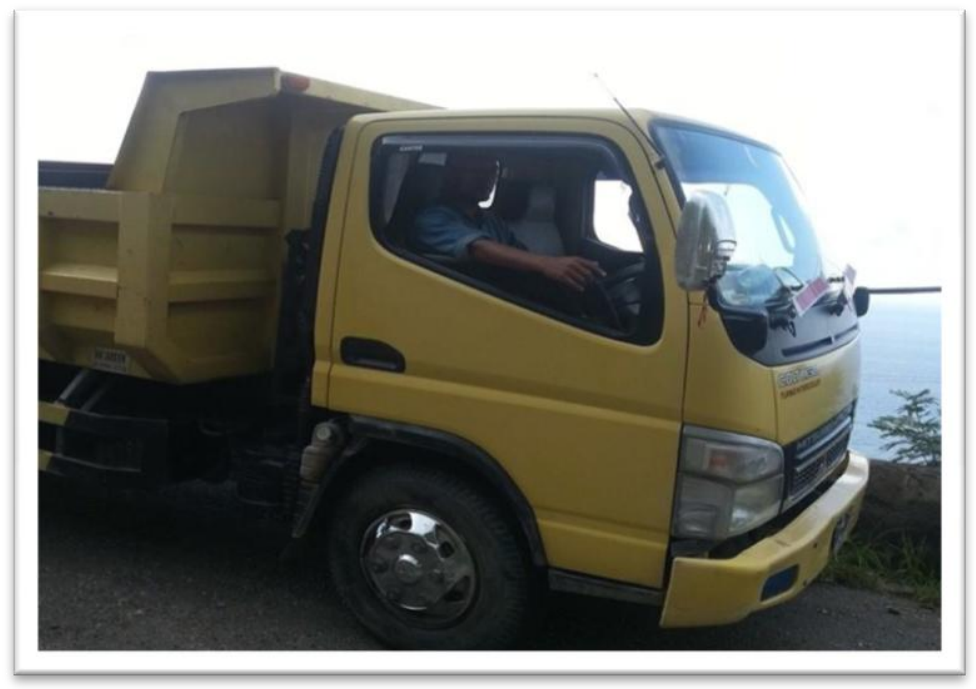

Figure 17. shows the significant impact of remittances on small to medium businesses. In Albania, Ermira (2010) found that households owning non-farm businesses prospered more than their farming counterparts. I agree with Elmira's statement as I found that those who were not involved in agriculture prospered more than those in farming, 6 of the 30 participants, in different locations in my study, informed me they had established grocery businesses with remittances and they were going well. One participant, from an urban area, told me that her husband worked in Northern Ireland for a few years and sent money back every month. She invested this in a small shop and stated:

\footnotetext{
${ }^{40}$ The price of one Mikrolet is usually under USD10.000
} 
When he sent money the first time I opened a small Kios. I sold groceries like coffee, sugar, candles and other small things people usually need to buy. Since then he has sent it every month and I have invested all the money into my business and you can see how the small business is growing. (Joao Almeida, Interview 14 of July 2014).

This statement reflects Osili (2007) who posited that the impact of remittance funds on the creation of businesses and/or investments made by families in the origin country are positive. This is an example of migrant families creating businesses in a different sector to their original work, based on opportunities in their home countries. Osili (2007) added to this topic, saying that these activities potentially lead to employment opportunities for the younger generation at the community level in general and for households in particular. In this study, self-employment creation is one of the positive results of the impact of remittances. In the example above a woman told of her experiences of building a grocery business with remittance funds. Grocery businesses are not medium sized businesses which employ others as they are run by the owners but the remittances have created the opportunities and have significantly increased the number of owner operated businesses in Timor-Leste thereby providing better incomes for families.

Besides the improvement in income or an alternative income for owner-operated businesses another advantages of these enterprises is less reliance on remittances. This is supported by Ang \& Opiniano (2013) who stated that the ownership of businesses and/ or investments could eventually serve as an alternative income for the families. I agree, as this study has shown that the numerous successful grocery businesses has proven a diminished reliance on remittance funds from relatives overseas and these recipient families will only ask for support when facing an emergency situation such as an accident, a relative's death or another emergency beyond their control. Moreover, grocery businesses have been chosen by families as they are relatively easy to set-up.

My observations, in this research, indicates a preference for opening grocery shops over other retail outlets. There are several reasons for this. Firstly, setting up a "kios" is not complicated in Timor-Leste as most of the participants have their own residence and they use a front room for 
their businesses. Secondly, this type of situation is convenient for everyone especially for a mother or wife or old people to manage the shop. Thirdly, it does not require travel away from home to work and it brings in a regular daily income. It also requires little reliance on remittances as they would be used to buy stock only. However, there are also challenges in managing this kind of business. These include separating business and personal needs and in some cases, the owner of the business at times, takes some of the stock for personal use. For example, when I was visiting one of the business participants I was offered a coke and some biscuits from the shelves. In my observation this attitude will not help businesses to grow. Therefore, business management training is necessary and important. Additionally, credit is a problem faced by many small businesses and can put shopkeepers into debt ${ }^{41}$. This is caused by neighbours and relations who often take goods saying they will pay later when they have the money. Moreover, my data proves that groceries are the second category for businesses using remittance funds.

\footnotetext{
${ }^{41}$ Debt in this case refers to the goods that take in advance and paid letter when the person has money.
} 
The picture below shows a successful participant outside her small-to-medium business made possible by remittances.

Figure 18. A grocery shop

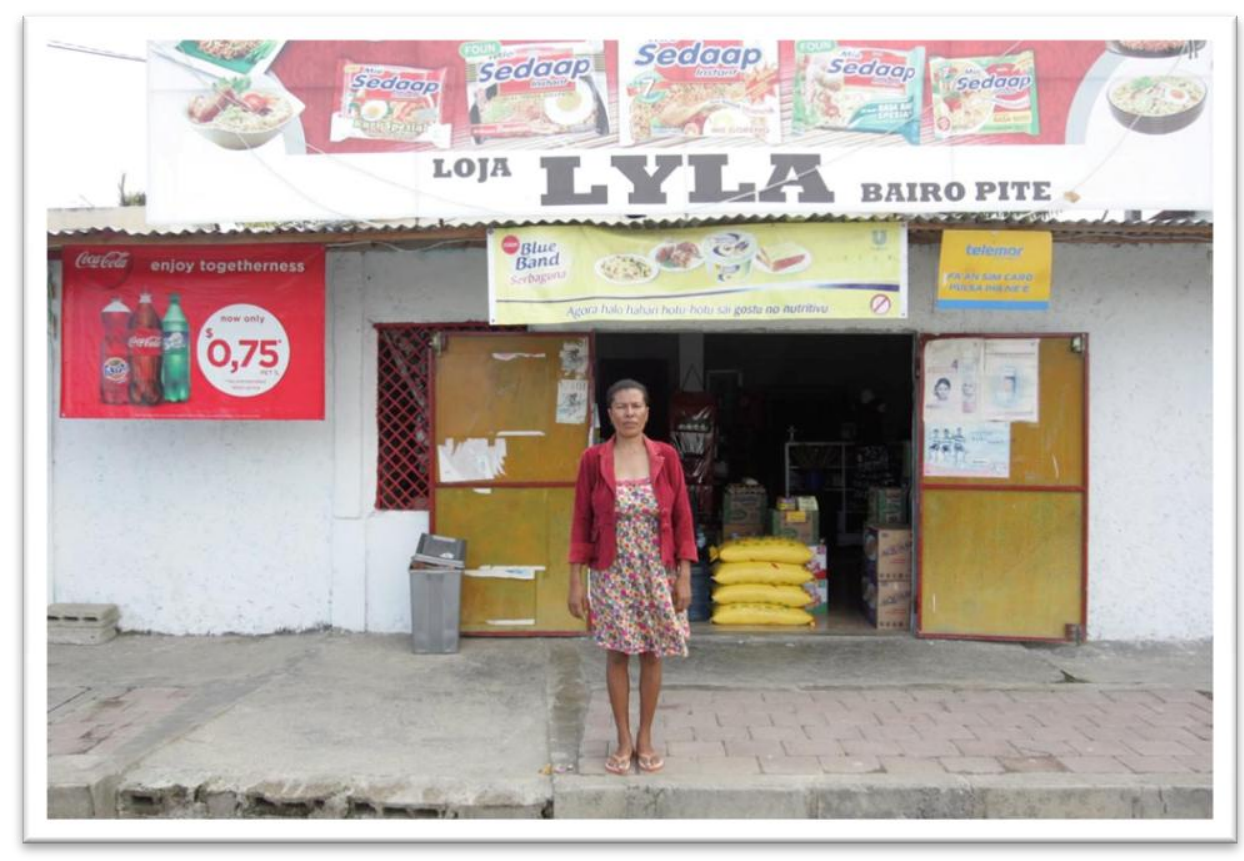

Photo by Lirio da Fonseca, 2014

\subsubsection{Remittance Funds Support for Medium Businesses in Timor-Leste.}

A significant business which employs many permanent and temporary young people in the country is the construction company business ${ }^{42}$. The aims of the National Strategic Plan of TimorLeste 2011-2030, are to: develop core infrastructure and human resources; strengthen the society; encourage the growth of private sector jobs in strategic industry sectors; develop a broad based agriculture sector; a thriving tourism industry and downstream industries in the oil and gas sector (The Governemnt of Timor Leste, 2010). Related to this statement, the infrastructure sector is one of the areas to be implemented during this period. This will be advantageous to members of the diaspora who have the initiative and capital to invest in construction businesses. This case study found that there are 3 households among the 30 participant' households who run construction businesses and they have had a significant impact on the local economy.

\footnotetext{
${ }^{42}$ Construction company business is the business or work on a building dwelling. In Timor-Leste, construction business are one of the business needed as the country started to focus on infrastructure sector.
} 
Further aspects of the significance of "construction company businesses ${ }^{43}$ " that have employed many permanent and temporary young people in the country are the government's initiatives in this area. According to the National Strategic Plan of Timor-Leste 2011-2030, it aims to develop core infrastructure, human resources and the strength of the society, and to encourage the growth of private sector jobs in strategic industry sectors-a-broad based on the agriculture sector, a thriving tourism industry and downstream industries in the oil and gas sector (The Governemnt of Timor Leste, 2010). Related to this statement, the infrastructure sector is one of the plans that were implemented during this period. It gives an advantage to diaspora who has the initiative and capital to invest in construction. This case study found that there are 3 households among the 30 participants which run company businesses and they have had a significant impact on the local economy.

In my observation, from 3 households running companies, one of them mentioned that when his company were running government projects in different areas of infrastructure, he hired more than 300 temporary workers. Following is the quote of his statement

Last year I got a project from our government I can tell that during I got project from the government in the sector of infrastructure such as build a sewer culvert, build a sport house and now I got one project to build a public garden. I have given temporary job for more than 300 people. The current project, I hired 100 temporary workers. (Interview, $27^{\text {th }}$ June 2014).

He added "Since I start this business, I have hired permanent staff about 10 people. They are working on in administration section, drivers, engineer and cleaner". Analysing his statement, remittance has a positive impact on reducing the numbers of unemployment in the country. Following are pictures of the current project.

\footnotetext{
${ }^{43} 43$ Construction company business is the business or work on a building dwelling. In Timor-Leste, construction business are one of the business needed as the country started to focus on infrastructure sector.
} 
Figure 19. A Recent Project, Using Remit-
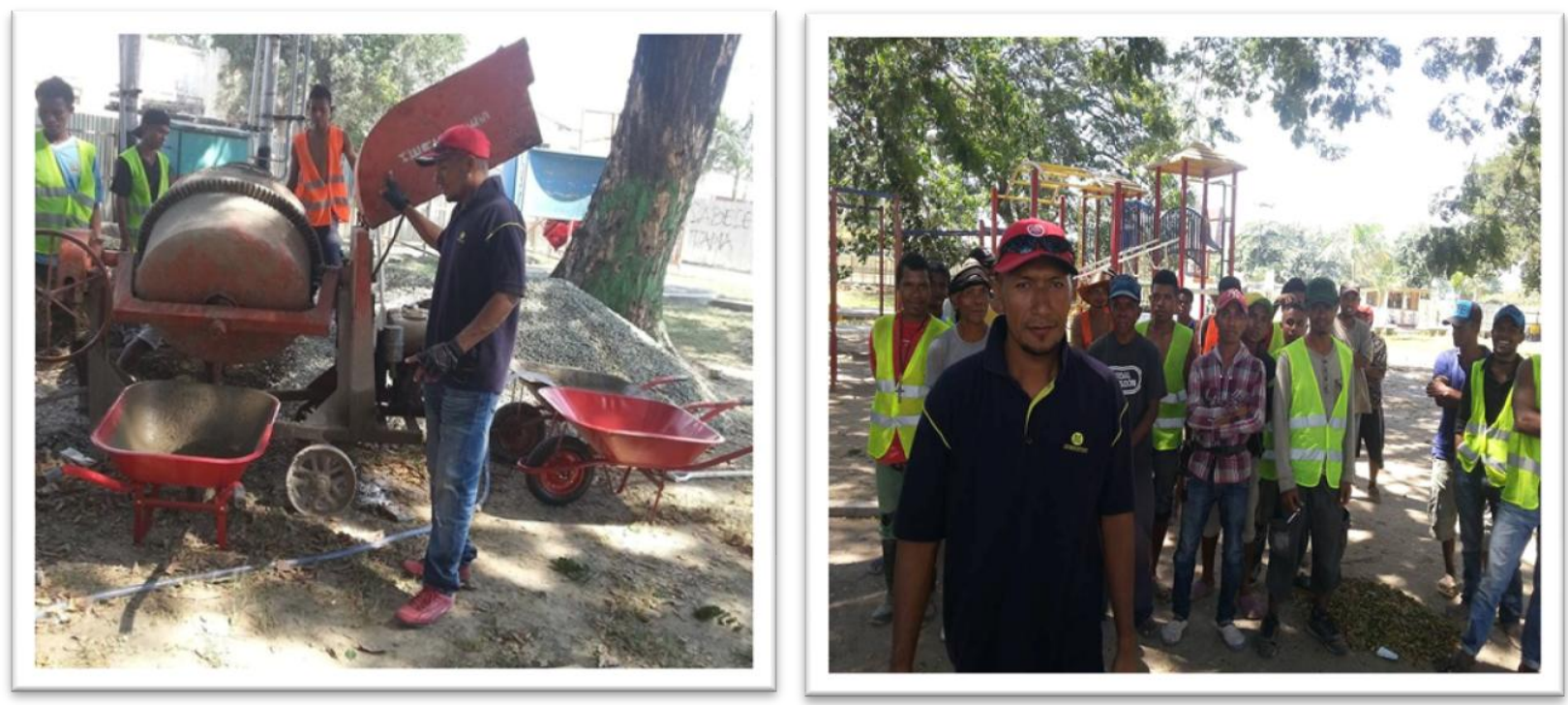

tances\& Workers on a recent project

Photo by Alvaro Silva, 2014

From my observations and the statement of this participant, it is clear that remittance funds play a significant role to enhance local development and provide more job opportunities. They also support self-employment in the country if the migrants and/or the householders have the initiative to invest their money in productive sectors as above. However, starting a construction business while others are working overseas might be a difficult decision to make. A fact noted by (Opiniano, 2013) is that although migrants have made money overseas and send it home regularly it is very difficult to make a decision to establish a business or a company. From this statement, several factors regarding starting a construction company arise. The first is the capital required and then there is the registration required by the government, which includes complicated documents. Finally, a strategic approach is required to gain customers. This is supported by Alvaro Costa (2014) who explained how difficult it is to influence family members to make a decision to start a business. He suggests "It is better to start a new business when you finally decide to return home". He continues, commenting "it is really difficult to involve family on something as big as this while you are far away". I observed that his argument is logical because most of the remitter recipients I interviewed and observed argue that they understood the importance 
of establishing a business but that it is very difficult to start a big and risky business such as construction while the owners are still working overseas.

\subsubsection{Migrant Remittances Enhance Agricultural Production in Rural Areas.}

The last significant business sector, which remittances enhance, is agriculture production. I found in this research, that remittances enhance agriculture production in rural areas. There are many studies which argue that remittances are spent only on basic needs including, education, family health, housing and conspicuous consumption. For example, Durand \& Massey, (1996); Diaz, (1991). In addition, with regard to a case study on migration, remittances and agriculture production, Jokisch (2002) found that migration has a negative impact on the agriculture sector as it replaces agricultural activity, which had led to stagnation in agriculture innovation and production. In a similar vein, Ferran and Pessar (1990) found that migration might lower agriculture production if households substitute remittances for agricultural income. However, in my study, the findings are contrary to the previous arguments. I have found that migrant remittances contribute positively to the enhancement of agricultural production in rural areas in Timor-Leste as is seen in one case in rural Baucau where the family has used them to buy necessary agriculture equipment.

A member of the family from Baucau told me they own paddy fields. She then told me about her brother who is working in South Korea and that he sends remittances home every month but when he found out these were wasted on consumables only he decided it would be better if they were invested in a business. He therefore said his remittances should be used to buy agricultural equipment for the paddy fields. The participant continued her story as follows:

We have many hectares of paddy fields which we manually sow and harvest every year. Since my brother is working overseas, he sends us money and he suggested we buy millers. Now my family can produce excess rice and sell it at the market (Interview, $28^{\text {th }}$ August 2014).

This comment illustrates that the purchase of the miller with the remittance funds is having a positive impact on the family's rice production but it also means that the household has not re- 
placed the income with the remittance fund but use it to enhance the productivity of agriculture production.

Figure 21. The Participant Shows the Miller her Family Purchased Using Their Remittance Fund.

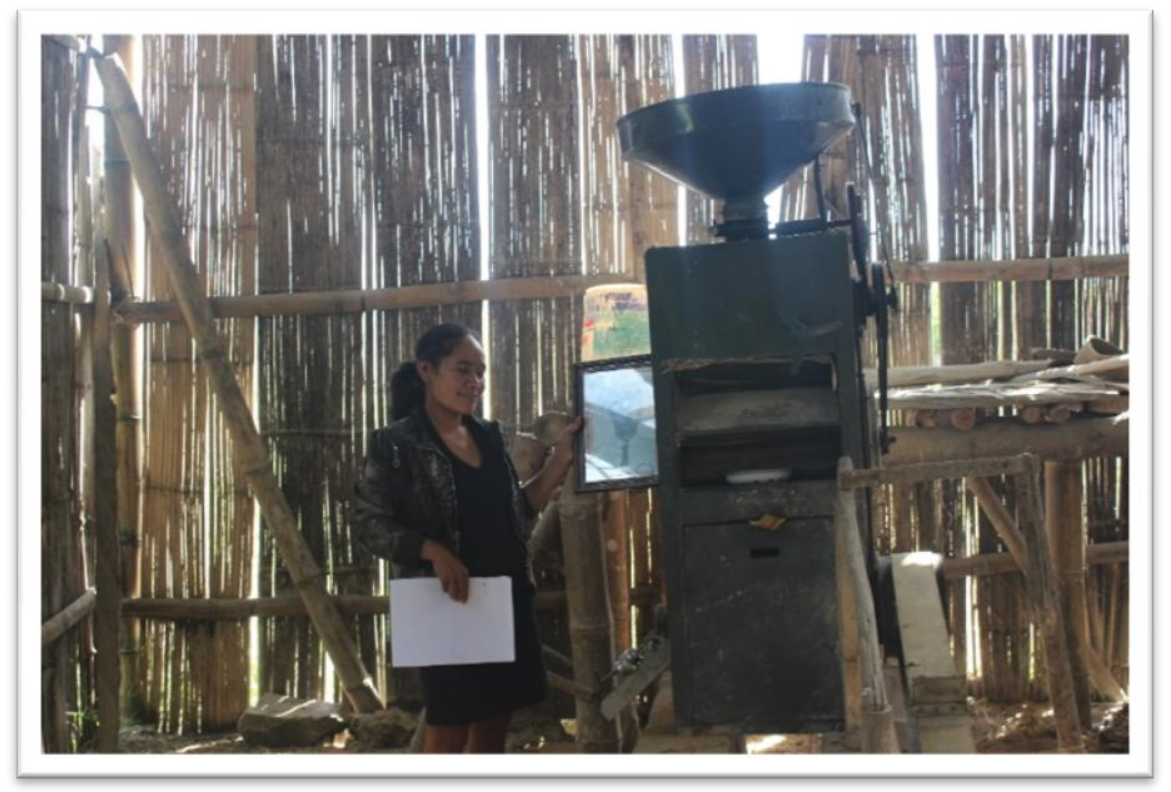

Photo by Brigida Soares, 2014

To sum up, the findings of this study contribute to the literature on the effects of remittances in Timor-Leste. It also points out that establishing medium businesses is not easy because of internal and external factors. The internal factor includes the opinions of the migrant workers who consider that business investment should be the ultimate result of their hard work and they should own them but the investment also depends on the willingness and support of the householders who manage the remittances. The external factor is that the environment of business opportunity in origin country, business network etc.

\subsection{Conclusion}

In conclusion, the big thesis question of what is the impact of remittances on Timor-Leste is answered. Remittances indeed have a positive impact to the development of household economies and household welfare. They also have significant positive impact on the development of the country through the investment in human capital through the education sector and on investment in small and medium business. 
This study also shows that remittances make a significant contribution to the enhancement of human capital in Timor-Leste, through the remittances the migrant workers send home. 90 percent of the participants used remittances to support their members to continue study at university level, 100 percent of them used them to buy their children material for school and 10 percent of participants acknowledged that thy support their members to attend vocational training course in the country. This is significant and positive in enhancing human capital in the country. There were only 30 participants involved in this study, if there are 16 thousand emigrants in the current World Bank investigation how many people could be supported by remittances to continue their study both formal and non-formal. Therefore, a future study needs to focus more on each impact as I have described in this chapter.

Another significant contribution of remittances is their investment in small and medium businesses in the country. 17 participants of the 30 have started small and medium businesses. The medium businesses in construction and transportation, as discussed, give more jobs to others while other participants used their remittances to start small owner-operated businesses in shops and agriculture.

In conclusion, although this study had only a small sample, of 30 participants the results indicate a significant positive impact of remittances on Timor-Leste. Overall, 51 percent of participants had used their remittances to invest in the productive sectors and 31 percent of them used it for consumption of both durable goods, such as building and or renovating a house for the family and non-durable goods, including food and other household necessities, which are categorized as unproductive spending. This category should be seen as a negative impact of remittances, however because of the economic conditions of remitters' families their welfare is enhanced by better nutrition and improvements in their living conditions by building a new house or renovating a family home and I argue that these demonstrate a positive impact on the remittance receivers in Timor-Leste.

Although the findings of the impact of remittances, in this study in Timor-Leste, support my supposition that they are positive more positive effects could be achieved by the government. 
These are accelerating policies to overcome the external and internal challenges, including; supporting the remitters and their families by easing the transfer and collection of the remittances, making it less complicated to set up businesses and finally to make attracting more remittances a priority. 


\section{CHAPTER VIII: SUMMARY, LIMITATIONS AND RECOMMENDATIONS.}

\subsection{Introduction}

This chapter summarises the research finding, discusses the limitations and reflects on the recommendations of this study. The main question of this research is "what is the impact of the remittances in Timor-Leste"? the aim of the study was to find how remittances funds support the participant households at the country of origin and how they contribute to the local economy in general.

This study aimed to explore and identify:

- The experiences of the diaspora with regards to the emigration processes and policies of remittances at the country of origin.

- The experiences of the particular householders, in Timor-Leste, when they receive remittances from their relatives overseas.

- The experiences of the participant's householders in spending remittances funds in the unproductive sector such as on durable and non-durable consumption.

- The experiences of the participant householders in spending remittances funds in productive sector including, human capital investment and business investment.

The research approach was qualitative which is explanatory- descriptive and contextual. Data was collected through in-depth interviews, the review of government papers and observation.

\subsection{Findings summary and inferences}

The major findings, in this study, are the result of the impact of remittances in Timor-Leste. This study provided three results of analysis. Specifically, the processes and policies of migration, remittances in the local context, the result of the unproductive use of remittances with a focus on consumption and the expenditure on housing. Further result includes, the result of the analysis of the productive sector of human capital and business investment. These three main findings support my conclusions as follows: the processes and policies on emigration and remittances have not been handled seriously by the government of Timor-Leste: the expenditure of unproductive remittances has positive and negative impacts on the participant households in particular and in 
the community in general and the remittances have a positive impact on human capital and business investment in Timor-Leste.

\subsubsection{Processes and policies of migration and remittance services in local context.}

The first finding is the processes and policies of emigration and remittances. This study found that these have not been handled seriously by the government of Timor-Leste. The data collected from government documents, in depth interviews with government officers and opinions and statements from participant householders indicate that labour migration and remittances are not a priority of the Timor-Leste Government. This is a concern because remittances bring in considerable amounts of money and have positive results on participant households, and they also bring wide benefits to the economies of local communities. In addition, the data showed that the government has little information about the labour migrants from Timor-Leste. In fact, it has no information about the migrants who work in the United Kingdom of Great Britain of Great Britain of Great Britain and Northern Ireland. According to the interviews, this is because these people have gained Portuguese citizenship and passports. Also, this study found that the income from remittances is not included in the country's annual GDP report nor is there any record of these in the country's statistics or in the Department of Finance which collects information about citizens' incomes from inside and outside the country. In addition, the lack of data on migrant labour in relevant ministries and NGOs, who work specifically in this area, resulted in challenges for me in this study of remittances and migration in Timor-Leste.

Apart from the processes and policies of migration, another significant finding concerned the processes and the policies of remittance services in Timor-Leste. According to the data, these are under the control of, and well regulated by the central Banks ${ }^{44}$ of Timor-Leste. Although the processes and policies of sending and receiving remittances are well documented in terms of the delivery services, administration fees, the timing of sending and receiving remittances and transferring these to participant households, there is lack of information provided to the remittance senders and receivers by the providers of these services. In particular, they are not informed about the different options to transfer remittances, including different rates.

\footnotetext{
${ }^{44}$ The Central Bank of Timor-Leste: The Banku Nacional Comesrion Timor-Leste (BNCTL)/ Bank Payment Authority (BPA)
} 
Also, this study found that the limited branches of these service providers, in the country, incur extra costs in transport and accommodation by the receivers. For example, many participants live in urban and rural areas where there are no money transfer operators or commercial banks. In addition, there is no programme from the Central Bank to inform the remitters and receivers about a reduction in transfer fees when remittances are put into saving accounts in Timor-Leste nor is there an initiative to induce competition, between the remittance service providers, to reduce transfer fees to attract more migrants to send money home. These are some suggestions for the Timor-Leste Government. It needs to disseminate information to remittance receivers and senders which would enable them to enhance their savings and invest in the productive sectors.

\subsubsection{The impact of remittances on durable and non-durable consumption.}

The second finding is that remittances used on consumption have both positive and negative impacts on participant households in Timor-Leste. Almost all the participants informed me that they use some of their remittance funds for the consumption of durable goods, including: building a house, buying land and also on non-durable goods such as food, clothing and other services. Although recent studies argue that the consumption of durable goods and housing is an unproductive use of remittances a noticeable fact, in my study, showed that investing in durable goods like housing has a multiplying effect on the local economy, the village and the district where most of the participant householders live. In these local contexts, where people live under the poverty line, of approximately USD0.50/day remittance funds have become an important source of income to small businesses such as small grocery shops, farms, building material shops, transportation businesses and many others. Furthermore, this study found that building a new house gave greater temporary job opportunities to the locals and builders around the district mentioned. They also have a positive impact on local markets in the locations of this study.

On the other hand, this study further found that the expenditure of remittances on other uses such as cultural activities is quite high. This is related to cultural beliefs which still hold and have a strong influence on Timorese people, whether they currently reside overseas as labour migrants, or live in Timor-Leste where the ceremonies are held. This spending might be categorised as unproductive as it does not support recipient households' or the local economy. 


\subsubsection{The impact of remittances on human capital investment and business investment.}

Lastly, the study found that remittances have a positive impact on human capital and business investment. According to the data, a significant amount of remittance funds go to support, one or more family members in university in Timor-Leste and in overseas tertiary institutions, including Indonesian universities. The other significant support for the development of human capital is the education of school children. Here, remittances complement education by the purchase of education necessities such as books, school uniforms and shoes and for extracurricular activities in public and private schools from primary to senior high school. Remittances also support the vocational education of youth to enhance their skills in languages, including English and computing. Although the numbers supported by remittances in these areas are small their impact is significant and positive.

Moreover, this study also found that remittances positively and significantly impact on business investment. According to the data, a noticeable fact collected, was that transportation business have become one of the most prevalent businesses run by participant householders in TimorLeste. Following this are groceries shop which also create self-employment. Construction companies are the next preference and the significant and positive impact of these is evident in the job opportunities and skill building they offer the unemployment of Timor-Leste.

Lastly, the remittance funds positively impact on agricultural production and loan' businesses. In support of these, this study not only provided data collected through interviews but also included photo evidence.

\subsection{Contributions}

Firstly, this study provides a broad description of migration and the processes and policies concerning remittances from Timorese emigrants working in the United Kingdom of Great Britain of Great Britain of Great Britain, Northern Ireland, South Korea and Australia. It also contributes significant information which will be useful to the government of Timor-Leste, NGOs and local and international organisations looking specifically at migration issues. Regarding this study identified the strength and weakness of the processes and policies of migration and remittances in Timor-Leste. In addition, it provides findings about how remittances impact both unproduc- 
tively and productively on receiving countries. This information will contribute significantly as a base line for the government to develop effective policies. These will benefit the remittance receiving households in particular and if included in the country's GDP will contribute to the development of Timor-Leste.

Lastly, this study contributes to the literature of transnationalism and migration particularly the impact of remittances in a new country like Timor-Leste. It is also providing an emphasis on the migration processes and remittance policies which have a significant influence on the impact of the flow of remittances into the country. Besides this, this study also brings together the literature of findings from other countries and enriches the literature of transnationalism and development from the positive and negative perspectives of the impact of remittance son recipient households in developing countries.

\subsection{Limitations}

Although this study is well conducted and well-constructed, various limitations may exist. As posited by Simon \& Goes (2013) "Limitations are matters and occurrences that arise in the study which are out of the researcher's control."

This study has limitations. These are as follows:

\subsubsection{Sample Method and data collection}

The snowball sampling method was chosen because it enables the possibility to include more participants where no identifiable list or cluster exists. Further, there are no specific data about the location of members of the diaspora and their families provided by the relevant ministries. Therefore, the snowball sampling method is the appropriate one to cluster participants. However, during the application of this method, in the local context of Timor-Leste it cost time because many of the participant householders live in different districts and this affected the projected timeline and the budget. 


\subsection{The focus of the study}

This study covered only the internal issues of migration and focused on the processes and policies of this and the use of the remittance found in Timor-Leste. It has not discussed or presented the same issues in the host countries.

\subsection{Recommendations}

Future research should focus on each chapter of these findings as follows:

- Apply another sampling method which is more effective and efficient and use another method designed to source secondary data on the impact of remittances on Timor-Leste's GDP.

- Look at the members of the diaspora, including; identifying their problems, policies concerning their migration from Timor-Leste to their destination countries, their protection, living conditions, social life and cultural exchanges. Also, within Timor-Leste, future research might focus on one location only. For example, conduct the study in the rural and urban areas of one specific district. 


\section{REFERENCES}

Abreu, A. (2012, April). The new economics of labour migration: beware of Neoclassical bearing gifts. In Forum for social economics (Vol. 41, No. 1, pp. 46-67). Routledge.

Abwaku, E. (2009). The Economic of Remittances Herrois and Issues. West Africa Institute, p.16.

Acosta, P. A., Fajnzylber, P., \& Lopez, H. (2007). The impact of remittances on poverty and human capital: evidence from Latin American household surveys. World Bank Policy Research Working Paper, (4247).

Acosta, P. (2006). Labour supply, school attendance, and remittances from international migration: the case of El Salvador. World Bank Policy Research Working Paper, (3903).

ACP. (2010). Overview on South-South Migration and Development Trends and Research Needs in Timor-Leste.Belgium: ACP observatory on Migration

Adams, R. H., \& Page, J. (2005). Do international migration and remittances reduce poverty in developing countries? World development, 33(10), 1645-1669.

Adams Jr, R. H., Cuecuecha, A., \& Page, J. (2008). Remittances, consumption and investment in Ghana. World Bank Policy Research Working Paper Series, Vol.

Adams Jr, R. H. (2011). Evaluating the economic impact of international remittances on developing countries using household surveys: A literature review. Journal of Development Studies, 47(6), 809-828.

Alcoff, L., \& Potter, E. (1993). Feminist epistemologies. New York: Routledge.

Andrew, N., Pheng, K. S., \& Philips, M. (2011). Fisheries Dependence in Timor-Leste: A Scoping Study. Coral Triangle Support Partnership.

Amuedo-Dorantes, C., \&Pozo, S. (2004). Workers' remittances and the real exchange rate: a paradox of gifts. World development, 32(8), 1407-1417.

Andrewes, D. (2013). Neuropsychology: From theory to practice. Psychology Press.

Ang, A. P., \& Opiniano, J. (2013). Business, Investment Probabilities and Remittances in Two Rural Hometowns in the Philippines.

Askland, H. H. (2014). East Timorese in Australia: Affective Relations, Identity, and Belonging in a Time of Political Crisis. Austrian Journal of South-East Asian Studies, 7(2), 199-216.

Aysa, D. S., (2005). Social Capital and International Migration from Latin America. Population DivisionDepartment of Economic and Social Affairs United Nation Secretariat, 1-24

Aydemir, A., \& Borjas, G. J. (2007). Cross-Country Variation in the Impact of International Migration: Canada, Mexico, and the United States. Journal of the European Economic Association, 5(4), 663-708.

Bakardzhieva, D., Ben Naceur, S., \&Kamar, B. (2010). The impact of capital and foreign exchange flows on the competitiveness of developing countries. IMF Working Papers, 1-30.

Bauer, T. K., \& Zimmermann, K. F. (1999). Assessment of possible migration pressure and its labour market impact following EU enlargement to Central and Eastern Europe (Vol. 3). Bonn: iza. 
Baruah, N. (2006). Remittances to least developed countries (LDCs): Issues, policies, practices and enhancing development impact. IOM Tirana, 1, 28.

Barajas, A., Cosimano, T., Fullenkamp, C., Gapen, M., \& Montiel, P. (2008). Macroeconomic consequences of remittances. Washington, DC: International Monetary Fund

Barajas, A., Chami, R., Fullenkamp, C., Gapen, M., \& Montiel, P. J. (2009). Do workers' remittances promote economic growth? IMF Working Papers, 1-22.

Beck, M., \& Araujo, S. (2013).11 Timor-Leste. School-Level Leadership in Post-Conflict Societies, 159.

Berelson, B. (1952). Content analysis in communication research.

Bickman, L., \&Rog, D. J. (Eds.) (2008). The Sage handbook of applied social research methods. Sage publications

Boswell, C., \&Straubhaar, T. (2004). The illegal employment of foreign workers: An overview. Inter-economics, 39(1), 4-7.

Bougha-Hagbe, Jacques. 2004. "No evidence of slowdown in Moroccan workers' remittances." IMF Survey. Volume 33. Number 14. July 26

Bryman, A. (1984). The debate about quantitative and qualitative research: a question of method or epistemology? British Journal of Sociology, 75-92.

Brett Inder. A. B., (2014). Poverty and the Agricultural Household in Timor-Leste: Some Patterns and Puzzels. Australia: Monah University

Bryman, A. (2012). Social research methods. Oxford: Oxford University Press.

Burns, R. B. (1997). Introduction to research methods. Addison Wesley Longman.

Bugess, R. (2005). Migration and Foreign Remittances in the Philipine.Vol5. International Monetary Fund.

Business Timor (2012). SEPFOPE HarukaTimor Oan 1064 servisuiha Australia-Korea. Dili, Timor-Leste: Business Timor.

Byegon, I. (2014). The New Economic of Labour Migration and the role of remittances in the migrant process.academia.edu.

Cai, F. (2011). The Labour Export Policy: A case study of Philippine. E-International

Relation Student

Cartwright, D. P. (1953). Analysis of qualitative material. Research methods in the behavioural sciences, 421-470.

Castaldo, A., \& Reilly, B. (2007). Do migrant remittances affect the consumption patterns of Albanian households? South-Eastern Europe Journal of Economics, 1(1), 25-54.

Castles, S., Miller, M. J., \&Ammendola, G. (2005). The Age of Migration: International Population Movements in the Modern World: New York: The Guilford Press, (2003), \$30.00, 338 pages.

Castelo, A., \& Reilly, B. (2007). Do migrant remittances affect the consumption patterns of Albanian households? South-Eastern Europe Journal of Economics, 1(1), 25-54.

Carling, J. (1996). International labour migration: Consequences for countries of origin. Available at SSRN 2231926.

Cynthia Brandi, D. C. (2006). The Crisis in Timor-Leste. Dili, Timor-Leste : USAID . 
Harrington, A. (2007). Ethnicity, violence and land and property disputes in Timor-Leste. East Timor Law Journal, 2(1), 35.

Cline, A. (2015). What is Epistemology? About Religion.

Cohen, J. H. (2005). Remittance outcomes and migration: Theoretical contests, real opportunities. Studies in Comparative International Development, 40(1), 88-112.

Conway, D., \& Cohen, J. H. (1998). Consequences of Migration and Remittances for Mexican Transnational Communities*. Economic Geography, 74(1), 26-44.

Connell, J., \& Conway, D. (2000). Migration and remittances in island microstates: a comparative perspective on the South Pacific and the Caribbean. International journal of urban and regional research, 24(1), 52-78.

Davis, J., \&López-Carr, D. (2010, September). The effects of migrant remittances on consumption in highland Guatemala. In Proceedings of the European Population Conference

Denzin, N. K., \& Lincoln, Y. S. (2008). Introduction: Critical methodologies and indigenous inquiry. Handbook of critical and indigenous methodologies, 1-20.

Denzin, N. K., \& Lincoln, Y. S. (1994). Introduction: Entering the Field of Qualitative Research, Handbook of Qualitative Research (pp1-17).

De Haas, H. (2010). Migration and development: a theoretical perspective1. International migration review, 44(1), 227-264.

De Haas, H. (2009). Mobility and human development

De Haas, H. (2007). Remittances, migration and social development. A Conceptual Review of the Literature.

Díaz-Briquets, S. (1991). The effects of international migration on Latin America. The Unsettled Relationship: Labour Migration and Economic Development, (33), 183.

DiCicco-Bloom, B., \& Crabtree, B. F. (2006). The qualitative research interview. Medical education, 40(4), 314-321.

Diamantino, R. (2009). History of the Settlement of the Portuguese- Timorese community in Darwin Northern Territory, The Northern Territory Community, Australia.

Durand, J., Parrado, E. A., \& Massey, D. S. (1996). Megadollar's and development: A reconsideration of the Mexican case. International Migration Review, 423-444.

Díaz-Briquets, S. (1991). The effects of international migration on Latin America. The Unsettled Relationship: Labour Migration and Economic Development, (33), 183.

Easton, B. (1994). The Maori in the labour force. Unpublished report commissioned by TePuniKokiri, 30.

Edwards, A. C., \&Ureta, M. (2003). International migration, remittances, and schooling: evidence from El Salvador. Journal of development economics, 72(2), 429-461.

Elmendorf, D. W. (1996). The effect of interest-rate changes on household saving and consumption: a survey. Federal Reserve Board. 
Elmendorf, D. W. (1996). The effect of interest-rate changes on household saving and consumption: a survey. Federal Reserve Board.

Fry, R. (2002). MMR vaccine debate: Debate crystallizes dilemma facing many medical disciplines. BMJ: British Medical Journal, 324(7339), 733.

Given, L. M. (Ed.) (2008). The Sage encyclopaedia of qualitative research methods. Sage Publications. Giulietti, C., Wahba, J., \&Zenou, Y. Who matters more for migration decision? Close friends or acquaintances?

Goldin, C., \& Katz, L. F. (1999). Human capital and social capital: the rise of secondary schooling in America, 1910-1940. Journal of interdisciplinary history, 29(4), 683-723.

Gorman, G. E. Clayton. P. (2005). Qualitative Research for the Information Professional.

Gordon, I. (1995). Migration in a segmented labour market. Transactions of the Institute of British Geographers, 139-155.

Goode, W. J., \&Hatt, P. K. (1952). Methods in social research

Gray, D. E. (2013). Doing research in the real world. Sage.

Guba, E. G., \& Lincoln, Y. S. (1981). Effective evaluation: Improving the usefulness of evaluation results through responsive and naturalistic approaches. Jossey-Bass.

Hanson, G. H., \& Woodruff, C. (2003). Emigration and educational attainment in Mexico. Mimeo. University of California at San Diego.

Hammett, D., Twyman, C., \& Graham, M. (2014). Research and fieldwork in development. Routledge. Homan, R. (1991). The ethics of social research. London: Longman.

Hertlein, S. (2006). Remittances - A Bridge between Migration and Development? Focus Migration, 7.

Hofer, B. K. (2001). Personal epistemology research: Implications for learning and teaching. Educational Psychology Review, 13(4), 353-383.

Holsti, O. R. (1968). Content Analysis, the Handbook of Social Psychology. Wesley: Reading MA, Addison

Ian Greener. (2011). Designing social research: A guide for the bewildered. Sage Publications.

Israel, M., \& Hay, I. (2006). Research ethics for social scientists. Sage.

Jokisch, B., \&Pribilsky, J. (2002). The panic to leave: Economic crisis and the "new emigration" from Ecuador. International Migration, 40(4), 75-102.

Kalaj, E. H. (2010). Remittances and human capital investment: Evidence from Albania. Available at SSRN 2285641.

Kanu, S. I. (2015). Foreign Capital Inflows and Economic growth in Sub-Saharan Africa: A Study of Selected Countries. Research Journal of Finance and Accounting, 6(1), 52-64.

Kaplan, A. (1943). Content analysis and the theory of signs. Philosophy of Science, 10(4), 230-247.

Khan, M., Rahim, T., Bakhtiar, Y., \&Nawab, B. REMITTANCES AS A DETERMINANT OF CONSUMPTION FUNCTION. 
King, R. (2012). Geography and migration studies: Retrospect and prospect. Population, Space and Place, 18(2), 134-153.

King, R. (2012). Theories and typologies of migration: an overview and a primer.

Kopcke, R. W., Tootell, G. M., \&Triest, R. K. (2006). Introduction: The macroeconomics of fiscal policy.

Kumar, R., Tripathi, R. C., \&Tiwari, M. D. (2011). A comprehensive study on content based trademark retrieval system. International Journal of Computer Applications (0975-8887) Volume.

Kumar,R. Research Methodology A step by step guide for beginners 3d Editions, sage. 2011

Kurekova, L. (2011, April). Theories of migration: Conceptual review and empirical testing in the context of the EU East-West flows. In Interdisciplinary conference on Migration. Economic Change, Social Challenge.

Kvale, S. (1999). The psychoanalytic interview as qualitative research. Qualitative Inquiry, 5(1), 87-113.

Lartey, E. K., Mandelman, F., \& Acosta, P. A. (2008). Remittances, exchange rate regimes, and the Dutch disease: A panel data analysis.

Lincoln, Y. S., \&Denzin, N. K. (Eds.). (1998). The landscape of qualitative research: Theories and issues. Sage.

Lincoln, Y. S., Lynham, S. A., \&Guba, E. G. (2011). Paradigmatic controversies, contradictions, and emerging confluences, revisited. The Sage handbook of qualitative research, 4, 97-128.

Lincoln, Y. S., \&Denzin, N. K. (2005). Epilogue: The eighth and ninth moments: Qualitative research in/and the fractured future. Handbook of qualitative research, 3, 1103-114.

Longhurst, R. (2003). Semi-structured interviews and focus groups. Key methods in geography, 117-132.

Lundahl, M., \&Sjöholm, F. (2013). Improving the Lot of the Farmer: Development Challenges in TimorLeste during the Second Decade of Independence*. Asian Economic Papers, 12(2), 71-96.

Lucas, R. E., \& Stark, O. (1985). Motivations to remit: Evidence from Botswana. The Journal of Political Economy, 901-918.

Mabogunje, A. L. (1970). Systems approach to a theory of rural-urban migration. Geographical analysis, 2(1), 1-18.

Magnusson Bernard, K. (2010). Remittances, regions and risk sharing.

Mansoor, A. M., \&Quillin, B. (Eds.). (2006). Migration and remittances: Eastern Europe and the former Soviet Union. World Bank Publications.

Matt Henn, Mark Weinstein, \& Nick Foard. (2009). A critical introduction to social research. Sage Publications.

Melissa A Hardy, \& Alan Bryman (Eds.). (2004). Handbook of data analysis. Sage.

Monette, D., Sullivan, T., \&DeJong, C. (2013). Applied social research: A tool for the human services. Cengage Learning.

Matt Henn, Mark Weinstein, \& Nick Foard. (2009). A critical introduction to social research. Sage Publications. 
McWilliams, A. (2011). Exchange and resilience in Timor-Leste. Journal of the Royal Anthropological Institute, 17(4), 745-763.

Miller, D., \& Paulson, A. L. (1999). Informal insurance and moral hazard: gambling and remittances in Thailand. Kellogg Graduate School of Management, North-western University Working Paper. Evanston, III.: North-western University.

Miller, F. D., \& Kaplan, D. R. (2001). On Trek for retrograde signalling. Neuron, 32(5), 767-770.

Ministry of Finance (2011), Timor Leste Household Income and Expenditure Survey. Dili, Timor Leste, Ministry of Finance.

Ministry of Natural Resources (2011). Timor-Leste Extractive Industries. Dili, Timor-Leste: Ministry of Natural Resources

M Massey, D. S., Arango, J., Hugo, G., Kouaouci, A., Pellegrino, A., \& Taylor, J. E. (1993). Theories of international migration: a review and appraisal. Population and development review, 431-466.assey, D. S., \&Aysa-Lastra, M. (2011). Social capital and international migration from Latin America. International journal of population research, 2011.

Morgan, G., \&Smirch, L. (1980). The case for qualitative research. Academy of management review, 5(4), 491-500

Murphy, A., Farley, H., Lane, M., Hafeez-Baig, A., \& Carter, B. (2014). Mobile learning anytime, anywhere: what are our students doing? Australasian Journal of Information Systems, 18(3).

McWilliam, A. Cultural heritage and its performativity modalities: Imagining the Nino Konis Santana National Park in East Timor. Cultural heritage, 1, 3.

Nguyen-Dumont, T., Hammet, F., Mahmoodi, M., Tsimicalis, H., Teo, Z. L., Li, R., \& Southey, M. C. (2015). Mutation screening of PALB2 in clinically ascertained families from the Breast Cancer Family Registry. Breast cancer research and treatment, 1-8.

Olson, H. (2013, November). Quantitative" versus" qualitative research: The wrong question. In Proceedings of the Annual Conference of CAIS/Actes du congrèsannuel de l'ACSI.

Osili, U. O. (2007). Remittances and savings from international migration: Theory and evidence using a matched sample. Journal of Development Economics, 83(2), 446-465.

Palley, T. I. (2008). The relative income theory of consumption: A synthetic Keynes-DuesenberryFriedman model. PERI Working Papers, 140.

Pessar, P. (1996). Dominican Transnational Migration: Uneven Benefits Back Home and the Contingency of Return. The Dominican Republic Today: Realities and Perspectives, New York, NY, BlindersCentre, 151-176.

Puri, S., \&Ritzema, T. (1999). Migrant worker remittances, micro-finance and the informal economy: prospects and issues. International Labour Office.

Poirine, B. (1997). A theory of remittances as an implicit family loan arrangement. World Development, 25(4), 589-611.

Poros, M. V. (2011). Migrant Social Networks: Vehicles for Migration, Integration, and Development by Maritsa V. Poros. Social networks.

PooT, M., Hoehn, H., Rünger, T. M., \& Martin, G. M. (1992). Impaired S-phase transit of Werner syndrome cells expressed in lymphoblastic cell lines. Experimental cell research, 202(2), 267-273.

Ratha, D. (2007). Leveraging remittances for development. Policy Brief, (3). 
Rajit, K. (2011). Research Methodology a step by step guide for beginner (3d Edition ed.). SAGE.

Rempel, H., \&Lobdell, R. A. (1978). The role of urban-to-rural remittances in rural development. The Journal of Development Studies, 14(3), 324-341.

Rose, H. (1983). Hand, brain, and heart: A feminist epistemology for the natural sciences. Signs, 73-90.

Riikonen, E., Smith, E. R. G. M., \& Smith, M. G. M. (1997). Re-imagining therapy: Living conversations and relational knowing (Vol. 17). Sage.

Rodriguez, E. R. (1998). International migration and income distribution in the Philippines. Economic Development and Cultural Change, 46(2), 329-350.

Rogers, D. W. (2014). Timor-Leste and Conoco Philips Improving Incomes for Rural Farmers. Frontlines.

Rose, H. (1983). Hand, brain, and heart: A feminist epistemology for the natural sciences. Signs, 73-90.

Reinharz, S. (1997). Who am I? The need for a variety of selves in the field. Reflexivity and voice, 3-20.

Saleh, W. A. (2006). The last of the Nishapuri School of Tafsir: Al-Wahidi (d. 468/1076) and his significance in the history of Qur'anic exegesis.

Schroeder, J. (2009). 2. Transnational perspectives on migration, employment and education

Schierup, C. U., Hansen, P., \& Castles, S. (2006). Migration, citizenship, and the European welfare state: a European dilemma. OUP. Catalogue.

Shuaib, F. I. K. R. E. T. H. (2008). Timor-Leste Country Report. Monash Asia Institute, Institute for Regional Development, University of, Tasmania, Foundation for Development Cooperation. http://www. ausaid. gov. au/publications/pdf/etimor_study. pdf.

Simati, A. M., \& Gibson, J. (1998). Do Remittances Decay? Evidence from Tuvaluan Migrants in New Zealand. Department of Economics, University of Waikato.

Singh, S. (2015). The Remittance Effect: Do Remittances Help Development? Discussions, 11(1).

Singer, D. A. (2010). Migrant remittances and exchange rate regimes in the developing world. American Political Science Review, 104(02), 307-323.

SEPFOPE. (2014, November 14). Sending people, generate more income. Retrieved from http://sepfope.gov.tl: http://sepfope.gov.tl/tet/artigu-1402161-hasai_ema_hatama_osan.html

Sheehan, C. M., \&Riosmena, F. (2013). Migration, business formation, and the informal economy in urban Mexico. Social science research, 42(4), 1092-1108.

Soinni, H. Kronqvist.L. Huber, L. Gunter. 2011 Epistemologies for Qualitative research. Enter for Qualitative Psychology e.V, Germany.

Soraya, J. S. (2007). Overseas Workers, Remittances, and Household Welfare in the Philippines.

Kalaj, E. H. (2010). Remittances and human capital investment: Evidence from Albania. Available at SSRN 2285641.

Spengler, J. J. (1977). Adam Smith on human capital. The American Economic Review, 32-36

Stake, R. Ratha, D. (2007). Leveraging Remittances for Development. Migration Policy Institute, Policy Brief.

Stark, O., \& Bloom, D. E. (1985). The new economics of labor migration. The American Economic Review, 173-178. 
Statistic Timor-Leste (2013).Census Publication, retrieved from http://www.statistics.gov.tl/

Sumner, M. (2006). Epistemology. The Sage Dictionary of Social Research Methods. London: Sage.

Suara Timor Lorosae, S. (2014). Trabalhador Timor oan illegal iha Korea sei Deporta.STL.

Tacoli, C. (1999). International migration and the restructuring of gender asymmetries: Continuity and change among Filipino labor migrants in Rome. International migration review, 658-682.

Taylor, E. J. (1999). The new economics of labour migration and the role of remittances in the migration process. International migration, 37(1), 63-88.

Tewolde, B. (2006). Remittances as a tool for development and reconstruction in Eritrea. An economic analysis. Journal of Middle Eastern Geopolitics, 1(2).

The Asian Development Bank, A. (2014). Timor-Leste Economy. ADB

The Central Bank of Timor-Leste. (2011, November 28). Central Bank of Timor-Leste. Retrieved from www.bancocentral.tl: http://www.bancocentral.tl/en/institution.asp\#history

The Central Bank Timor-Leste. (2014). Guidelines for the Licensing and Operations of Money transfer Operator.

The Council of Minister. (2013). Extraordinary Meeting of the Council of Ministers, of The 23rd December 2013. Dili, Timor-Leste: The Government of Timor-Leste.

The Government of Timor-Leste, R. (2010). Timor-Leste Strategic Development Plan 2011-2013. Dili, Timor-Leste: The Government of Timor-Leste

The Ministry of Finance. (2011). External Trade Statistic; Annual Reports 2011.Mintery of Finance

The Ministry of Foreign Affair Timor-Leste. (2014). Direito a Nacionalidade Portuguesa. MNEG

The national parliament of Timor-Leste. (2011). Timor-Leste Strategic Development Plan 2011-2030. Dili: Democratic Republic of Timor-Leste

The World Banks. (2014). Timor-Leste Country Overview. WorldBank. Dili: The World Bank Group The World Bank (2013). Conserving Cultural Heritage in Timor-Leste to Build Livelihood.

The World Bank. (2010). Migration and Remittances.

The World Bank. (2013). Country Brief. The World Bank Group.

The World Bank. (2011). Migration and Remittances Fact book 2011. The World Bank.

The Trading Economics. (2014). East Timor Unemployment Rate. Trading Economic.

Tsai, C. C. (2000). Relationships between student scientific epistemological beliefs and perceptions of constructivist learning environments. Educational Research, 42(2), 193-205. )

Udoy Saikia, M. H. (2012). Population growth, youth bulge and social conflict; The challenge of the nation building process of Asia's newest nation - Timor-Leste. Population Studies, Flinders AustraliaUNFPA. (2013). LinkingPopulation, Poverty and Development. UNFPA.

UNESCO. (2013). Timor- Leste UNESCO Country Programming Document 2009-2013. UNESCO

Yu, T. F. L., Wai-Kee, Y., \& Kwan, D. S. (Eds.). (2014). International Economic Development: Leading Issues and Challenges. Routledge. 
Woodruff, C., \&Zenteno, R. (2007). Migration networks and microenterprises in Mexico. Journal of development economics, 82(2), 509-528.

World Health Program, W. (2013). A More Inclusive Health Reform Process in Timor-Leste. Dili, TimorLeste: Universal Health Coverage Partnership.

Yang, D. (2005). International migration, human capital, and entrepreneurship: evidence from Philippine migrants' exchange rate shocks. Human Capital, and Entrepreneurship: Evidence from Philippine Migrants' Exchange Rate Shocks (February 2005), 02-011.

Yi, S. (2013). Low-skilled labor migration: Korea's Employment Permit System. South Korea: The World Bank

Zarate-Hoyos, G. A. (2004). Consumption and remittances in migrant households: toward a productive use of remittances. Contemporary Economic Policy, 22(4), 555-565. 